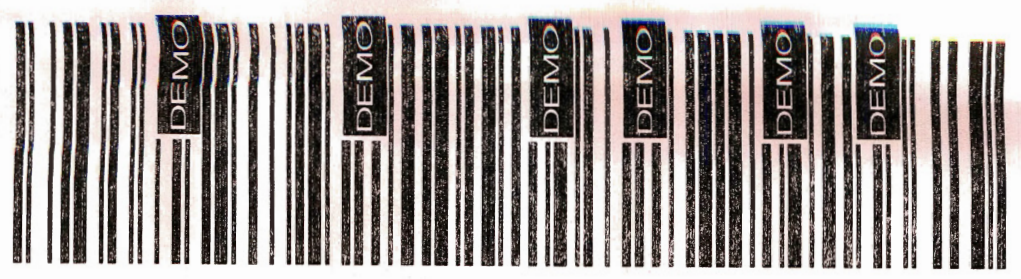

\title{
THESIS 1983D L531E
}

\section{Dissertation}

Leinberger, Gary, 1947-

Page Number $\mid 91$

$\square$ Images

$\square$ Foldouts

Maps

Scanned

$\square$ Clean-up

$\square$ PDF

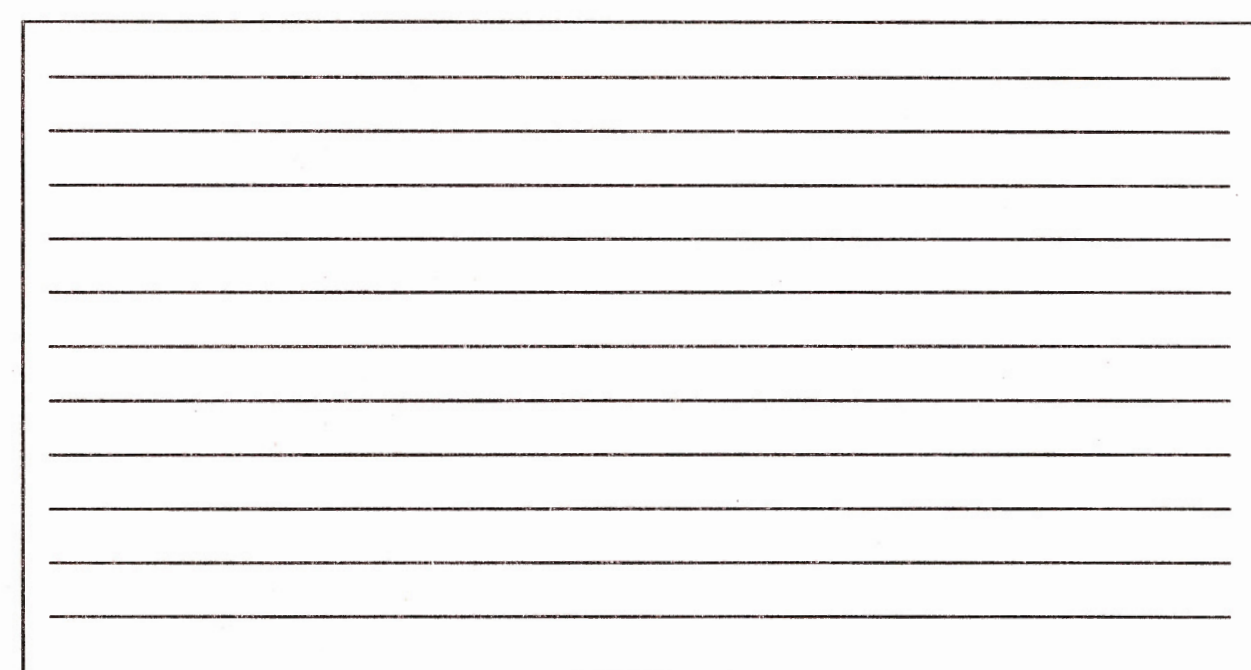

$\square$ Archive $\underset{\text { Projects }}{\square}$

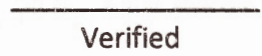

Date 


\section{AN EMPIRICAL INVESTIGATION OF THE DYNAMIC \\ RELATIONSHIPS OF DEBT LEVEL AND \\ BUSINESS RISK \\ By \\ $\leftarrow$ \\ GARY LEINBERGER \\ Bachelor of Arts Lehigh University \\ Bethlehem, Pennsylvania 1970 \\ Bachelor of Arts \\ Lehigh University \\ Bethlehem, Pennsylania \\ 1970}
Master of Business Administration Boston University Boston, Massachusetts 1976

\footnotetext{
Submitted to the Faculty of the

Graduate College of the Oklahoma State University in partial fulfillment of the requirements for the Degree of DOCTOR OF PHILOSOPHY December 1983
} 


$$
\begin{aligned}
& \text { Thesis } \\
& \text { 1983D } \\
& \text { L531e } \\
& \text { Cop. } 2
\end{aligned}
$$


AN EMPIRICAL INVESTIGATION OF THE DYNAMT

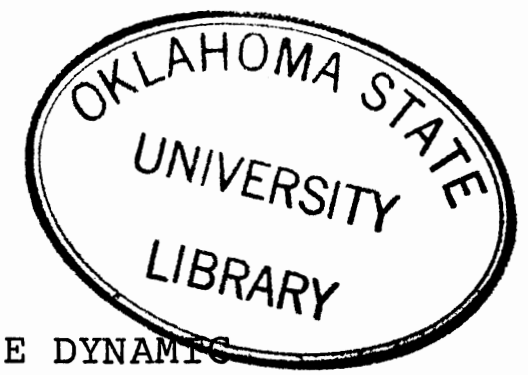

RELATIONSHIPS OF DEBT LEVEL AND

BUSINESS RISK

Thesis Approved:

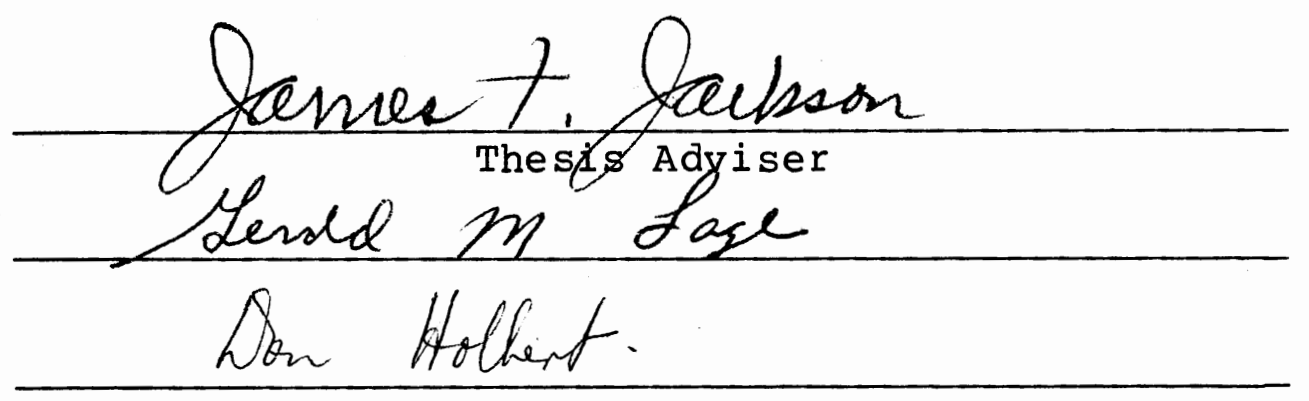

U. Saref frompson

topewer

Derman $\bigcap_{\text {Dean of Graduate School }}$ 


\section{Preface}

This study is concerned with anaylzing the use of debt by corporations over time and comparing these policies with the risk of the firm. The primary onjective is to find whether firms, in their debt policy decisions, react to changes in risk.

The author wishes to express his appreciation to Dr. James Jackson, his major advisor, and the other members of his committee, Dr. Gerry Lage, Dr. Gary Simpson, Dr. H.L. Brewer and Dr. Donald Holbert.

Further, a special note of thanks is due to the Irwin Foundation which provided fellowship funding to help underwrite the costs of this study.

The author would like to dedicate this study to his father, F. A. Leinberger, who unfortunately did not live to see the final product. The author hopes it is up to his high standards. Without the moral and financial support of both parents, this study would not have been possible.

Finally, the author would like to express his appreciation to his wife, Ms. Gail Sanderson, for her support and technical aid through these long years of study. 
TABLE OF CONTENTS

Chapter

Page

I. INTRODUCTION • • • • • • • • • • • • • • • 1

The Importance of Studying Debt . . . . . 1 Lack of Consensus on the Effects

of Debt . . . . . . . . . . 4

Increasing Importance of Debt Policy . 7

Purpose of the Study. . . . . . . . 8

Approach of the Study . . . . . . . . 9

The Theoretical Model . . . . . . . . 11

Importance of This Study . . . . . . 12

Assumption of the Model. . . . . . 13

The Model. . . . . . . . . . . . 14

The Existence of an Asymmetrical

Distribution of Information . . - 15

Changes in Financial Structure . . . 18

Time Lags in Changing Financial

Structure . . . . . . . . . 21

Information Content of Financial

Structure Changes - . - . . . 22

Summary of the Theoretical Model . . 23

Developing Empirical Backing. . . . . . 24

The Hypotheses . . . . . . . . 24

Assumptions. . . . . . . . . . . 25

Overall View of the Model. . . . . 26

The Sample . . . . . . . . . 27

The Use of Changes in Debt

and Changes in Risk . . . . . . 31

The Reasons for a Time Series

Model . . . . . . . . 32

Development of the Business Risk

Measure • • • • • . . . 33

Development of the Debt Measure. . $\quad 37$

Correlation Method . . . . . . 38

Results of Empirical Testing . . . . 38

II. LITERATURE REVIEW. • • • • • • • • • • • 40

Introduction. . . . . . . . . . . 4 40

Macroeconomic Approach to Valuation

of Debt. . . . . . . . . . . . 42

Proposition I. . . . . . . . . . 43

Proposition II . . . . . . . . . . . 44

Theoretical Support of MM. . . . . 45

Early Empirical Studies. . . . . . . 47 
Equivalent Risk Class Testing. •. . 51

Macroeconomic Approach with Taxes. . 55

The Cost of Bankruptcy . . . . . 58

Optimal Capital Structure . . . . . . 60

Determinants of Capital structure • • • . 64

Multivariate and Multiperiod Models. • 65

Multivariate Models. . . . . . 66

Concept of Multivariate Models . . . 67

The Problems of Multivariate

and Multiperiod Models. . . . 68

Canorical Correlation. . . . . . 70

Maximum Likelihood Procedure . • . 71

Cluster Analysis . . . . . . . 73

Multiperiod Models . . . . . . 80

Alternate Approaches. . . . . . . . 83

Recent Work . •. . . . . . . . 87

Conclusion. • • • • • • • • . • . 92

III. THE THEORETICAL MODEL • • • • • • • . • • 94

Introduction. • . . . . . . . . 94

The Problem. . . . . . . . . . 95

The Cost and Value of Debt . . . 98

The Theoretical Model.......... 98

Purpose of the Model . . . . . 98

Assumptions. . . . . . . . . . 99

The Model. . . . . . . . . . 101

The Cost of Debt . . . . . . . . 102

Managerial Expertise and Market

Freedom . . . . . . . . . 106

Timing of Financial structure

Changes • • • • • • • • • • • 106

The Assymmetrical Distribution of

Information . . . . . . . . 107

Changes in Financial structure... . 110

Time Lags in Changing the Financial

Structure . . . . . . . . . 111

Information Content of Financial

Structure Changes ....... . 113

Summary of the Model. . . . . . . . 113

Implications of the Model . . . . . . 115

IV. THE EMPIRICAL MODEL. • . . . . . . . . . 120

Purpose of the Empirical Model. . . . . 120

Specific Hypotheses . . . . . . 121

Assumptions • . . . . . . . . 121

Overall View of the Model • . . . 122

The Sample. • . . • . • • • • . 123

The Empirical Model • • • • • • • • . 128

The Use of Changes in Debt and

Changes in Risk. •. • . . 128 
The Reasons for a Time Series Model . . . . . . 128 Development of the Business Risk Measure. . . . . . . . 130 Development of the Debt Measure . 135 Correlation Method. . . . . . 136 Raw Results of Empirical Testing. . 138 The Results of the Hypotheses Testing . . 1 149 Hypothesis I. . . . . . . . 149 Hypothesis II . . . . . . . . 150 Conclusions of the Study.:. : : : : . 151 Implications of the Study . . . . . . 151 Further Avenues of Approach . . . . . 153

A SELECTED BIBLIOGRAPHY . . . . . . . . . 155 APPENDIX A - LIST OF COMPANIES INCLUDED IN STUDY. • • 163 APPENDIX B - RAW RESULTS OF CORRELATIONS. • • • • 172 


\section{LIST OF TABLES}

Table

Page

I. Firms Showing Significant Leading or Lagging Relationships. • . • • • • . . 139

II. Total Significant Correlations by Relationships . . . . . . . . . . 143

III. First Significant Relationship . . . . . . . 145

IV. Significant Initial Relationships as a Percentage of Expected Equal Distribution of Relationships. . . . . . . 148 


\section{LIST OF FIGURES}

Figure $\quad$ Page

1. The Development of the Risk Measure . . . . . . 133

2. An Explanation of the Development of the Correlation Series Used in the Six Different Correlations. . . . . . . . . . 140 
CHAPTER I

INTRODUCTION

The Importance of Studying Debt

The understanding of debt and the debt policies of firms remains one of the major problems of finance. The questions of how debt affects the value of the firm and how firms should utilize debt over time (debt policy) remain unanswered. Despite a great deal of study, debate, and argument, there is no accepted, coherent theory or capital structure. Without a theory to explain capital structure, it is impossible to develop coherent debt policies, either on a firm level or on a national level.

Further study of this area is critical for three reasons. First, debt has been and will continue to be a major source of funding for firms. Second, the lack ot consensus on the effect of debt upon the firm has left decision makers on both the firm level and the national economic level with few tools with which to make debtrelated decisions. Finally, debt policy, from buth the firm and the national economy viewpoints, will become even more important in the future.

Debt is a major source of funding for firms, with 
manufacturing firms averaging approximately $30 \%$ of their total funding from debt. The use of debt among publicly traded firms is almost universal, although the actual debt level employed varies widely.

Debt levels in firms, however, have remained fairly consistent over time, despite massive differences in tax policy and major changes in the economy from the 1920's to the post-World-War II era (60). This almost universal and reasonably consistent use of debt suggests that debt has some value to firms and that there should be some optimal debt level for a particular firm.

That this use of debt entails some risk for the firm is evident from the record number of bankruptcies during the recessions of the early 1980's. Many of these bankruptcies were caused by an inability either to meet fixed payments or to refinance past indebtedness. A trend toward higher debt levels started during the early 1970's and possibly contributed to the instability of the late 1970's as well as the bankruptcies of the 1980's (54). This non-prudent use of debt (at least in hindsight) was due in part to a lack of understanding of how debt and debt policies affect the risk of the firm. If the actual relationship of debt, risk and value were properly understood, firms employing excessive debt would have been identified by the market and such debt

1 The actual average percentage of debt to total assets is dependent on the sample used. The figure of 308 is from the sample utilized in this study, over the twenty years of data used. 
policies discouraged.

The effect of debt on both the value of the firm and the risk of the firm has long been debated. From a microeconomic standpoint, the use of debt can increase the stream of income available to shareholders. This increase in income to shareholders that results from financial leverage also causes an increase in the variability of this income stream over time as the sales level varies. The use of debt obligates the firm to a fixed charge of interest and a repayment of the principal at some future time period. These fixed charges increase the probability of bankruptcy, as bankruptcy would occur at a higher sales level for a levered firm than for an unlevered firm. In addition, this leverage can reduce the stream of income available to stockholders if sales do not rise above the "switch" or "breakeven" point. This switch or breakeven point is the sales level where returns to shareholders are greater if the firm is levered rather than unlevered.

The value of debt to the firm can be approached from either a Capital Asset Pricing Model (CAPM) or a Cost of Capital approach. From a CAPM approach, it can be shown that as the debt level of the firm increases, the standard deviation of returns of the firm will increase, thus increasing the Beta of the stock. As long as this use of debt increases the stream of income available to stockholders sufficently to remain above the Security Market Line, this further addition of debt will aad value to the firm. This would argue that there is some trade-off between 
increasing returns and bankruptcy costs and that firms have some optimal debt level.

From a Cost of Capital approach, the use of debt reduces the weighted average cost of capital. Debt cost begins to increase as more debt is used (the firm is more risky), but the increasing use of less expensive debt rather than more expensive equity reduces the average cost of capital. At some point, the weighted average cost of capital (WACC) is minimized. By minimizing the WACC, a firm maximizes the "spread" between the return on projects and the cost of financing these projects, and increases the number of projects the firm can undertake. This maximizing of the spread between the cost of financing projects and the return on the projects would also argue that there exists some optimal debt level for a firm.

Lack of Consensus on the Effect of Debt

While the microeconomic approach to estimating the value of debt is appealing, from a macroeconomic or market approach, the value of debt is much less certain. In their seminal paper (1958) Miller and Modigliani (62) (henceforth MM) demonstrated that in a world with no taxes, leverage should have no effect upon the value of the firm. In a later paper (1963), MM (64) further argued that in a world with taxes, debt does add a small amount of value through the tax shield, which represents a risk-free perpetual stream of income. The implication of these two papers is that firms, 
in the absence of taxes, should have no debt (or be indifferent to the level of debt), or, with taxes, should have all debt (66).

Since these two papers, the debate and arguments have continued, with disagreements even between Miller and Modigliani. Miller $(60)$, in 1977, argued that the supply of debt offered by firms is limited because firms must raise rates on bonds enough to attract investors, and this rate is so high that debt is no longer of value to the firm. Miller indicated that firms may be indifferent to debt levels even with the tax shield. Modigliani (66), in 1982, argued that debt does have value due to the tax shield. However, the earlier estimates of the value may be too high, since investors regard these tax savings as a flow subject to risk, like the underlying profit stream, rather than as a risk-free perpetuity.

Thus, Miller argues that debt level is a matter of indifference to firms while Modigliani argues that debt level is of importance but the level is less than would be expected, given the value of the tax shield, because of four reasons. Modigliani argued firms did not use a maximium amount of debt because of bankruptcy costs, agency costs, possible foregone valuable opportunities, and the increasing probability, as debt increases, that income will fall to a level where the tax shelter has no value (66).

Further, this lack of consensus over the value of debt is not limited to issues orginally raised by MM. Others have argued that factors divorced from the issues raised by 
MM greatly affect the determination of the value of debt to a firm. Myers (67), in 1977, argued that leverage is a function of the value and relative size of the two "bundles" of assets that comprise the total assets of the firm. These two bundles are assets in place and options on possible new projects for the firm. This would suggest that leverage is of varying value to different firms, depending on the relative size and value of the two bundles of assets. This would also suggest that estimating the optimal debt ratio for a firm would require much more information not currently available to the market.

Ross $(73,74)$ in 1977, and Leland and Pyle (52), in 1977, argued that debt is more than a means to affect the value of the firm. These authors felt that debt is a "signal" used by the firm to alert investors and the market about the future of the firm without disclosing privileged information.

Jensen and Mechling (47), in 1976, argued that agency costs determined the optimal "ownership" structure. This ownership structure was defined as composed of manager-held equity, outsider-held equity, and outsider-held debt. Jensen and Mechling suggested that these agency costs (which can be viewed as essentially fixed costs regardless of size), result in different optimal structures for firms, in part, due to the scale of the firm and the types of agency costs incurred.

From the variety of certainly non-exclusive viewpoints 
presented above, it is obvious that there exists no accepted, coherent theory explaining either the value of debt or the parameters that determine an optimal debt level. This lack of a theory presents great problems, as questions regarding debt level and debt policy are likely to become even more important in the future.

\section{Increasing Importance of Debt Policy}

During the post-World war II period there has been a great change in the financial environment. In the early post-World War II period there was a conscious policy of keeping interest rates down through monetary policy. Coupled with the inflows of money from abroad in this period and the high personal savings rate, this policy resulted in stable, low cost funding for firms. However, in the early 1970's the greater demands for funds, both here and abroad, and the inflationary pressures, in part generated by monetary policy, pushed up the costs of funds drastically.

This increasing cost of funds came at a time when firms were facing ever greater competition, with the resultant lower profit margins, making cost control a critical area. Due to the increase in interest rates, interest has become a major cost for most firms. From a cost of capital standpoint, the higher interest rates have decreased the number of acceptable projects for the firm, further cutting growth and profitability. While in the past, technology generally gave some firms a decided advantage, technology is no longer a monopoly of a few companies or countries. 
Further, the rapid pace of technological innovation requires more frequent changes in machinery and, hence, more frequent financing. These factors of higher cost funding, more rapid technological obsolescence, and greater competition means firms must make financing decisions more often, and the margin for error on these decisions will be much less.

Further, the access to capital markets will continue to be unequal. In numerous industries, companies are able to obtain below market rates and, in some cases, guarantees to help meet fixed charges, which gives them a decided advantage in world markets. The aggressive use of government backed financing of targeted industries, the financing of projects to meet state goals such as employment, and protectionist, political and defensive considerations will make survivial and growth of firms with normal access to markets even more difficult.

As a result of these changes in the environment, firms will be faced more often with the question of what is optimal debt policy. The answer to this question requires a better understanding of the value of debt and also requires a model that accounts for both the macroeconomic or market viewpoint and the microeconomic viewpoint.

\section{Purpose of the Study}

The purpose of this study is twofold. First, the study presents a theoretical model that argues the importance of the inter-period timing relationship of changes in leverage 
and changes in business risk to understanding the value of debt. From this it is argued that leverage has great value to certain firms, even though leverage, on average, may have only slight value to all firms as suggested by MM and Modigliani, or may be a matter of indifference, on average, to firms, as suggested by Miller $(60)$.

Second, the study presents empirical testing that suggests firms function in a manner consistent with the theoretical model.

Approach of the Study

The theoretical model is built upon several basic assumptions. The first is the importance of timing relationships between changes in financial structure and changes in business risk. Prior studies have generally been static in nature, with single period horizons and assumptions that allowed instantaneous changes in financial structure. The majority of empirical studies, in particular, relied on cross-sectional analysis, in part because of the difficulties inherent in modeling leading and lagging variables. The present study assumes that the results of financial structure decisions, at least in terms of the results shown on the balance sheet, are not instantaneous. There is a time lag between the decision to change the financial structure and the actual recording of that change on the balance sheet. This time lag results because there are legal and regulatory delays and because the results of financial structure change are noted at the 
end of the period when reports are issued. For the purposes of this study, since annual data were utilized, the period is defined as one year. This means that a decision made late in one period may not be recorded until the end of the next period. Thus, there is a lag between when the decision to change financial structure is made and the recording of that change.

Further, the study assumes that managers are future oriented and make changes now to ensure that stockholder wealth is maximized in the future. To this end, managers use debt as a means to "signal" investors of upcoming changes in the firm.

A third assumption is concerned with the conflict between the microeconomic and the macroeconomic approach. The macroeconomic approach correctly uses marginal analysis, but shows at the margin, debt is of little or no value (depending upon the assumptions of the macro-model) to the average firm. However, the value of leverage, from a microviewpoint, is not equal for all firms. First, the opportunity to issue new securities differs between firms because of past financing decisions, relative stability of earnings, bankruptcy costs, agency costs, and indenture provisions. Second, the value of debt, again from a microviewpoint, differs between firms because of the varying costs of debt to different firms, thus affecting their cost of capital and the investment opportunities open to firms. From an MM, or macroeconomic standpoint, the value of 
debt is greater for firms that are less risky. The stream of income from the tax benefit of debt should be discounted at a rate closer to the risk free rate for a less risky firm. Second, for less risky firms, there is a lower probability that income will drop to the point where tax benefits lose value. Third, for less risky firms, issuing of debt has only slight effects on future bankruptcy costs and agency costs, so future opportunities are not as affected by present decisions. Finally, some firms can issue debt at rates that are lower than the rate described by Miller (60) as necessary to attract investors. These firms can issue bonds at rates which ensure marketability yet add value to the firm.

This segmentation of firms into groups based on the relative value additivity of debt would first suggest that some firms would use no debt if indeed debt was of little value to that firm. Rather, however, this assumption (that some firms can better use debt to increase value) means that the relationship between debt policy, value and risk should be clearer in a sample composed of firms which can best use debt to increase value.

The Theoretical Model

This study presents a theoretical model that explains the relationship between business risk and financial structure. Business risk is defined as that basic risk inherent in a firm's operations resulting from the inherent uncertainty or variability of expected pretax returns 
(usually measured in terms of standard deviation) on the firm's portfolio of assets. The purpose of this model is to show that, as financial theory suggests, there should be a measurable relationship between the financial structure and business risk of a firm, and hence, that the financial structure, as measured by the debt to total asset ratio, of the firm is important. The theoretical model to be developed explains why this relationship between financial structure and business risk is lagged, and how managers adjust financial structure to maximize firm value.

In particular, this study develops a theoretical model that explains the timing of changes in business risk and changes in financial structure. The relationship between changes in business risk and changes in financial structure is important for two reasons. First, this relationship is critical to understanding how and why managers change financial structure in attempting to maximize shareholder wealth. Second, this relationship explains why empirical studies in the past have been unable to link financial structure, business risk and value.

\section{Importance of This study}

Financial theory generally accepts that firm value can be changed through the use of debt and that the financial structure that maximizes the value of the firm is strongly correlated with expected returns (measured as net operating income) and hence, the business risk of the firm. However, 
no theoretical model has yet fully explained the timing relationship between financial structure and business risk. In addition, no empirical evidence strongly supports links between debt level and business risk. This study is concerned with how debt and business risk are related, and how this relationship supports the importance of financial structure.

This study presents a theoretical model that explains the inter-period relationship between financial structure and business risk. This inter-period theoretical model concentrates on the relationship between year-to-year changes in financial structure and changes in business risk. From this theoretical model, an empirical model was developed. This empirical model demonstrates that firms exhibit behavior that tends to support the hypothesized relationship of financial structure and business risk, and hence, adds support to the concept that financial structure does influence value. In addition, this model provides support of the "signaling" function of financial structure change suggested by Ross $(73,74)$ and Leland and Pyle $(52)$.

\section{Assumptions of the Model}

The model proposed makes several implicit assumptions about the behavior of managers, the effect of debt on the firm, the effect of financial markets on firm value, and the time necessary to make changes in financial structure. One assumption, following the work of Jensen and Mechling (47), is that managers attempt to maximize the value of the firm 
because it is in their best interests. A second assumption is that debt can increase the value of the firm as suggested by modern financial theory. A third assumption is that financial markets are efficient in the sense that markets utilize all available information. Finally, this study assumes that some amount of time is necessary to carry out a change in financial structure ${ }^{2}$.

The Model

The theoretical model proposed explains the relationship between changes in financial structure and change in the business risk of the firm. The model postulates that there is an inter-period lag (with a period being defined as one year) between changes in financial structure and changes in business risk. This lag is due to four factors: an asymmetrical distribution of information between managers and the financial markets, the increase in the information known to the financial markets over time, the time necessary to change financial structure, and the use of changes in financial structure to "signal" to the financial markets about the future propects of the firm.

2 This amount of time to carry out a change in financial structure is dependent on numerous factors explained later. The important point here, particularly from an empirical standpoint, is that any change in financial structure will not be recorded, at best, until the next annual or year end report. 
The Existence of an Asymmetrical

Distribution of Information

If the value of the firm is estimated from a viewpoint of Myers' (67) model of the firm, it can be shown that the manager is in the best position to estimate the future business risk of the firm because of the superior information the manager has regarding the future business risk of the firm. As a result of this superior information, the manager can make decisions that will adjust the financial structure to ensure that the value of the firm is maximized.

Myers' model (67) of the firm suggests that the firm's value is the summation of the value of two "bundles" of assets: the assets in place and the options the firm holds on future projects. Over time, the value of each one of these bundles can change as future sales for the present output of the assets in place changes and as the relative value of the options that the firm holds (i.e., future projects) changes. Thus, even though the future sales of the present products of the firm may remain constant, the future business risk of the firm may change as the value of the options held by the firm changes. This information about future projects is known, at best, only in general to the market. As a result of this superior information about the options of the firm and the assets in place, the manager of the firm is best able to estimate the value of the firm. The value of the firm, using Myers' model is: 


$$
V=A_{p}+O_{f}
$$

where $A_{p}=$ value of assets in place

$o_{f}=$ value of future projects the firm has options on. The information that the market has about the firm is made up two subsets: information known to the market about the assets in place and information known to the market about the future options of the firm. The market has some information about the value of assets in place. This information known by the market about the assets in place will generally be less than the information known by the firm.

The information about the assets in place of the firm can be defined as:

$$
I_{\mathrm{pa}}=I_{\mathrm{am}}+\mathrm{I}_{\mathrm{af}}+\mathrm{I}_{\mathrm{au}}
$$
where $I_{p a}=$ total information about assets in place if no

$$
\begin{aligned}
& I_{a m}=\text { information about assets in place known to the } \\
& \text { market (and the firm) } \\
& I_{a f}=\text { information about assets in place known only to } \\
& \text { the firm } \\
& I_{a u}=\text { information that is unknowable because of } \\
& \text { uncertainty. }
\end{aligned}
$$

As noted above, in most cases, the management of the firm will have superior information to the information known to the participants within the markets (i.e., $I_{a f}>0$ ). This means that the management of the firm is in a superior position to the participants in the financial markets in 
estimating the value of the assets in place. But the amount of information known by the management is not much greater than the amount of information known by market participants. This slight difference between information known only within the firm and information known to the market results because a great deal of background information is available if a product has been on the market for awhile. In addition, information from competitors, suppliers, marketing surveys and other non-firm sources of information can be used to estimate future sales and future risk of the existing product.

However, the second subset of information about the future projects on which the firm has options has a different distribution between the firm and the market. The second subset of information, about the options of the firm, can be divided in the same fashion as the information about the assets in place. The financial markets have little information regarding the value of the future options of the firm. Because of competitive needs for secrecy about future projects, firms cannot give the financial markets very much specific information about future projects. The total information about the future projects on which the firm has options can be defined as

$$
I_{\text {op }}=I_{\text {om }}+I_{\text {of }}+I_{\text {ou }}
$$

where $I_{o p}=$ information about future projects assuming perfect certainty

$$
I_{\text {om }}=\text { information about future projects known to }
$$
financial markets and the firm 
$I_{\text {of }}=$ information about future projects known only to the firm

$I_{\mathrm{ou}}=$ information about future projects that is unknowable because of uncertainty.

As in the case of the assets in place, $I_{\text {of }}>0$, but the difference in information known only by the firm and that known by the market is far greater than for the assets in place. The information known only to the firm may in fact include the existence and feasibility of projects completely unknown to the markets. This would be particularly true in larger firms with many diversified divisions, where research and development endeavors are wide-ranging and where the firm has numerous channels available to develop new ideas.

\section{Changes in Financial Structure}

As new information becomes available to the firm, the future prospects of the assets in place and the options on future projects change. Thus, as new information is gained, the business risk of the firm and the estimated future business risk of the firm changes. At any given point in time, the firm generally enjoys a slight advantage in information over the market regarding the assets in place and a large advantage in information regarding future projects on which the firm holds options. But this "firm" information, which affects the business risk of the firm, will become known, at least in part, to the market. Because part or all of this information will become 
known to the market, management of firm must adjust the financial structure of the firm to maximize the value of the firm, given the new level of business risk. This flow of information from that known only to the firm to that known by the financial markets is continuous, although not necessarily regular. Firms realize this, and also realize that once this new information is known to the market, the value of the firm will change. Given the new level of business risk resulting from the new information, management must adjust the financial structure of the firm in order to maximize the value of the firm.

Management adjusts the financial structure of the firm to maximize value for the predicted conditions of the firm. This adjustment is made irrespective of whether this adjustment increases or decreases the value from the present value. The case for changing the financial structure is obvious if the change in business risk is such that changes in the financial structure will increase value. However, the case for changing financial structure if such changes will reduce value is not as clear. Management may have to make changes in financial structure which will decrease the value of the firm from $P_{0}$ to $P_{1}\left(P_{0}>P_{1}\right)$ if such a change will avoid a decrease from $P_{0}$ to $P_{2}$ where $P_{2}<P_{1}$.

This case for decreasing the value of the firm can be seen by again assuming that management will attempt to maximize the value of the firm, thus insuring the maximium wealth for shareholders and management. Assume that the management has received new information that affects the 
future business risk of the firm. This new information increases management's advantage from $\left(I_{a f}+I_{o f}\right)$ to. ( $I_{a f}$ ' I of 1). But management is aware that this information that changes the business risk of the firm will become public knowledge. Given the following definitions,

$$
\begin{aligned}
& \mathrm{V}_{\mathrm{m}}=\text { present market value of firm based on } I_{a m} \text { and } \\
& \mathrm{I}_{\mathrm{Om}} \\
& V_{f m}=\text { future market value of firm if } I_{a f} \text {, and } I_{o f} \text { ' } \\
& \text { were known to the market and } \\
& \text { financial changes are made to } \\
& \text { maximize value given the new level } \\
& \text { of business risk } \\
& V_{f m}{ }^{\prime}=\text { future value of the firm if financial } \\
& \text { structure changes to optimal } \\
& \text { level are not made given } I_{a f} \text {, and } \\
& I_{\text {of ' }} \text { are known to market }
\end{aligned}
$$

it can be shown that management will change the financial structure even if the change in financial structure lowers the value of the firm. Assuming that the new information results in changes in the business risk, the management faces not doing anything and risking having the value of the firm fall to $V_{f m}$ ' once this new information is available to the market. However, if the management acts immediately, by the time the new information is available to the market, the financial structure can be adjusted to maximize the value of the firm, given the new level of business risk. This means the value of the firm will fall, but only to $V_{f m}$ 
which will always be greater that $v_{f m} \cdot$

Time Lags in Changing the Financial

Structure

Changes in the level of debt of the firm cannot be made instantaneously. There is a time lag between the perception of the non-optimal debt level and the necessary change. This lag in changing the financial structure can be greater than one year, or at least not be recorded on annual data for a year or more. Since the data available were yearly data, the time periods in this study are considered to be one year. This time lag is influenced by such factors as the amount of time to make the decisions, to gain acceptance of the changes within the firm, to check for legal and regulatory problems, to engage and negotiate with an investment banker, and to fulfill SEC requirements.

The time necessary to make changes in the financial structure is also influenced by the method used to change the financial structure. If the financial structure is changed by selling new stocks or bonds, the time necessary to make the change will be longer because of regulatory, legal and marketing constraints. If debt or stock is repurchased, some length of time will be necessary to carry out the repurchase. If debt is paid off using available cash, the time necessary could be short. In any case, management must allow some time for the change in financial structure.

Because of the constantly changing factors influencing 
business risk, managers face a difficult problem in making adjustments in the financial leverage. Assume that the management makes a change in the financial structure of the firm at a point in time "x" in order to maximize the value of the firm, given the business risk of the firm at time "x". By the time the change in the debt level is completed, the business risk of the firm could have again changed. Consequently, the management would end up chasing a optimal debt ratio. However, by the time the new financial structure is implemented, the financial structure could be optimal only for the business risk of the firm in a prior period. Rather than doing this, managers begin the process of changing their financial leverage at time " $x$ ", attempting to move to a financial structure that will maximize the value of the firm in the future, based on an estimated level of business risk in the future. Managers must make decisions, at time "x", about the level of debt that will maximize the value of the firm in the future, at time " $x+$ $f "$, given the future business risk at time $" x+f "$, because of the time required to change debt levels. The time period " $f$ " is dependent on the process used to adjust the debt level, the condition of the financial markets at that time, and the speed with which the firm can make and implement a decision. 
Information Content of Financial

Structure Changes

There is an additional reason that management may change debt levels prior to anticipated changes in business risk. Ross $(73,74)$ and Leland and Pyle (52) suggest that managers may be using the change in debt level to "signal" some information to investors and the market about the anticipated situation of the firm. While the market uses all publicly available information in estimating the future value of the firm, "insider" information cannot be released because of the risk of alerting competitors.

Managers can, however, "signal" something about the firm's future by announcing financing plans and starting to carry them out. Managers give "honest" signals because it is in their best interests to do so. If managers attempt to "signal" dishonestly (i.e., issue a security to mislead the market), the cost to them is quite high, for their wealth is tied to the wealth of the firm through stock options, bonuses, and other agency costs that will affect their compensation. In addition, if managers signal dishonestly, they will lose creditability with the market and therefore limit their ability to use the market to signal in the future.

Summary of the Theoretical Model

In summation, if the managers of the firm are to maximize both the wealth of the shareholders and themselves, 
they will change the financial structure, based on estimates of future changes in business risk of the firm, in order to maximize the value of the firm in the future. Since it is impossible to make instantaneous changes, because of the time lag necessary to make such changes in financial structure, managements begin the process of adjusting the debt level at a point in time "x", so that at a future point in time $" x+f "$ the financial structure will maximize the value of the firm at time "x $+f "$. This means the management must estimate at time " $x$ " the business risk of the firm at time $" x+f "$.

Management is in the best position to estimate the business risk of the firm at time " $x+f$ " because the managers has available "insider" information on both the future sales of the present products of the firm and the relative value and timing of the future projects the firm has the option of undertaking. It is also possible that managements use these changes in financial structure as a "signal" to the markets of the future prospects of the firm, thus giving the market "insider" information without giving competitors important specific information.

Developing Empirical Backing

The Hypotheses

The theoretical model developed above hypothesized that there is a relationship between debt and business risk, that the relationship is across periods (defined as one year in 
been developed using a time series model. The two hypotheses tested are as follows:

Hypothesis I: The debt level changes of a firm are strongly correlated with the changes in business risk of the firm.

Hypothesis II: The changes in debt level of the firm occur prior to changes in business risk ${ }^{3}$.

The first hypothesis is concerned with whether there is a relationship between changes in debt and changes in business risk. To test this hypothesis, a correlation model is used to ascertain whether there is a relationship between changes in debt and changes in risk. The second hypothesis is concerned with whether the relationship between changes in debt and changes in business risk is leading or lagging. To test the second hypothesis, the timing of the significant relationships is analyzed.

\section{Assumptions}

In developing an empirical model to test relationships over time between changes in debt and changes in business risk, several assumptions were necessary. First, it was assumed that there is some time delay in carrying out a change in debt level. Second, it was assumed that the amount

3 since the empirical model is concerned with changes in debt levels and changes in business risk, the relevant correlation is between changes in debt and business risk between year end accounting reports. Thus, if the debt level of a firm changes during the time period from $t_{0}$ to $t_{l}$, then it is hypothesized that business risk will change at some future time, for example, between $t_{1}$ and $t_{2}$. 
of time necessary to effect this change was not constant within any firm or any industry. This time to adjust debt levels, defined above as " $f$ ", was dependent on such factors as the state of the economy, the method used to effect the change in debt level, and the particular situation of the firm at the time of the change. Third, it was assumed that management consistently attempts to maximize the value of the firm, using, as possible, changes in debt level.

Overall View of the Model

The empirical model tests for significant correlations between changes in business risk and changes in debt level across time periods. It is hypothesized that there is a leading relationship between changes in debt and changes in business risk. This type of relationship would suggest that managers use their information to estimate the future business risk of the firm and begin to adjust the debt level to maximize firm value, based on the estimated future business risk.

The model was used to test six different relationships between changes in business risk and changes in debt level. Because the data available were annual data, a point in time ( $t$ ) is defined as one year, so that $(t-3)$ refers to a point in time three years prior to ( $t)$. The six relationships tested were:

1. Changes in Debt $(t-3)$ with Changes in Risk ( $t$ )

2. Changes in Debt (t-2) with Changes in Risk ( $t$ ) 
3. Changes in Debt (t-1) with Changes in Risk ( $t$ )

4. Changes in Debt $(t+1)$ with Changes in Risk ( $t)$

5. Changes in Debt $(t+2)$ with Changes in Risk ( $t)$

6. Changes in Debt $(t+3)$ with Changes in Risk ( $t)$

with the figure in parentheses indicating the relative timing of the change.

The Sample

The data used in the empirical tests are annual data from Compustat for the twenty years from 1959 to 1978. The firms are predominantly from the manufacturing sector. The firms were screened in several ways. First, all firms have "pure" debt and "pure" equity. Pure debt is defined as debt that is not convertible or "quasi-debt," such as leasing. pure equity means that only one class of common stock has been issued. This definition avoids problems of classification of hybrid and convertible issues.

The second screening required all firms to be large. All firms in the sample are listed on the New York Stock Exchange and the Standard and Poor's 400 Industrial Index. This requirement ensured that the firms had access to major financial markets.

The final screening required that all firms show a consistent profitability during the twenty years used in the study. This profitability requirement ensures that the firms in the sample have consistently positive cashflow.

This sample used to test the hypotheses is critical to the empirical model. It is hypothesized that managers 
estimate the future business risk of the firm and, acting on this information, change the debt level of the firm to maximize value. This hypothesis assumes that,generally, managers of firms in the sample are correct in their estimates of future business risk, are able to correctly decide the debt levels that maximize value, and are able to implement their decision. Miller and Modigliani assumed that the market forces all firms to adjust to an optimal debt level. While there are no studies that have investigated possible debt optimization differences between firms, it is assumed that firms that consistently generate positive cashflows are better able to optimize the value or the firm by using debt since these firms will have a higher probability of producing the minimum cashflows necessary to service the debt. Because of the lower risk of default by these firms, these firms have the widest range of debt levels open to them. Further, it is assumed that firms that consistently generate positive cashflows are, in part, generating these consistent, positive cashflows because management in these firms is better able to estimate the future. These firms are able to attract the best management because of their higher and more consistent profitability.

Firms with positive cashflow are better able to optimize the value of the firm through debt policy because of the wider range of options open to them. Since the probability of bankruptcy is less with consistent, positive cashflows, firms in the sample should be best able to 
implement optimal debt policy.

Hong and Rappaport (46) have defined insolvency as a state in which a firm's operating cash flows are inadequate to meet contractual debt obligations. In valuing a firm, Hong and Rappaport added an insolvency term to the Miller and Modigliani (64) formula for valuation in a world of taxes and no bankruptcy costs. The original Miller and Modigliani formula was

$$
V=\left(X(1-T) / k_{e}\right)+\left(T k_{D} D / k_{D}\right)
$$

where

$$
\begin{aligned}
\mathrm{X}= & \text { the expected (perpetual) before tax operating } \\
& \text { cashflows } \\
\mathrm{T}= & \text { the firm's tax rate } \\
\mathrm{D}= & \text { market value of the firm's debt } \\
\mathrm{k}_{\mathrm{e}}= & \text { capitalization rate for the cash flows of an } \\
& \text { unlevered firm } \\
\mathrm{k}_{\mathrm{D}}= & \text { capitalization rates for interest payments } \\
& \text { rates on debt. }
\end{aligned}
$$

Hong and Rappaport assumed that the insolvency cost is related positively to financial leverage, given some annual operating cashflow distribution. This insolvency cost was a function of the debt level, the mean of the cashflows and the standard deviation of the cashflows. Hong and Rappaport defined this insolvency cost as

$$
k_{I}=f(D, X, s)
$$

where

$$
\begin{aligned}
& D=\text { debt level } \\
& X=\text { mean of cashflows }
\end{aligned}
$$




$$
\mathbf{s}=\text { standard deviation of cashflows. }
$$

This $k_{I}$ is the cost of insolvency per unit or debt. The Miller and Modigliani formula, using the Hong and Rappaport adjustment for bankruptcy costs, becomes

$$
V=\left(X(1-T) / k_{e}\right)+T D-k_{I} D
$$

The implication from Hong and Rappaport is that firms with lower and more risky cashflows can not support higher debt levels. This restriction on their debt levels could prevent firms from undertaking a more optimal debt level because of these bankruptcy costs. While it has not been shown that the optimal debt level for a particular firm lies outside the set of possible debt levels for a firm, given its cashflow characteristics, it is assumed that firms with more consistent, positive cashflows have greater freedom to pursue optimal debt levels.

A second assumption regarding the relationship of positive cashflows and the ability of management to better predict future cashflows appears reasonable as firms that have consistently positive cashflows can hire better management. No specific studies have shown that firms with consistently positive cashflows hire management that is better able to predict future business risk, but such a relationship appears reasonable.

As a result of these two assumptions, a sample was selected that minimized the probability of bankruptcy and maximized the probability of having superior management. 
While it is not assumed that managers of the firms in the sample always made correct estimates of business risk and always made the optimal debt level decision, it is assumed that managers of the firms in the sample would be most likely to make good estimates of future business risk, to make good decisions regarding optimal debt levels, and to have the maximum range of debt level options open.

The Use of Changes in Debt and Changes in Risk

The empirical model concentrates on changes in debt and changes in business risk rather than absolute values because it is assumed that management attempts to maximize value of the firm at all times. The debt level that maximizes value is dependent on conditions in the company and the environment at that time period. Thus, the optimal debt level or ratio for a firm could vary from year to year. This assumption means that management uses all the information available to optimize the debt level of the firm. Hence, the only time management will change the debt level is when new information re-defines that optimal debt level. This means that the driving force for change is new information. Only when this new information affects the optimal debt level for the firm will there be a change in the debt level. The driving force is change and, hence, the model must define the relationship of debt and business risk by evaluating the relationship between changes in debt and changes in business risk. 
The Reasons for a Time Series Model

The empirical model is designed to allow investigation of the relationship of changes in debt and changes in business risk. It has been assumed that changes in debt level require some time "f", which is not necessarily constant either between or within firms. This time required between the perception of the need to adjust the debt level and the actual recording of the change in debt level on the firm's balance sheet could extend over more than one period. This lag in the recording of changes in debt levels is in part the result of the utilization of yearly data and in part the result of the non-constant time "f " required to actually carry out the change. As an example of this problem, assume that a firm, using a calendar accounting year, decides to change the optimal debt level (debt/total assets) of the firm in september, 19xl, by selling a new issue of debt. By the time the debt issue is actually recorded on the year end balance sheet, possibly fifteen months have passed, since it would be very difficult to carry out a new issue in time to record the issue on the balance sheet for 19x1. However, if the same change in debt level was made by buying back stock from one large investor using available cash, it is possible that the change in the debt level could have been recorded in $19 x 1$ rather than 19x2. In both cases, the debt level would have changed in the same direction, but the time of recording would be one 
period different.

It is apparent that these two different methods to affect a change in the debt level (measured by debt/total assets) would have differing effects on the overall riskiness of the firm. The major point, however, is that changing the debt level of the firm can be accomplished in a number of ways, and the time necessary to effect this change depends in part on the method used. Since the model is attempting to relate changes in debt and changes in risk and these changes in debt may be recorded in different periods than the decision, a time series model is necessary irrespective of the timing relationship between changes in debt and changes in business risk. Further, since it is hypothesized that there is a leading relationship between changes in debt and changes in business risk, a time series model is necessary.

\section{Development of the Business Risk Measure}

The risk measure is designed to measure changes in business risk while allowing for two adjustments to normalize the raw measure of business risk change. These adjustments are necessary because the management of a firm does not look at merely the raw change in the business risk. The management must also make allowances for the overall changes in the economy, and for what is a "normal" change within the company. This normal change is what past experience would indicate is a reasonable change in the operating income of the company. Any firm shows some 
variation in its EBIT (earnings before interest and taxes) over time. This variation, usually measured by standard deviation, gives the management a range within which variations can be judged as normal or otherwise. Hence, the actual raw measure of the change in business risk must first be adjusted for the normal changes expected in business risk for the firm.

The raw measure of business risk change is between year change in earnings before interest and taxes (EBIT). This measure was used for several reasons. First, EBIT is a traditional measure of business risk. Second, the change in EBIT captures both changes in sales and changes in operating leverage. Finally, the use of changes in EBIT as a measure of business risk has been empirically tested and found to be a very strong indicator of business risk by zumwalt and Shin (96).

The change in EBIT risk was first adjusted for the normal business risk change expected in the firm. The raw measure of change in business risk, change in EBIT, was adjusted using the standard deviation of the EBIT for the firm over the period. After the first adjustment, the risk measure becomes

$$
R M_{t, i}=\left(E B I T_{t, i}-E B I T_{t-1, i}\right) / S . D \cdot i
$$

where $\mathrm{RM}_{t, i}=$ risk measure for time period tor firm i

$$
\begin{gathered}
\text { S.D. } i=\text { standard deviation of EBIT for firm } i \text { over the } \\
\text { twenty year period. }
\end{gathered}
$$


The resulting risk measure relates the amount of change in EBIT from one year to the next relative to a measure of "normal" change in the EBIT of the firm. This adjustment is made by using one standard deviation as a measure of the "normal" change experienced by the firm. This change in EBIT must also be evaluated in terms of the rest of the economy. If all firms are showing a great increase in EBIT, then a larger than normal change for the firm may not signify any real change in the business risk of the firm.

The second adjustment is to adjust for the changes in the economy and essentially "de-trend" results over the twenty year period. A ranking and differencing procedure is used. The change in EBIT, relative to the standard deviation, is ranked for each firm relative to all firms in the sample for each year. Hence, for each year there is a number assigned to each firm, based on the firm's change in EBIT, relative to its standard deviation of EBIT. The change in this number from one year to the next is the relative business risk change of the firm. The larger the change in EBIT, relative to the standard deviation of EBIT for the firm and relative to the changes in firms in the sample, the larger the relative change in business risk.

These two procedures of ranking and differencing detrend the data by ensuring that the firm registers a change in business risk only if the level of EBIT changes relative to the normal changes expected for the firm, and relative to the changes in all firms in the sample. Hence, a firm can 
show a change in business risk only if the change in EBIT is large relative to the standard deviation of the EBIT of the firm over the twenty year period and this change is large relative to the changes in the EBIT of other firms. If all firms are showing a gain (or loss) in EBIT, then the ranking of any one firm which shows a change in EBIT will not change. A change in EBIT, even if it is large relative to the standard deviation of EBIT for the firm, may not be large enough to register as a change in business risk. If all other firms are also experiencing a large increase in EBIT (as in an upswing in the economy), then the change in the individual firm's EBIT will not result in a change in business risk measure.

This numerical rank ordering of the firms in each year, dependent upon the ratio of the change in EBIT to the standard deviation of EBIT of the firm, has been tested by Z umwalt and Shin (96). They found that when rank ordered business risk variables were used, all ot the eight variables tested were significant in ANOVA tests of industry financial structure. When the raw variables were tested, only three of the eight variables were significant.

In this manner, changes in business risk were developed for all firms over the twenty year-period. This measure of risk was not designed to measure exactly the business risk of a firm at a particular time. Rather, this measure is designed to indicate changes in risk for the firm, relative to the changes in risk that the firm would generally expect 
and relative to the changes in other firms in the economy. The purpose of this risk measure is to integrate two sets of information used by the management to assess the business risk of the firm. The management uses the (estimated) performance of the firm and this performance relative to other firms to judge the business risk of the firm.

Development of the Debt Measure

Two different variables are used to measure the debt level. The debt level was measured using total debt as a percentage of total assets and long term debt as a percentage of total assets. Both of these measures were found to be significant indicators of differences in financial structure between industries by $\mathrm{zumwalt}$ and Shin (96). Zumwalt and Shin tested the variables used by numerous earlier studies and their own study, using an ANOVA procedure to test for differences between industries. They found that total debt to total assets, as used by Ferri and Jones (32) and Remmers et al. (71), and long-term debt to total assets, used in their own study, were consistently significant variables.

The change in debt level percentage (debt as a percentage of total assets) for each firm was used to measure the change in debt. This resulted in nineteen changes in debt measures for each firm for the twenty-year period utilized in the study. 
Correlation Method

The two measures for each firm, the measure of change in risk and the measure of change in debt, were correlated using a Pearson product-moment correlation. Two sets of six different correlations were calculated for each company in the sample, using the appropiate leads and lags described in the section on the Overall view of the Model. The two different sets of correlations used two different measures of debt, long term debt to total assets and total debt to total assets.

Results of the Empirical Testing

The empirical testing generally supported the theoretical model. The majority of the firms (66\%) showed a correlation between changes in business risk and changes in debt level at a $10 \%$ observed significance level. Of those firms that showed a correlation between changes in debt and changes in business risk, a large majority (69\%) showed changes in debt leading changes in business risk. If the contemporaneous changes in debt level and business risk are included, over $90 \%$ of the firms showing significant correlations had leading or contemporaneous relationships between changes in debt and changes in business risk.

While the empirical evidence is far from overpowering, the trend of anticipating risk changes and adjusting debt levels seems to be, at least weakly, supported. It would appear that firms do anticipate changes in risk and adjust 
their debt levels in anticipation of these changes. Thus, both hypotheses, that there is a correlation between changes in business risk and changes in debt levels and that changes in debt levels tend to lead changes in business risk, have some empirical support.

It is impossible to "see inside" a manager's mind and understand the motivations, variables and calculations that determine a particular mangerial decision. It is dangerous to blindly use the results of empirical study to estimate motivations, variables and calculations that make up that a decision. From the empirical results of this study, it appears that managers do make changes in the debt level of firms prior to changes in business risk. This type of behavior would suggest that managers are cognizant of the relationship of business risk and firm value and of the time necessary to make changes in debt and do make estimates of future business risk. These results also possibly support the hypothesis of Ross and Leland and Pyle that changes in debt are a signaling device, used by management to provide information to investors about the future of the company without releasing proprietary information. 
CHAPTER II

\section{LITERATURE REVIEW}

\section{Introduction}

This chapter will present the theoretical and empirical literature relevant to the background of the present study. The purpose of this chapter is twofold: first, the chapter will provide a survey of the literature on financial structure, and second, the chapter will provide background and relevant arguments for both the theoretical and empirical models developed in this study.

In the area of financial structure, a major problem is the conflict between the microeconomic (or firm level) approach to valuing debt and the macroeconomic (or market) approach to valuing debt. As discussed in Chapter I (pages 2-4), the use of debt in the financial structure of the firm has an effect on both the size and standard deviation of the cashflows available to shareholders. Even prior to the seminal paper by Miller and Modigliani (62) in 1958, Durand (23), in 1952, had outlined three problem areas.

1. What is the cost of the various methods of financing?

2. Do the costs of financing discourage business expansion? 
3. Does the tax structure have any effect on the cost of financing?

Durand assumed that any answers to these three questions would require a better understanding of security appraisal if the cost of capital was to be measured and would also require an analysis which was involved with maximizing wealth rather than income. Although now the former assumption is almost universally accepted, at the time, the problem was being approached from a viewpoint of maximizing income. An analysis that maximized wealth, while greatly compounding the difficulties of measurement, is more in line with modern studies and reality.

The problem of security appraisal was approached by using a required return or capitalization method. This capitalization of income method had two approaches, a net operating income (NOI) and a net income (NI) method. The NOI method gave a lower value for the stock, for it assumed the existence of debt decreased the value of the firm. The NI method gave a higher value for the stock, for it assumed that the firm's value was not affected by debt as long as the firm used debt in a "reasonable" manner.

Durand did postulate that a firm could increase its value through the use of debt and that there was some optimal debt level beyond which increasing debt reduced firm value. Durand also postulated that, since bond interest was tax deductible, the use of debt gave the firm a definite tax advantage. Durand felt that the key to the problem of the cost of capital was to devise a method of measuring the 
value of securities. Durand postulated that only after the appraisal of securities was possible could the problem of cost of capital be defined and solved.

Macroeconomic Approach to Valuation of Debt

Miller and Modigliani (henceforth MM), in a series of papers (62), (63), (64), used a market approach to value firms and then attempted to solve the problem of the cost of capital, the effect of taxes, and the effect of debt on the value of the firm. MM's was a static model (in the sense that only cross-sectional data was utilized) which attempted to correlate cost of capital (estimated by using returns and market valuations of firm value) with debt levels (also estimated using market valuations of firm value). In the notax case, MM postulated that a levered firm could not command any premimum over a debt-free company because investors could just as easily use "home-made" leverage by borrowing on their personal accounts to end up in the same risk and return position.

MM, in their Proposition I, further postulated that the value of the firm is independent of its capital structure and this value is found by capitalizing its expected return at a rate appropriate to its risk class. This proposition implied that the value of a firm was strictly a function of expected income and risk class.

This proposition also implied that the cost of capital of a levered firm was the same as for a unlevered firm. This 
cost of capital was the capitalization rate of a pure equity stream of a firm in the same risk class.

From this Proposition I, MM developed Proposition II which stated that the return on stock of a levered firm was equal to the appropriate capitalization rate for a pure equity firm of its class, plus a premium because of the increased risk of bankruptcy caused by the debt.

\section{Proposition I}

MM developed their Proposition I by first assuming that all stocks earned a return equal to that of similar risk stocks. The value of the firm was the discounted value of a perpetual stream of income, using as a discount rate the proper rate of return for a stock of that class. Thus, for a firm which issues only stock, the value of the stock is determined by the required return for a stock of that risk class and the income stream available to stockholders.

$$
P(j)=x(j) / p(k)
$$

where

$$
\begin{aligned}
& P(j)=\text { the price of stock } j \\
& x(j)=\text { the expected return for stock } j \\
& p(k)=\text { expected rate of return for stocks in class } \\
& k \text {. }
\end{aligned}
$$

This is equivalent to

$$
p(k)=x(j) / P(j)
$$

where $p(k)$ is a constant for all firms $j$ in class $k$. When firms issue bonds, the expected value of the 
income stream will change because of financial leverage. But the amount of debt held will not affect the market value of the firm. MM postulated that in the no tax case, the market value of the firm is independent of its capital structure and is determined by capitalizing the expected return at the rate appropriate to its class.

$$
V(j)=S(j)+D(j)=X(j) / p(k)
$$

where $\quad V(j)=$ market value of the firm

$$
S(j)=\text { market value of the outstanding stock }
$$$$
D(j)=\text { market value of the outstanding debt. }
$$

This valuation formula can also be expressed in terms of the average cost of capital, $x(j) / V(j)$.

$$
x(j) /(S(j)+D(j))=x(j) / V(j)=p(k)
$$

Thus, the average cost of capital to any firm is completely independent of its capital structure and is equal to the capitalization rate of a pure equity stream of income of a firm in its class.

\section{Proposition II}

From Proposition I, MM developed Proposition II, regarding the rate of return, $i(j)$, on common stock of a levered firm.

$$
i(j)=p(k)+(p(k)-r)(D(j) / s(j))
$$

That is, the expected yield on a share of stock is 
equal to the appropriate capitalization rate, $p(k)$, for a pure equity stream in the risk class, plus a premium related to the financial risk. This premium is equal to the debt to equity ratio times the difference between $p(k)$ and the riskfree rate $(r)$.

Theoretical Support of MM

The great impact on the accepted ideas of corporate finance caused by MM's work resulted in further works of both a theoretical and empirical nature. The further theoretical work was mainly concerned with the validity of MM's assumptions and the conditions under which their proofs were developed. Stiglitz (83) enumerated five limitations of the MM proof.

1. It depends on the existence of risk classes.

2. The use of risk classes seemed to imply objective rather than subjective probability distributions over the possible outcomes.

3. It was based on partial equilibrium rather than general equilibrium analysis.

4. It was not clear whether the theorem held only for competitive markets.

5. Except under special circumstances, it was not clear how the possibility of firm bankruptcy affected the validity of the theorem.

Stiglitz showed that the MM theorem holds under far more general assumptions than MM required. In particular, Stiglitz showed (83) that, using a general equilibrium state 
preference model, the MM theorem holds without the assumption of risk classes, competitiveness of capital markets, or agreement about the probability distributions of outcomes. Stiglitz also showed that MM's results may still be valid even if there are limitations on borrowing for individuals. Stiglitz did find however, that the possibility of bankruptcy still raised serious problems.

Baron $(5,6)$ showed, using a stochastic dominance model, that under certain conditions, the value of a levered firm may be greater than the value of an unlevered firm. However, under the general conditions of MM's model, MM's theorem is valid if all investors can borrow at the same interest rate as firms.

Hirshleifer (44) used a time-state-preference model to show that under the idealized MM conditions, all possible ratios of debt are equivalent in market value. Where these conditions do not hold, there will be in general an optimal debt ratio.

Fama (27, 28) showed that MM's results hold even if the holders of the firm's securities are unable to protect themselves from default risk. Fama and Miller labeled this default risk protection "me-first" rules. Fama showed that even without "me-first" rules, in perfect capital markets, the firm's financing decisions have no effect on its market value and its financing decisions are of no consequence to its security holders.

While many authors argued that MM's results were true 
under the conditions stated, there was far from universal agreement. Both Solomon (81) and Lintner (53) disagreed with MM, using microeconomic-based arguments. Solomon argued that MM failed to incorporate the increase in the cost of equity as the debt level rose, resulting in their belief that the cost of capital is constant for any level of debt. Lintner argues from a marginal cost of capital standpoint that increased debt-financed investment will raise the value of the firm as long as the return on the investment is sufficient.

\section{Early Empirical Studies}

MM's theories on debt were based primarily on two studies by Allen ( 1 ) and Smith ( 80 ) and tested with empirical work they themselves did. While MM's contributions were mainly theoretical, it is important to understand the empirical method utilized by MM, both to appreciate the problems inherent in empirical testing in this area and to understand the design of the empirical model in this study. Further, many of the studies after MM utilized a similar methodology.

MM used data from 1947 and 1948 for electrical utilities and oil companies. Allen used data from 1947 and 1948 from forty-three large electric utilities to analyse the relationship between security yields and financial structure. Smith did a similar study using data from 1953 for forty-two oil companies.

MM's study used cross-sectional regressions to study 
the correlations of the cost of capital with the debt ratio to test Proposition I. The cost of capital was approximated by :

$$
x=x(j) / V(j)
$$

$$
\text { where } x=\text { cost of capital }
$$

$$
\begin{aligned}
& \mathrm{X}(j)^{\prime}=\text { the return to firm } j \\
& \mathrm{~V}(j)=\text { the value of firm } j
\end{aligned}
$$

This was regressed against the debt ratio $d$, where $d$ was defined as

$$
d=D(j) / V(j)
$$

where $D(j)=$ market value of the debt of firm $j$

and $V(j)=$ market value of the company.

When MM regressed the cost of capital ( $x$ ) against the debt ratio (d) they found that, for both the oil companies and electric utilities, the correlation coefficients were insignificant and of the wrong sign. This supported MM's Proposition I that the cost of capital was independent of the financial structure. From a microeconomic viewpoint, an increased debt level should have decreased the cost of capital to a point, and if the firms were prudent in their debt usage, it would be expected that the correlation between the cost of capital and increased leverage would lead to statistically significant, negative correlations.

MM also empirically tested Proposition II by regressing the yield on common stock against the degree of leverage. stock yield was approximated by net income to stockholders after taxes divided by market value of the common stock. 
Leverage was measured using the market value of senior securities divided by market value of common stock. MM felt their results supported Proposition II as the $y$-intercept of the regression line approximated the required yield on the securities and the slope of the regression line approximated the required return minus the risk-free rate. The correlation coefficient was positive in both cases (for both the electric utilities and oil companies) and felt by MM to be highly significant $(r=.53)$.

Both Durand (21) and weston (93) did similar regression studies using banks and utilities, respectively. Both found that their empirical results refuted MM's findings and both raised objections regarding possible mis-specifications of the cost of capital by MM.

Weston postulated that MM's static model failed because it did not properly account for the correlation of leverage with other influences, such as growth, that change the gross relationship between cost of capital and leverage. Weston's model was very similar to MM's, but weston used utility company data from 1959. Weston postulated that the years studied by MM (1947-1948) were years of low equity prices and high price/earnings ratios, and this particular data tended to skew their results.

Durand, like Weston, used later data than MM. Durand utilized bank and utility data from 1955 and ran tests similar to MM's. Durand criticized MM mainly because of their reliance on perfect markets and used the restrictions on margin buying and the wide variance of stock prices from 
book values as examples of imperfections in the market. Durand postulated, like weston, that MM had not, in their static model, accounted for growth and its effects on leverage and the cost of capital. Durand also empirically demonstrated that dividend payout ratios affected cost of capital, another area which MM felt should not affect the cost of capital.

Durand regressed stock price against book value, earnings, and dividends and found that dividends greatly affected price, and thus, cost of capital. Durand also noted that the period studied by MM was an era favorable to bond financing. Durand postulated that the use of this data had two effects. First, it skewed MM's results, and second, it was evidence of the problems of cross-sectional analysis as opposed to more dynamic models spanning different types of markets.

Using models similar to MM's, but with different data, Durand and Weston obtained empirical results opposite to MM's. Durand thought that MM's differing results could be due to their static model. In addition, both Durand and Weston thought that the unique period utilized by $M M$ in their empirical work could have skewed their results. Masulis also questioned MM's statistical methods, noting that since only regulated firms were examined, the empirical findings might have been the result of the regulatory environment of the sample.

In the present study, the empirical model uses data 
from a twenty year period and investigates the cross-period relationships of business risk and debt level. This use of a multi-year data sample and a dynamic model should avoid the criticisms of MM's empirical work by weston and Durand. Further, since the data sample is from non-regulated industries, the problem suggested by Masulis should be avoided.

\section{Equivalent Risk Class Testing}

MM also postulated that firms belonged to a risk class which defined the proper discount rate for the firm. However, attempts to find some grouping that approximated MM's concept of risk classes have been generally unsuccessful when other than very broad groupings are made.

MM's concept of distinct risk clases was tested in four studies which resulted in two opposing views. By using an analysis of variance procedure, two of the studies confirmed MM's concept of risk classes having unique financial structure. However, wippern (95) showed a flaw in the use of analysis of variance, which resulted in his postulating that the concept of risk class, at least as evidenced in different financial structures, was invalid. In addition, the study by Remmers et al.(71), using analysis of variance, found no support for MM's risk class concept in either the United States or in five industrialized foreign countries.

Schwartz and Aronson (76), scott (78), Wippern (95), and Remmers et al. (71) employed analysis of variance tests 
on debt level measures and estimates of business risk to test whether the mean of the business risk or financial structure variables were significantly different between industries.

Schwartz and Aronson used the mean of the common equity to total asset ratio of firms in four broadly defined industry groups, assuming some direct linkage between a firm's financial structure and its business risk. They found that there were significant differences in the mean of the equity to total assets ratio between industries and insignificant differences intra-industry.

Scott (78) used the ratio of book value of equity to total assets to measure financial structure. Scott expanded the work of Schwartz and Aronson by using ten industrial groups rather than just four and by using data from ten years rather than just two years. Scott, using analysis of variance, found that there was greater variance in financial structure among groups than within groups. This finding lent support to Schwartz and Aronson's conclusions that firms in the same industries tended to develop similar "optimal" financial structures.

Remmers et al. (71), also used analysis of variance procedures on firms from five different industrialized countries to test the assumptions that industry classification can be used as estimate of business risk. They also tested the sample for the effect of size on the debt ratios. Remmers first replicated Scott's study, using 
firms in nine different industries from the United States for 1966, 1970, and 1971. Using a larger sample size (258 firms in 1966,319 in 1970 and 328 in 1971), they found no support for scott's findings. Remmers then tested industry as a determinant of financial structure in five different countries, using analysis of variance on debt ratios of firms in different industries within each country. Remmers found that industry and size were not determinants of financial structure in any of the countries for the years tested.

Wippern (95) used a different measure of business risk, mean net operating income per share variability, and initially found evidence to support Scott's and Schwartz and Aronson's conclusion of a strong link between business risk, financial structure, and industry class.

However, Wippern noted that analysis of variance, using an F-test to ascertain if means differ significantly, gives a total measure of difference, rather than shows whether the significant difference is due to all the means being significantly different from each other or is due to one or two means being significantly different from the rest.

Wippern, using Schiffe's test of multiple comparison, found that the significance of the F-test in the original analysis of variance was due exclusively to differences between the utilities industry and four of the eight industries in the sample. There were no significant differences between any of the other industries.

Wippern concluded that there were no significant 
differences between industry groups (with the exception of utilities) when using net operating income per share variability as an estimate of business risk. Wippern's conclusions are important for two reasons.

First, wippern's results suggest the possibility that the industries used by MM, Allen, and Smith were unique firms and that any results from studies of such firms are applicable only to regulated industries. Second, since there appears to be little difference between manufacturing industries in their financial structures, it is possible that the determinants of "optimal" financial structure are more closely tied to other factors rather than the industry of the firm.

In the present study, industry classification is assumed to be, at best, of marginal importance in determining financial structure. For this reason, the sample used in this study is drawn from a wide variety of manufacturing industries. It is assumed that financial structure is a function of factors other than industry, and if indeed risk classes do exist, the determination of these risk classes is a far more complex relationship than industry grouping.

The research detailed in this section highlights the problems involved in testing for the relationships of financial structure, valuation, and risk. The initial studies of Smith, Allen, MM, Scott and Schwartz and Aronson, using general classifications and one-dimensional risk or 
debt measures in a limited number of years, provided clear cut results. However, when MM's theories were subjected to more sophisticated models spanning many years and different types of markets and employing larger samples, the results were found to be directly opposite to the earlier studies. Remmers, Weston, Durand, and wippern demonstrated that if the classifications for industry were made less general, the studies expanded to more years of data, and the sample size increased, the theories of MM lacked empirical backing, at least in the sense of applying their basic, no-tax model. MM, however, realized that the existence of taxes and bankruptcy costs greatly complicated the problem of the value of debt. The approaches to the question of the value of debt in a world with taxes are detailed, in the next section.

Macroeconomic Approach With Taxes

MM's original study assumed no taxes, but MM did postulate that the effect of taxes would be slight on their two propositions. MM surmised that the value of the tax deductibility of interest payments affected only the value of $x(j)$. In a correction to their original paper (63), MM modified this view somewhat, showing that the tax advantage of debt financing is greater than originally assumed, but that the tax advantages are the only permanent value of debt. With taxes, $x(j)$ becomes $x(j) '$. 


$$
\begin{aligned}
x(j)^{\prime} & =x(j)-r(D(j))(1-t)+r(D(j) \\
& =q(t)+r D(j)
\end{aligned}
$$

where $q(t)=$ the after tax return net of taxes

$r \quad=$ the cost of debt.

The value of the levered firm, $V(1)$, is

$$
\begin{aligned}
V(1) & =x(j) / p(t)=(1-t) x(j) / p(t)+t R / p(t) \\
& =V(u)+(r / p(t))(t D(j))
\end{aligned}
$$

where $t=$ tax rate

$$
\begin{aligned}
& x(j)=\text { expected income } \\
& p(t)=\text { rate market capitalizes expected returns } \\
& \text { net of taxes for an unlevered company in } \\
& \text { class } \mathrm{k} \\
& V(u)=\text { the value of a unlevered firm in class } k \\
& r=\text { rate at which market capitalizes a sure tax } \\
& \text { savings generated by debt } \\
& R=\text { interest cost. }
\end{aligned}
$$

Proposition I becomes

$$
p(k)^{\prime}=x(j)^{\prime} / V(j)
$$

and Proposition II becomes

$$
i(j)=p(t) / S(j)=p(j)^{\prime}+\left(p(k)^{\prime}-r\right)(D(j) / S(j))
$$

The after tax earnings yield becomes

$$
i(j)=x(j) / V(j)=p(t)-t(p(t)-r)(D(j) / V(j))
$$

This implies that the only effect of leverage on return is the tax deductability of interest payments. The value of the firm is a function of both leverage (but only because of the tax savings of debt) and the expected returns as compared to an unlevered firm. MM postulated that if (3) and (4) did not hold between pairs of firms in a class, then 
arbitrage would restore the stated equalities.

This postulated increase in value due to the tax deductability of interest ( or rather, the risk-free stream of future income from the tax shelter) implies that firms should use all debt, or very close to all debt, in their capital structure. While this high level of debt is approached occasionally by utilities, almost all manufacturing firms have a much lower level of debt than MM would suggest. In addition, the existence of higher tax rates should entice firms to use a higher level of debt. Miller (61) however, in comparing pre- and post World War II debt and tax levels, found no evidence that the higher tax rates of the post-World War II era were associated with higher debt levels.

MM (64) suggested that firms do not use as high a level of debt as possible because of "the tax status of investors," "other dimensions (and kinds of costs) in realworld problems of financial strategy," and "the need for preserving flexibility." MM readily admitted that their static analysis was unable to handle many of the complications of the real world, such as inter-period tax adjustments, carryforwards and carrybacks, and investment tax credits. These problems have been approached in a number of ways by later authors, who concentrate on two general areas, the cost of bankruptcy and the value of debt from a tax standpoint. 
The Cost of Bankruptcy

Hong and Rappaport (46) have identified two types of bankruptcy costs, direct and indirect. The indirect costs result from the problems of insolvency, where the firm cannot meet contractual debt obligations from the present stream of income. The firm must then raise the needed funds by other, probably sub-optimal, means. If the firm is unable to raise these funds to meet contractual obligations, the loss in value of the firm is the direct cost of bankruptcy. Hong and Rappaport postulate that the level of debt would be balanced with the possible costs of insolvency or bankruptcy. MM's equation for valuing the firm (using Hong and Rappaport's symbols) is

$$
\mathrm{V}=\mathrm{X}(1-\mathrm{T}) / \mathrm{k}_{\mathrm{S}}+\mathrm{Tk_{ \textrm {D } }} \mathrm{D} / \mathrm{k}_{\mathrm{D}}
$$

where $\mathrm{V}=$ the value of the firm

$$
\begin{aligned}
X= & \text { expected annual before tax cashflows } \\
T= & \text { firm's tax rate } \\
D= & \text { market value of debt } \\
k_{S}= & \text { rate at which the market capitalizes the after- } \\
& \text { tax cashflows of an unlevered company in the } \\
& \text { same risk class } \\
\mathrm{k}_{\mathrm{D}}= & \text { rate at which the market capitalizes interest } \\
& \text { payments on debt. }
\end{aligned}
$$

Hong and Rappaport added a term to MM's equation to account for the insolvency cost function, assuming that the average insolvency cost is proportional to the probability risk of insolvency $P\left(X<=D k_{D}\right)$. MM's equation then becomes

$$
V=X(1-T) / k_{S}+T D-D k_{I}
$$


where $k_{I}=$ the average insolvency cost per unit of debt. Thus, at the optimal capital structure, the marginal tax benefits are exactly offset by the marginal insolvency costs. By differentiating equation (15) with respect to $D$, the value of the firm, at the optimal debt level becomes

$$
\mathrm{V}=\mathrm{X}(1-\mathrm{T}) / \mathrm{k}_{\mathrm{S}}+\mathrm{TD}^{*}-\mathrm{k}_{\mathrm{I}} \mathrm{D}^{*}
$$

where $D^{*}=$ the optimal debt level.

While Hong and Rappaport do not offer any empirical support of the above, Baxter (7) and Warner (91) did empirical studies that attempted to estimate the cost of bankruptcy. Baxter used personal bankruptcy data and found that the cost of bankruptcy was approximately twenty percent of the individual's assets. Warner, however, found that, when using data from a number of bankrupt railroads, the cost of bankruptcy was about one percent of the market value of the firm prior to bankruptcy. Warner was careful to point out that the relevant cost of bankruptcy was the expected cost rather that the actual cost. Since the firm is unable to know ex ante the actual cost of bankruptcy, at best the firm would have to pick a level of debt that would assume some probability of bankruptcy. In any case, the expected cost for "reasonable" debt levels would appear to be rather low for larger firms.

From a theoretical standpoint, Haugen and senbet (42) also argued that bankruptcy costs were rather trival and that even liquidation costs have no effect on capital structure decisions. Haugen and senbet disassociate the 
costs of bankruptcy (the transfer of ownership to creditors) from the costs of liquidation (dismantling the unprofitable firm) and point out that liquidation is an independent capital budgeting decision. Haugen and senbet argue that because prices in a competitive market reflect the actual value of the firm, bankruptcy costs must be trival and thus, bankruptcy costs do not have an effect on the optimal capital structure for a firm.

Despite the work of Haugen and Senbet, it is generally assumed that bankruptcy costs have some effect on the level of debt utilized by a firm. From the standpoint of the empirical portion of this study, the probability of bankruptcy is minimized by the careful choice of sample. Rather than arguing for or against the importance or size of bankruptcy costs, this study assumes that for some subset of firms in the economy the existence or effect of bankruptcy costs is of minimal importance, for the probability of bankruptcy is slight. Since the probability of bankruptcy is slight, the effect of bankruptcy costs on optimal capital structure is minimal. This is not to say that bankruptcy costs are of no concern to managers of these firms. Rather, the choice of sample ensures that the managers of these firms have the greatest freedom from worry about bankruptcy.

\section{Optimal Capital structure}

The concept of an optimal capital structure has long been an accepted concept in finance. Numerous bond rating services and stock market reports regularly publish the 
industry average debt ratios, implying that these ratios have some importance. MM's later work (64) in a world with taxes suggests that debt does add some market value to a unlevered firm. The exact level of debt, that optimal debt level that maximizes firm value, however, remains an area of dispute. Various attempts to group firms, for example by industry, into risk classes as suggested by Mi have, as noted earlier, been unsuccessful.

Robichek and Myers (72) used a state-preference framework to show that in a world with taxes, an optimal degree of leverage exists. Further, their argument does not depend on the "market imperfections" which are alleged to prevent the arbitrage process described by Modigliani and Miller. Robichek and Myers argued that several of MM's assumptions did not, in fact, hold in a world with taxes and that a optimal capital structure results from the balancing of the added value of debt to the firm and the disadvantages of debt, such as bankruptcy costs, to the firm.

Kraus and Litzenberger (51) also used a statepreference model to show that "the total market value of the firm is not in general a concave function of financial leverage." Kraus and Litzenberger postulated that the taxation of corporate profits and the existence of bankruptcy penalties are market imperfections that are of major importance to any theory of an optimal capital structure.

Kim (48) used a mean-variance approach to show that a 
firm's debt capacity, the amount of debt the market would allow, is greater than the optimal debt level for the firm. This model showed that the value of the firm followed the "traditional" model where increasing levels of debt increased the value of the firm to a point where further increases in debt decreased the value of the firm. Moreover, this model showed that the traditional market value of the firms as a concave function with a global maximium holds in a capital market equilibrium framework.

Turnbull (90) also showed that the traditional concave function of market value holds using a more rigorous closed form approach. Turnbull's results showed that the debt capacity of the firm, as allowed by the market, will be greater than the optimal debt ratio.

Masulis (58) showed that the addition of debt tends to increase the value of a firm in an empirical study of issuer exchange offers and recapitalizations. This would tend to support the concept of an optimal capital structure.

Scott (79) developed a multiperiod model of firm valuation with bankruptcy costs to show that a unique optimal capital structure exists for a firm. Scott's model assumed that the market for real assets was imperfect and that the value of a firm was a function of the expected future earnings and the liquidating value of the assets of the firm. A comparative statics analysis showed that "the optimal level of debt was an increasing function of the liquidation value of the firm, the corporate tax rate, and the size of the firm." 
Brennan and Schwartz (12) approached the concept of an optimal capital structure by assuming the value of the levered firm was related to the value of an unlevered firm, which in turn they assumed to follow a Gauss-Wiener process. Using a differential equation similar to the option pricing model of Black and Scholes, and Merton, Brennan and Schwartz show that an optimal capital structure exists even if the tax savings due to interest deductability do not constitute a sure stream.

Hamada (39) derived MM's three Propositions using a mean-variance approach, showing that the assumption of homogeneous risk classes and the MM arbitrage proof are unnecessary. In a later paper, Hamada (38) tested MM's results in an empirical study, showing that approximately $23 \%$ of the systematic risk of firms is due to the use of debt and preferred stock. Hamada also found that MM's model of the effect of financial leverage better explained the use of debt by firms in their sample than the traditional view. Hamada's work tends to support the concept of an optimal capital structure determined by a maximization of value of the firm, within a mean-variance framework.

Williamson (94) investigated the moral hazard effect on optimal financial structure, following the work of Myers (67). Williamson empirically tested whether firms would reject projects with a positive net present value because of their need for the use of financial leverage. Williamson showed that growth opportunites support less long term debt 
than physical assets. This aspect of optimal financial structure, involving the composition and relative size of the assets of the firm, has only recently been integrated into the question of capital structure. In the present study, the changes in capital structure are thought, at least in part, to be driven by changes in the composition of assets that comprise the firm.

The above studies show that, in general, the concept of a optimal capital structure is accepted. While there remain arguments about how various disadvantages of debt offset the value of the tax deductability of interest, the concept of an optimal debt ratio, or range, has been shown valid using a wide range of financial tools and under a wide range of assumptions. What determines the actual optimal debt ratio is still a major question of finance. In the next section, some of the attempts to isolate the determinants of capital structure will be detailed.

\section{Determinants of Capital Structure}

As demonstrated in the previous section, the concept of an optimal capital structure for a firm is accepted by many. The question of what determines that optimal capital structure is not so well developed. The work cited earlier in the section on Equivalent Risk Testing showed that there does not appear to be a homogeneous grouping of firms by industry in terms of their capital structures. Much of the work in this area has involved empirical testing using either multivariate or multiperiod models. Since these 
studies are important to the present study from both a theoretical and empirical standpoint, some discussion of the advantages and disadvantages of these types of models follows.

\section{Multivariate and Multiperiod Models}

This section will discuss the use of multivariate and multiperiod models that have been utilized in research of debt policies. While multivariate and multi-period models require more complex mathematical and statistical techniques, as pointed out earlier, the use of univariate measures in cross-sectional studies has resulted in conflicting results. Moreover, as shown in the preceding section, when these univariate models are expanded to larger samples and more rigorous group classification, the results become open to criticism, for these more rigorous univariate classifications ignore important interactions and influences.

Just as univariate models do not capture interactions between different variables, single period or crosssectional models miss the effect of changes in earlier periods or of information available from forecasts made of later periods. These variables could have significant effects on decisions made about debt policies.

The effect of variables in periods other than the present have a particular importance to debt decisions. Debt decisions are generally not recorded on accounting 
records in the period in which they are made. Because of the time lag necessary to change the financial structure of the firm, in order to effectively relate the variables that differentiate firms' debt policies, it is necessary to look at variables in different time periods than that period in which the financial structure actually showed the change.

Multiperiod models, however, suffer from many of the same problems that affect multivariate models. Because of these problems, particularly in regressions using lagged or leading variables, few studies have attempted to use multiperiod data in investigations of debt policy.

Despite these problems, the importance of multiperiod information on debt decisions requires that a multiperiod model be used. The methodology of the present study was chosen to avoid many of the problems of multiperiod models while still allowing for inclusion of the effects of information in periods other than the period in which the financial structure change was recorded.

In the next section, multivariate models and studies will be examined, and following that section, multiperiod models and studies will be examined.

\section{Multivariate Models}

Multidimensional or multivariate models attempt to capture the different effects that determine what is unique about a firm or a group of firms. Like univariate models, these multivariate models attempt to differentiate firms (and the behavior of these firms in such things as debt 
policy). But since multivariate models use several factors to differentiate firms, it is necessary to have some systematic method to weigh the effect of different variables on the final grouping of the firms.

Besides the weighting decision, the more basic problem of any multivariate model is the original choice of which variables are important in differentiating firms. To define the best variables to differentiate firms according to debt policy, this section will look at various studies on debt policy which used multivariate models.

From these studies were drawn the variables used in the present study to relate firms to specific debt policy. In particular, the studies of zumwalt and Shin (43) found that EBIT volatility measures were significant predictors of financial structure if a rank ordering procedure was used.

This section will explain the concept and usefulness of multivariate techniques, summarize some of the problems of their usage, and along with the results of these debt policy studies, detail three multivariate techniques used in these debt studies. These studies will be examined to better define which variables differentiate firms according to their debt policies.

\section{Concept of Multivariate Models}

Multivariate techniques allow better grouping of members in a sample by assuming that the group can be defined as a function of some vector defined by independent 
variables and some error term. Elton and Gruber (14) discussed the need for the disaggregation of economic data into meaningful groups to isolate firms that act in some sense in a similar manner, to hold some effect of an omitted variable constant, or to gain a homogeneous relationship between variables in a model.

In the present study, the main concern is with the first use, that of grouping firms that may be expected to function in a similar manner with regards to their debt policies in response to changes in business risk. In part, this differentiation was done by careful sampling, selecting firms which were always profitable so that changes in debt policy would generally be guided by decisions to maximize value rather to avoid bankruptcy. This differentiation of firms was also accomplished by using variables which had been shown to be effective in dividing firms according to their debt policies.

The variables that these studies showed useful in differentiating firms were utilized in defining the measures of debt usage and risk in the present study. The methodology utilized to relate these two measures was chosen to avoid many of the problems of multivariate and multiperiod models.

The problems of Multivariate and Multiperiod Models

The major problem with multivariate models is concerned with the independence of the variables used to define the vector. Independence in a mathematical sense assumes that 
variables are, in n-space, at right angles, or orthogonal, to each other. This problem of orthogonality, or rather the lack of orthogonality, is particularly acute in economic data, for economic variables tend to be interrelated. This lack of orthogonality leads to two major problems, particularly when multiple regressions are used.

The two major problems faced in using multivariate models are multi-collinearity and auto-regressive disturbances. Multi-collinearity occurs when variables contain the same information. This essentially means that the variables are no longer perpendicular to one other, and, hence, the results of using such variables are suspect. Auto-regressive disturbances can result from using lag or lead variables that cause a "lingering" effect, which, again, makes the results using such variables suspect.

While there are numerous methods for correcting for these problems, the use of multiple regression must be approached with caution. The statistical problems involved are difficult to detect and cumbersome to correct and, even under the best of conditions, can lead to spurious results.

In order to avoid the problems of multicollinearity and auto-regressive disturbances while still using multiple variables, researchers have turned to somewhat nontraditional tools. In the area of financial structure, canonical correlation, maximium likelihood, and clustering analysis have been utilized to better define variables that most affect financial structure. 


\section{Canonical Correlation}

Canonical correlation was employed by Martin, Petty, and scott (22), henceforth MPS, in attempting to assess the determinants of financial structure. MPS used Myers (28) hypothesis of an inverse relationship between a firm's financial leverage and its growth prospects. MPS developed a model to test Myer's hypothesis. The model stated that

$$
\begin{aligned}
F=f(G, P, C, R, B) & \\
\text { where } F= & \text { a surrogate for corporate financial } \\
& \text { policy } \\
G= & \text { an estimate for the relative value of } \\
& \text { growth opportunities in relation to } \\
& \text { assets in place } \\
C= & \text { measure of profitability } \\
R= & \text { measure of importance of capital gains } \\
& \text { relative to dividend income for common } \\
& \text { stockholders } \\
B= & \text { a surrogate for the level of expected } \\
& \text { costs of bankruptcy faced by the firm. }
\end{aligned}
$$

Since none of the variables were directly observable, "proxies" were developed to define the variables. To avoid problems of auto-regressive disturbances, the variables were defined in terms of time series data rather than using any lagged variables directly.

Canonical correlation procedures "force" variables to be orthogonal but in doing so require the researcher to interpret the results somewhat, ratherthan observe the 
effect of a variable directly.

MPS found that non-industry variables performed better than industry specific counterparts in predicting financial structure. Industry specific variables were effective predictors, but not as effective as non-industry variables. MPS found that bankruptcy costs, profitability, and capital intensity were the best predictors of financial structure.

\section{Maximum Likelihood Procedure}

Taub (37) used a different methodology to estimate a firm's capital structure. Using a model somewhat like a multiple regression, Taub employed a maximium likelihood procedure to estimate the type of security a firm would use once it had decided to expand. Taub used two sets of predictor variables: variables that affect the firm's choice of financial structure directly, based on the firm's decision process under uncertainty, and variables that influence the firm's choice indirectly due to their influence on the firm's cost of issuing aifferent securities.

Because these predictor variables were grouped into two groups and the maximum likelihood estimation procedure was used, many of the problems of multiple regression were avoided while allowing the testing of several variables and combinations of variables on financial policy decisions.

Taub's study attempted to predict a firm's behavior in issuing new securities by finding the most probable action given the firm's position relative to other firms, its own 
history of decision making, and the cost of debt relative to the rate of return for the firm.

Taub found that the size of the firm, and the differences between return to the firm and the long-term rates of interest were a positive influence on the firm's debt/equity ratio. Taub also found that the uncertainty of the firm's earnings had a negative influence on the firm's debt/equity ratio.

Taub's results are important because they demonstrate that the financial structure of firms is affected by relative success and size (which relates to past success). Taub's results regarding the negative relationship between a firm's uncertainty and its financial structure suggest that any model attempting to relate financial structure and risk should account for both present rates of return and past variability of returns and their relationship to the experience of other firms.

In a recent study (1982), Marsh (55) used an approach similiar to Taub's. Data from UK companies from 1959-1970 were utilized in a regression model to determine the factors that influenced firms to issue either debt or equity. Marsh found that firms act as if they had target debt ratios and that these target debt ratios are functions of company size, bankruptcy risk, and asset composition. Further, Marsh found that companies are heavily influenced by market conditions and past security prices in deciding between debt and equity. 
These results from Taub and Marsh are integrated into the model used in the present study. The present level of EBIT and a measure of the uncertainty of the stream of earnings are used in a relative ranking procedure. This procedure is designed to measure business risk both in terms of the historic experience of the firm and in terms of how other firms are doing relative to the present performance of the firm. Also, firms in the sample were both large and profitable, which, according to both Taub's and Marsh's study, meant that these firms should have maximum freedom to choose debt levels since the probability of bankruptcy is slight.

\section{Cluster Analysis}

Another multivariate method for grouping firms is cluster analysis. Cluster analysis is a technique which attempts to place similar objects within the same group based on a n-dimensional set of parameters. There are two main problems in the use of this technique.

First, the sensitivity of the parameters used to measure similarity may vary because of differences in units of measurement and the parameters may be correlated, resulting in "double-counting." Generally, principal components can be used to avoid the problem of double counting. The problem of sensitivity is handled by careful scaling of the various measures used.

second, cluster analysis is an attempt to maximize between group variance and minimize within group variance. 
It is a geometric technique, which, because of the impossibility of representing n-dimensional space graphically, relies on some algebraic logarithm to determine the number of groups and the relative parameters for group membership. Generally, studies using cluster analysis differ in the logarithm used, the parameters defining risk and debt levels, and the nature of the clustering.

Clustering can be done in two ways, divisive and additive. The divisive technique divides the whole group into two parts, with the members of each group as different as possible in terms of the cluster parameters. Then each group is again divided, attempting to include firms in a group most similar and ensure maximum dissimilarity between groups. This process is continued until some optimal number of groups is obtained, maximizing between group variance and minimizing within group variance. Ferri and Jones (16), henceforth FJ, used this technique to develop risk and debt classes.

The second way to cluster is to start with the same number of groups as are in the sample. Each member of the sample is compared with all other members for similarity. The clusters are formed by combining the one member clusters based on similiarity. Thus, in a sample of ten objects, there would be originally ten clusters. If a member of one cluster were found to be sufficiently similar in terms of a set of multivariate parameters to another cluster, the two would become one cluster, and the total number of clusters 
would now be nine. This process would continue until an optimal number of clusters is reached.

This method, used by Martin, Scott, and Vandell (21), henceforth MSV, is best suited to prove the negative hypothesis of no similarity within groups. By the nature of its clustering, the additive method tends to result in many one member groups.

Clustering analysis has several advantages and avoiás some problem areas encountered with more traditional tools. Clustering allows the assessment of relative risk of a firm within the sample to be judged relative to the riskiness of all firms in the sample. Regression methods, besides the problems of multi-collinearity and auto-regressive disturbances, result in forcing firms into risk categories dependent on a preconceived notion of the appropriate risk measures.

Clustering allows firms to be put into risk categories relative to the riskiness of other firms in the sample in that year, much as firms are judged in comparison to their relative riskiness in the marketplace. Clustering also avoids the problem of dealing with trends, for clustering looks at relative risk within a particular year.

These advantages of clustering were incorporated into the model used in this study. Because risk and debt data were used from a twenty-year period for firms, trends and changes in other firms in the sample would tend to distort risk and debt changes of a firm.

In the model utilized in the present study, a ranking 
procedure assessed the risk and debt changes in a firm relative to the changes in all other firms in the sample rather than just assessed that change relative to past performance. This procedure allowed data from twenty years to be utilized in trying to isolate what constitutes actual debt policy for these firms.

While clustering would help isolate different behavior within a single year, if it were used to analyze data over several periods, the effect of trends could cause firms similar in their overall approach to debt to be placed in different groups if the proper category or categories defining debt policy were not properly utilized. Since these debt defining characteristics are what such a study is searching for, ex ante it would be hard to design those attributes to be used for clustering.

Clustering does, however, point out the need for dealing with trends in analyzing time series data. The studies done with clustering also help define the factors which best measure business risk and also best explain differences in debt policy behavior.

Ferri and Jones (16), henceforth FJ, and Martin, Scott and Vandell (21), henceforth MSV, used cluster analysis to develop relative risk classes, and, in the study by FJ, also to develop relative debt classes. FJ used the coefficient of variation in sales, the coefficient of variation in pretax cashflows, the standard deviation of the standardized growth in sales, and the standardized growth in cashflows as 
parameters to measure business risk and thus differentiate firms into groups.

MSV used firm sales/industry average sales, variance in firm sales/share, variance of EBIT over variance of sales, compound growth of EBIT, covariance of industry and firm sales, and size of sales as their differentiating measures of business risk.

Using these measures to cluster firms into groups, FJ found a slight relationship between debt structure and industry class, had mixed results for size influence on debt structure for the two years studied, and found a linkage between income volatility and financial leverage. However, this linkage between income volatility and financial leverage was questionable because a basic condition for the discriminant tests had been violated.

FJ also found that business risk, as measured by historic volatility in sales and cashflow, was a poor predictor of financial structure.

MSV employed principle components as a further refinement to cluster analysis to avoid problems of multicollinearity, or double counting. Variables were formulated into two classes, environmental or firm specific, to cluster firms into risk classes. MSV found 1 ittle support for the idea of equivalent risk classes. However, their study, like that of FJ, depended heavily on historical volatility of sales (both industry wide and firm specific), sales size and covariance of firm and industry sales.

While MSV and FJ found that sales volatilty were poor 
predictors of business risk, zumwalt and shin (43), henceforth ZS, found that sales and EBIT volatility measures were significant predictors of financial structure if a rank ordering procedure was used. zS postulated that absolute measures of business risk (i.e. without ordering) may not adequately discriminate differences between groups since extreme values might cause high standard deviations for groups and, thus, group overlap.

The findings of $\mathrm{ZS}$ would suggest that using some measure of historical volatility to define groups, and then classifying firms by these groups would lead to misspecification and overlap of groups. It would appear that a better method to measure business risk, one that would differentiate between firms, would be to utilize a measure of sales or EBIT volatility, adjusted to avoid problems of wide parameters of group membership by scaling the level of sales or EBIT by some measure of historical volatility. The findings of $\mathrm{ZS}$ show that sales and EBIT volatility were significant predictors of financial structure. To link business risk changes with debt structure changes, it is necessary to have a measure that shows both the volatility of either EBIT or sales relative to their respective historical volatility and also relative to the changes occurring in other firms in the sample.

This need to relate changes in sales or EBIT to both historical volatility and the relative experience of other firms is necessary to properly define membership in a group 
according to business risk.

A basic assumption of this study is that firms adjust their financial structure to optimize value. The financial structure will be adjusted only when the business risk of the firm changes. The manager can only judge the change in business risk of the firm in terms of the historical volatility of that firm and the changes in other firms.

These multivariate studies are important, however, because these studies highlight some of the problems of using multivariate groupings to differentiate firms. The work of FJ, MSV, and $\mathrm{ZS}$ suggest that estimating business risk, at least in attempting to predict financial structure, is best done using a measure of EBIT or sales volatility.

These studies also show, first, that historic measures of volatility have little predictive power and, second, that the grouping of firms using sales or EBIT volatility can be adversely affected by group overlap. This group overlap is possibily caused by differences within the groups leading to high deviations caused by extreme values, which results in wide and overlapping groupings which lack discriminating power.

This section has detailed some of the attempts to use multivariate methods to better define and relate business risk and financial structure classes. While the studies have employed time series data in defining variables, the models generally were not dynamic in the sense of testing business risk changes in one period as a determinant of debt level changes in an earlier or later period. 
Rather, these studies have used measures of historical volatility from several periods to predict debt levels in a particular period. The problems inherent in modeling the effect of changes in one period on decisions made about financial structure changes in other periods will be examined in the next section. In particular, the use of dynamic models, in the sense of using lagging or leading variables, will be discussed. The use of dynamic models is important because this study is concerned with the relationship of debt level changes and risk level changes across different periods.

\section{Multiperiod Models}

Multiperiod models assume that factors or variables from other time periods affect the decisions made in the present time period. While these models represent significiant mathematical and statistical difficulties, the inter-relationship of leading or lagging variables on present decisions is well accepted. This type of model is important to the present study because both the theoretical and the empirical models attempt to explain financial structure decisions by viewing the inter-relationships of changes in debt and changes in business risk across periods.

Dhrymes and Kurz (19) developed a two-stage least squares model in an attempt to study the relationship between investment, dividend, and financing decisions. They attempted to use some lagged variables in their equations 
but found that the problems of multicollinearity were too severe for meaningful results.

Fama (29) used time series data to investigate the relationship between dividends and investment decisions and found no evidence to support the concept of interdependence of dividend and investment decisions. McCabe (59), noting some of the problems with Fama's study, developed a further version of Dhrymes and Kurz's model using lagged variables. Using an ordinary least squares model, McCabe showed that dividends have a negative effect on investment. McCabe concluded that there is strong evidence to support the interdependence of spending (investment and dividend) decisions and fund raising decisions (new debt or equity).

Myers and Pogue (69) used a mixed integer programming model to relate investment and financing decisions to the risk of the firm and the risk of the projects undertaken. Specifically, their model tied debt capacity to project risk characteristics and not arbitrarily determined debt ratios.

Myers (68) also developed a mathematical programming formulation of the interaction of financing and investment decisions which depended on lagged changes in variables to develop a model for optimal financing decisions.

These studies, which demonstrated that noncontemporaneous variables and risk are critical to understanding financing decisions, are integrated into this study. This dynamic approach to understanding financial structure is further supported by Ang (3), who used a time series model to show that firms tend to act as if they were 
aiming for some target debt ratio. Ang found that a simple partial adjustment model best explained firm behavior in adjusting debt ratios, with indications that firms adjust their debt behavior to anticipated future increases or decreases in assets.

Taggart (88) used a flow of funds approach based on Federal Reserve data to empirically test how firms determine long-term debt capacity. Taggart postulated that firms adjust to permanent capital target levels rather slowly, implying that leading or lagged variables are critical to understanding financial structure decisions.

Spies (82), using a complete partial adjustment model, with lagged variables, showed that long term investment adjusts to a new optimal level quite slowly. This time lag results in financing decisions being subjected to great uncertainty. Spies postulated that this uncertainty results in temporary financing being frequently utilized until longer term financing can be arranged. This concept implies that there is a significant time lag between changes in the firm and changes in the permanent financing. Spies' results, regarding the timing of financial structure changes and the change in business risk (which, at least as measured by changes in EBIT, would presumably show up after the new investment was in place), tend to support the timing relationship between changes in debt and changes in business risk hypothesized in this study.

From the above studies, it is obvious that decisions 
regarding financial structure are affected by noncontemporaneous variables and that debt levels are adjusted slowly, over several time periods. This slow adjustment process and the effect of non-contemporaneous variables are used in the present study to form the basis for both the theoretical and empirical models.

\section{Alternate Approaches}

The question of optimal capital structure has generally been approached in a somewhat linear fashion, assuming that some particular factor, such as bankruptcy cost or market imperfections, is responsible for the particular level of debt that optimizes value. Recently, several alternate approaches have suggested that the level of debt that optimizes value for a firm may be the result of a more complex process.

Myers (67) postulated that the level of debt that optimized value was the result of the value of two "bundles" of assets held by the firm. Myers postulated that the relative size and composition of these two "bundles", real assets and real options, determined the optimal level of debt. Real assets have market value independent of the firm's future investment strategy. Real options are opportunities to purchase real assets on possibly favorable terms.

If the firm decides to invest in an option, the firm must raise money. If the firm issues what Myers calls "risky debt", the debt is backed mainly by the value of the 
investment. If the option is found to have value less than the value of the debt, the shareholders must supply the difference. Myers shows that this "risky" debt affects the market value of firms differently depending on the the relative riskiness of a firm's options and its real assets. The impact of risky debt on the market value of the firm is less for firms holding investment options that are risky relative to the firm's present assets. In this sense, risky firms can borrow more thà safe firms.

This concept would also account for firms not borrowing "as much as possible." The debt level of the firm is affected by the relative risk of the future options as compared to the riskiness of real assets. Debt level changes, then, are influenced by the effect of the new debt level of the firm on shareholder wealth, rather than by the effect of some particular debt level on the total value of the firm. Thus, it appears to be necessary to look at changes in risk for the firm in order to understand the resultant debt levels.

This emphasis on changes in debt levels rather than on absolute debt levels is utilized in the present study. This is in part because of Myers' contribution and in part because of the lack of any standard to measure absolute debt level against over the twenty years studied. Myers postulated that real assets should be financed with more debt than growth opportunities. He also postulated that capital intensity, high operating leverage, and 
profitability should be associated with heavy debt financing. These two concepts imply that growing, profitable manufacturing firms tend to make changes in their debt levels more frequently as options are turned into real assets. In the present study, the sample was picked to include mostly large, profitable, growing manufacturing firms in order to maximize the possibility of observing this changing of the debt levels as the composition and size of the real assets and options change in the firm.

Since the value and possibly even the existence of options available to the firm are generally unknown to investors, firms face a problem in changing debt levels. The problem of making changes in debt levels when investors do not have the same information as managers has been approached by both Ross $(73,74)$ and Leland and Pyle (52). Ross and Leland and Pyle suggest that firms use the change in debt level as a "signal" to investors that the firm is in the process of changing. In a later empirical study, Masulis (58) noted that his results supported the concept of debt level changes releasing information about changes in firm value. Heinkel (43) developed a theoretical model that supports the concept of capital structure relevance when asymmetrical information exists and that also supports Myers' argument that riskier, more valuable firms will have larger amounts of debt financing.

In order for signals to be of use to management, the signals must be perceived by the market as honest, and they must not give away insider information. The critical point 
to both Ross's and Leland and Pyle's argument is that for a signal to be perceived as honest by the market, the signal must be costly to managers if incorrect. obviously, a move away from the optimal debt structure is costly to shareholders, and through "agency costs" mechanisms are made costly to managers.

Jensen and Meckling (47) have pointed out that owners of a firm are willing to incur what they call "agency costs" to ensure that their "agent", the manager, acts in the best interest of the owners. The agency costs of concern for this study are compensation packages for managers. By proper structuring of these compensation packages, shareholders make wealth maximization for managers the same as wealth maximization for shareholders. These compensation packages ensure that poor decisions made by managers are costly to managers. Thus, agency costs ensure that managers, in their decisions, send signals that will be costly to themselves if incorrect.

Signals from managers will also be honest because if managers attempt to influence the market in the short run with incorrect signals, they will lose the confidence of the market and lose their ability to influence market perceptions toward management perceptions of the value and risk class of the firm. The firms picked in the sample in this study are all firms which have a long history of profitability and have little to gain by attempting to "trick" the market for short term gain. 
This concept of "agency costs" has also been forwarded as a possible constraint on both growth and the issuance of additional debt. Since there is an agency cost associated with issuing new debt, larger firms would be more likely to issue debt, because the agency cost of issuing debt would be a much smaller percentage of the total issue. For a smaller firm, agency costs could represent a substantial burden on the firm, effectively raising the interest cost and either making the project unprofitable or forcing the firm to use other, less-optimal methods of financing. In the empirical section of this study, the sample was selected on the basis of size in order to keep agency costs a very small percentage of total costs and total value, thus ensuring that managers of firms had maximium flexibility to make optimal decisions.

These alternate approaches to estimating how debt level decisions are made are critical to the present study, for it assumes that agency costs represent a smaller percentage cost for larger firms (thus giving larger firms more flexibility in choosing financing instruments), that signaling is used by managers to inform the market of upcoming changes in the firm, and that debt decisions are tied to both the size and composition of the real assets and options held by the firm.

Recent Work

Much of the recent work has focused on the effect of differential tax rates and the possibility of clientele 
effects. This clientele effect results from different personal tax rates of investors, which means that investors in tax brackets higher than the marginal corporate rate prefer personal debt to corporate debt. Low income investors prefer corporate debt.

Farrar and Selwyn (31) investigated this concept of a clientele effect. Using MM's basic tax-free model, they developed increașing complex models embodying increasing amounts of the actual tax code. From their results, they concluded that actual tax rates tend to affect the value of the firm to different investors. They postulated that increasing leverage would make firms more attractive to lower income investors, while firms with lower leverage would attract larger shareholders whose portfolios contain considerable private leverage.

Elton and Gruber (25), investigating the effect of dividends and corporate investment policy on shareholder wealth, found that definite clienteles exist for particular firms, a reflection that firms not only attract a clientele but they also attract a rational clientele.

Miller (60) argues that financial leverage is irrelevant to any given firm in a world of differential personal taxes. He postulated that the combination of the marginal personal tax disadvantge of debt and supply side adjustments by firms would reduce the corporate value of debt and would also drive market prices to equilibrium. From the supply-side, Miller postulated that firms 
would not offer debt because the interest rate necessary to attract investors would be too high to benefit the firm, even with the tax-advantage of debt. Further, if the firm uses all of its income to re-invest in the company, the shareholders are moved from ordinary income to capital gains income. Thus, the cost of using debt, from a shareholder's perspective, is very high. Any tax advantage to debt is cancelled out by the need to pay higher rates to sell bonds, given that bonds have higher ordinary tax rates than equity's capital gain rate. The only time debt will be issued is when it helps the wealth of owners. This will only happen when bond rates are unusually low.

Miller's argument depends a great deal on the concept of clientele effects, where the tax rate of investors differentiates the different clienteles. Kim (49) thought these clientele effects tended to reduce the effect of tax benefits on capital structure. Kim further pointed out that from a mean-variance portfolio standpoint, the benefits of investing in firms where the leverage level of the firm maximizes after-tax income to the investor may be outweighed by the losses of portfolio efficiency. Kim, Lewellen, and McConnell (50) conducted empirical tests of this leverage clientele hypothesis and found the results somewhat mixed. They found a statistically significant relationship between corporate leverage policies and investors' tax rates, but the magnitude was much less than the theory would predict.

This work by Miller brought forth numerous studies 
attempting to show the value of debt to the firm, in particular emphasizing the tax issue. Taggart (89) found that as Miller had postulated, the tax advantages of debt were less than previously supposed. However, by reintroducing debt costs, Taggart showed that capital structure was not a matter of indifference to firms.

DeAngelo and Masulis (18) extended Miller's model to include more realistic estimates of the corporate and personal tax rates using a two date state-preference model. They found that the existence of corporate tax shields, such as depreciation deductions or investment tax credits, is sufficient to overturn the leverage irrelevancy theorem. From this, they postulated that each firm has a unique interior optimal leverage decision due solely to the interaction of personal and corporate tax treatment of debt and equity.

Harris, Roenfeldt, and Cooley (40) used a generalized personal and corporate tax (PACT) model to empirically test the effect of personal tax on corporate capital structure. On average, they found that personal tax effects offset almost half of the corporate tax incentives associated with the use of financial leverage. They also found that there were significant differences between firms in terms of the value of debt to them, and one-fifth of the firms maintained an average personal tax ratio implying a net tax advantage for the use of additional equity. Further, it was found that substantial tax incentives for the use of debt exist for 
many other firms. These incentives for change in financial structure from a personal tax standpoint would imply firms should change their financial structure. However, since few changes were noted over a nine year period, it appears that other significant factors precluded these changes suggested from the personal tax aspect.

Cordes and Sheffrin (16) attempted to estimate the effect of increasing interest costs on the value of the firm, holding constant all other income statement items and investment and production decisions. Their results supported DeAngelo and Masulis (18) in regard to the effect of additional interest payments reducing the ability of the firm to effectiely use nondebt tax shelters, thus implying an optimal capital structure for each firm. Further, Cordes and Sheffrin found a significant difference in the after-tax marginal cost of capital between firms.

Modigliani (66) used a mean-variance approach to show that leverage is valuable, but if the market regards the tax saving flow as subject to risk, then the value of debt would be low. Further, he postulated that differential rates of taxation will result in a clientele effect.

This recent work on the effect of different tax rates on the value of the firm demonstrates the continued lack of consensus on the value of debt. This work on the demand side of debt, while important, is not particularly relevant to the present study. This study is concerned with the timing of the supply of debt by firms, and its relationship to the business risk of the firm. 
The work of Miller (60) on the supply-side, however, is of importance to the present study. Miller notes that generally the rate necessary for firms to sell debt will be higher than the rate at which debt is of value to the firm. While this may be true on average, the rates for firms at a particular time vary considerably, as evidenced by the different bond ratings of firms. Thus, it is possible that on average debt may not be of value to all firms, for specific firms with lower rates (due to their strong bond ratings), debt may be of value. Further, larger firms will - have smaller (in terms of percentage) agency costs for issuing debt, making their effective cost of debt lower.

Miller notes that debt can be of value to firms if it can be issued below some rate. To attract more investors requires that the corporation pay higher rates. Miller argues that as a result of these higher rates, there will exist an equilibrium level of aggregate corporate debt but no optimal debt ratio for individual firms. While this may be true on average, or even on the margin in the aggregate, from the viewpoint of the individual manager, since debt can have value to the firm, managers will take advantage of these opportunities to increase value. The possibility of increasing value through issuing debt will be highest for those firms which can issue debt at the lower rates.

\section{Conclusion}

From the works cited above, several areas can be seen 
as critical to this question of debt level. Bankruptcy and agency costs seem to be important in determining an optimal capital structure. The value of debt is closely tied to the effect of taxes, both corporate and personal. In order to gain value from the tax shield of debt, the firm must produce sufficient income. The cost of debt is important to firms, for this determines whether debt has value to the firm. This importance of cost also implies the the timing of debt issues is critical, for rates vary considerably over time.

There are several important implications for the present study. First, bankruptcy and agency costs are relative. All firms face them, but for some firms, these costs are relatively minor, since the probability of bankruptcy is slight and the relatively fixed nature of agency costs makes them minor for larger firms. The ability to use the tax shield is dependent on firm income, and more successful firms have the greatest probability of using the full value of the tax shield in the future.

A further implication of the above study is that debt may have additional uses to the firm, such as signaling. The changes in the capital structure of the firm may be a method for managers to alert investors of upcoming changes in the firm. These changes could be due to changes in the assets in place of the firm or to changes in the options available to the firm. 
CHAPTER III

THE THEORETICAL MODEL

Introduction

\section{The Problem}

There remains in financial literature, and in the minds of practitioners and academicians, a fundamental conflict concerning the value of debt to the firm. From a microeconomic, or firm level, the lower cost (relative to equity) and the tax-deductibility of interest make debt valuable to the firm. Hence, firms that utilize debt should show superior returns to shareholders and thus command a superior price in the market place. Empirical evidence supports this view, in the sense that most firms do utilize some debt. From the amount of attention paid to debt ratios by financial analysts and bond rating services, the actual level of debt appears to be of some importance.

However, from a macroeconomic basis, debt either has little importance according to MM (62), in the case of no taxes, or is of maximum importance in a world with taxes as pointed out by Modigliani (66). This importance of debt in a world with taxes implies that debt should be used almost exclusively for funding by firms. Authors after MM have attempted to use market imperfections, such as 
bankruptcy or agency costs, to explain this lack of agreement between the macroeconomic view and the microeconomic view, and the lack of agreement between either viewpoint and the empirical evidence of the marketplace. The present study presents a theoretical model which will address several of the major questions in this area of financial structure.

1. Why is there no recognizable, common strategy for debt usage?

2. Why are some firms able to approach the level of debt estimated by microeconomic theory to be optimal, while other firms seem unable to utilize debt very well?

3. Why have earlier empirical studies been unable to ascertain the relationship between risk and debt level?

4. How do market imperfections affect the ability of the firm to utilize debt?

Prior to the presentation of the model, a discussion of several of the important market imperfections and attributes of debt is in order.

The cost and value of Debt

The costs of debt, beyond the actual monetary cost of interest, have been generally viewed as market imperfections. If these market imperfections did not exist, then firms would use far more debt than usually employed. That is, in a world with taxes, if there were no risk of bankruptcy or financial distress from too much debt and no 
issuing or agency costs, then firms would make maximum use of the lower cost and tax shelter effects of debt. Thus, in the absence of these market imperfections, it would be expected that firms would use almost all debt, with the firm value maximized by the sure stream of income generated by the tax-sheltering effect of the debt.

This sure stream of income generated by the tax deductibility of interest would increase the stream of income to shareholders and thus increase shareholder wealth. With no market imperfections, this stream would be discounted at the risk-free rate, thus adding the maximum value possible to the firm.

The existence of market imperfections such as bankruptcy and agency costs are used to explain the generally lower levels of debt observed. Because of the risk of bankruptcy, firms tend to use less than the level of debt allowed by the market since too much debt could hurt the firm in the future. MM (64) noted that excess debt could make the firm less flexible. Hong and Rappaport (46) felt excess debt made the firm more subject to "financial distress". Or, if the firm was unable to pay either interest or principal, possible bankruptcy and reorganization could occur, with possible loss of value. Baxter (7) and Warner (91) have estimated some of these costs of bankruptcy. Agency costs include the cost to the firm of protecting investors in bonds from actions of management detrimental to the wealth of bondholders. As pointed out by Jensen and 
Meckling (47), the firm is willing to pay these costs, such as bonding of employees or the hiring of trustees, in order to ensure the lowest possible risk for investors and hence the lowest cost to the firm for the debt. In addition to these agency costs are the actual costs of issuing securities, which have both a fixed component, tied to actual registration costs and fees, and a variable component, tied to the risk and the size of the security issue. These costs, of course, affect the actual interest cost of the funds to the firm and reduce the value of debt to the firm. These costs are seen as another market imperfection that keeps firms from utilizing a higher debt ratio.

While debt has been viewed as mainly having value because of the value additivity of this stream of additional income, several authors, including Ross $(73,74)$, Lel and and Pyle (52), Myers (67), and Williamson (94) have noted that debt may have additional uses for management by allowing managers to "signal" investors of upcoming, significant changes in the firm by changes in the debt ratio. By signaling these changes, managers can calm investors' fears about rumors or upcoming changes and ensure investors that management is not only aware of future problems or opportunities but also actively moving to maximize firm value under these new conditions.

This signaling concept suggests that the timing of the change in debt ratio should be in advance of the actual change in the business risk of the firm if the signal is to 
be of any aid to the investors. In addition, because of the time lag involved in issuing debt, if a manager is to maximize firm value in the future, it is necessary to make adjustments in the debt ratio at the present time in order to have the firm at the optimal debt level when the future change in business risk occurs.

This time lag has been noted in empirical studies by Ang (3), Spies (82), and Marsh (55) and possibly explains why earlier cross-sectional empirical studies of the relationship of debt ratios and risk produced generally disappointing results. The change in debt and business risk does not occur contemporaneously, for firms take some time to adjust debt ratios, and, as postulated in this study, it is possible that firms changed debt ratios in anticipation of future changes in risk. Cross-sectional studies, therefore, would at best capture only those firms in equilibrium during a particular year and miss all those firms in the process of changing debt ratios in anticipation of upcoming changes in the firm. The importance of noncontemporaneous variables in modeling investment and financing decisions has been noted by Myers (68) and McCabe (59).

The Theoretical Model

Purpose of the Model

The purpose of the model is to provide additional support to the importance of financial structure to firms. 
The model shows why only certain firms are able to make full use of debt because they enjoy relatively lower costs of debt and greater market freedom. In particular, the model will explain the timing of changes in financial structure relative to changes in business risk and also the importance of these changes. Further, the model will explain why crosssectional empirical studies have failed to demonstrate a relationship between business risk and debt level.

\section{Assumptions}

The theoretical model is based on seven assumptions.

1. Debt has value.

2. The level of debt is, in part, a trade-off between cost of insolvency and value of debt.

3. A change in the level of debt has information value to the market.

4. Managers attempt to maximize the value of the firm because it is in their best interest.

5. There is an unequal ability between firms to use the full tax shield of debt.

6. The value of debt is dependent on the cost of debt.

7. There is a discrete time necessary to change financial structure.

These assumptions are generally well accepted in the literature of finance. The concept that debt has value in a world with taxes has been shown from a macroeconomic 
viewpoint by MM (64) and Modigliani (66). The value of leverage on a microeconomic basis, based on the tax shield of debt, is presented in most basic textbooks (11). The level of debt used by a firm is the result, in part, of a trade-off between cost of insolvency and the value of debt, as pointed out by Kraus and Litzenberger (5I) and Robichek and Myers (72). The importance of debt levels and debt level changes, at least to investors, is demonstrated by the constant coverage of debt ratios by the various investment services. Jensen and Meckling (47) have demonstrated the mechanism by which managers' compensation packages tend to ensure that wealth maximization for managers and shareholders are similar. The assumption that firms have unequal abilities to use the tax shield of debt is suggested by both DeAngelo and Masulis (17) and Cordes and Sheffrin (16). Miller (60), Hamada (38), and Marsh (55) have pointed out the importance of the cost of funds to the decisions regarding debt.

In the MM study (62), it was assumed that firms could make essentially instantaneous changes in their financial structure. In actuality, firms require some time to make financial structure changes. Ang (3) and spies (82) have discussed the definite intertemporal behavior of changes in debt. The time necessary to make changes in financial structure is influenced by several factors, including the time necesary to make decisions regarding the correct direction of debt level change, to gain acceptance within the firm, to check for legal and regulatory problems, to 
engage and negotiate with an investment banker, and to fulfill SEC requirements.

Further, this time necessary to carry out changes in financial structure is influenced by the method used to change financial structure. If debt is merely paid off using internally available funds, the time required to change debt level could be quite short. However, if a new issue is used, the time necessary could be significantly longer, because of the aforementioned regulatory, legal and marketing constraints.

\section{The Model}

From the assumptions presented above, a theoretical model is postulated that will address many of the troubling questions of financial structure. In the past it has been assumed that all firms were "forced" by the market toward an optimal debt ratio, in the sense that all firms should show optimal debt ratios, given their "respective" situations. The firm's respective situation is defined by such factors as past earnings, risk, growth opportunities, economic outlook, and managerial expertise. While all managers may attempt to optimize the value of the firm using financial structure changes, firms do not necessarily have an equal ability to follow an optimal path because of their respective situations.

In this study, it is postulated that the ability to approach this optimal use of debt is limited to firms that 
enjoy low market rates, that have low issuing, bankruptcy and agency costs, that can make full use of the tax shield of debt, and that have the managerial expertise and market freedom to change financial structure at the optimal time.

\section{The cost of Debt}

The cost of debt to an individual firm, particularly after-tax, depends on many factors. These factors include the market rate of debt for the firm, the ability of the firm to use the tax shelter provided by the debt, and the additional costs of debt.

These three cost factors affect the actual, after-tax cost of debt to the firm. This actual, after-tax cost of debt determines the value of debt to the firm. Thus, the concept of lower cost debt implies the ability to garner the full savings on debt resulting from the tax deductibility of interest, to enjoy minimal issuing and agency costs, and to issue at the lowest possible rates. As pointed out by Miller $(60)$, if the cost of debt is above some point, debt no longer adds value to the firm.

Not all firms can issue debt at the lowest possible cost. The bond rating of the firm determines, in part, the market cost of debt to the firm. Stronger firms can obviously issue debt at lower market rates. In addition, larger firms have an advantage because of economies of scale in terms of issuing and agency costs. These issuing and agency costs have both fixed and variable components. For larger firms, involved with large issues, the fixed part of 
the cost adds only slightly to the total cost and even the variable costs may decrease significantly for larger issues. Further, many of these issuing and agency costs are not marginal costs for larger firms, but costs incurred whether or not the firm issues securities.

Assume for a particular risk class of firms, possibly categorized by bond rating agencies, that the market rates for long-term debt instruments range between some level " $\mathrm{n}$ " and "Y" with $X<Y$. The mean of $X$ and $Y$ and the range between $X$ and $Y$ over time changes dependent on market conditions. Further assume, as suggested by Miller, that there is some market rate " $Q_{i}$ " below which debt is of value to firm "i". The market rate to firm "i" is " $M_{i}$ ". The rate below which debt is value to the firm, $Q_{i}$, could be within three different ranges. If $Q_{i}<x$, then debt is not of value to the firm. If $Q_{i}$ is between $X$ and $Y$, then debe will be of value to the firm if $Q_{i}$ is less than $M_{i}$. If $Q_{i}$ is above $Y$, then debt will always be of value to the firm.

This market rate $M_{i}$ is not the only rate of importance to the firm. The firm is also interested in the after-tax cost of debt, " $C_{i}$ ". This after-tax cost of debt is determined, in part, by the ability of the firm to use the tax shield fully. This would mean that the firm can fully utilize both the tax savings generated by the interest payments and the possible additional tax-savings generated by the new investment depreciation allowances and tax 
credits if the funds are used for new investment. If $c_{i}<$ $Q_{i}$, then the firm will add value to the firm by issuing debt.

If the firm is unable to fully utilize all the tax advantages of the debt, then the effective after-tax rate to the firm would be higher, possibly moving $C_{i}$ above $Q_{i}$. Thus, even with a low market rate $M_{i}$, it is possible that, because of the inability to utilize the full benefits of the tax shelter, a firm would not add value by issuing debt since $C_{i}$ would be greater than $Q_{i}$.

This adjustment of $M_{i}$ to $C_{i}$, as a result of the ability to use the tax shelter of debt, can be further developed to include other costs to firms, such as bankruptcy, issuing and agency costs. These costs vary for each firm and affect the value of $C_{i}$. In all cases, these additional costs will increase $C_{i}$ to some level " $A_{i}$ ". Again, if $A_{i}$ is greater than $Q_{i}$, then additional debt will not add value to the firm. A firm could have a low market rate, $M_{i}$, and be fully able to utilize the tax shelter of the debt so that $C_{i}$ is lower that $Q_{i}$. But if the issuing, bankruptcy and agency costs are too great, then $A_{i}$ will be greater than $Q_{i}$, and debt will not add market value to the firm. This does not mean firms will not issue new debt. Firms may issue debt if there are potential control problems and funds are needed, for example, to remain competitive, or to meet government pollution standards. This is of course a sub-optimal path, but possibly the only path open to management at the time. 
Whether debt is of value to a firm is dependent, then, upon market rates, the ability to use the tax shield, and the size of various other costs associated with issuing debt. Certain firms would have a greater probability of having debt add value. These firms would be firms that enjoy the lowest possible rates in the market, have the ability to fully utilize the tax shelter of the debt, and enjoy low issuing, bankruptcy and agency costs.

These firms would of necessity have to be the larger firms, with strong histories of earnings, and strong future potential of earnings. Having larger firms ensures that there is a high probability that earnings would be taxed at the maximum rate and that earnings would remain strong in the future so that tax shelter will continue to be of value. The firms would also have to be large in order to enjoy economies of scale in their agency and issuing costs.

Larger, successful firms would have low bankruptcy costs, however measured. These firms would have a small probability of earnings falling below some level where actual bankruptcy and reorganization would occur or where even financial distress would occur.

The strong history of earnings and strong future potential would ensure lower market rates and increase the probability that the firm could utilize the full benefit of the tax shelter. Thus, larger, more successful firms have a higher probability of $A_{i}$ being less than $Q_{i}$ and thus debt having value to the firm. 
Managerial Expertise and Market Freedom

Market freedom and managerial expertise imply that firms do in fact have a choice about raising funds and changing financial structure and are willing and able to make this choice. Firms with stronger financial histories have greater freedom in the marketplace and are less restricted by prior convenents on debt issue. Many firms, because of past financial problems, are restricted in what types of securities they can issue and in what volume. Firms with poorer financial histories or control problems may be constrained from issuing the optimal security because of fears of loss of voting control or restrictive covenents. Larger, more successful firms can also hire, either permanently or short-term, additional expertise and staff to properly address the many facets of running the corporation. This ability should increase the quality and timeliness of decisionmaking.

Further, large firms with strong financial record are less affected in future decisions by present decisions. That is, the potential opportunity costs of present financial structure decisions are low, further increasing the flexibility and market freedom of managers.

Timing of Financial Structure changes

The timing of changes in financial structure is dependent upon several factors, including the asymmetrical distribution of information between managers and investors, 
the need for managers to adjust the financial structure as business risk changes to ensure firm value maximization, the actual time constraints on changing financial structure, and the information content of financial structure changes.

The Asymmetrical Distribution

of Information

Myers' model (67) of the firm suggests that the firm's value is the summation of the value of two "bundles" of assets: the assets in place and the options the firm holds on future projects. Over time, the value of each one of these bundles can change as future sales for the present output of the assets in place change and as the relative value of the options (i.e., future projects) that the firm holds changes. Thus, even though the future sales of the present products of the firm may remain constant, the future business risk of the firm may change as the value of the options held by the firm changes. This information about future projects is known, at best, only in general to the market. As a result of this superior information about the options of the firm and the assets in place, the manager of the firm is best able to estimate the value of the firm.

The value of the firm, using Myers' model is:

$$
V=A_{p}+O_{f}
$$

where $A_{p}=$ value of assets in place

$$
o_{f}=\text { value of future projects the firm has options on. }
$$


The information that the market has about the firm is made up two subsets: information known to the market about the assets in place and information known to the market about the future options of the firm. The information known by the market about the assets in place will generally be less than the information known by the firm. However, the information known to the market about the options of the firm will be much less than the infomation known by the firm.

The information about the firm's assets in place can be defined as

$$
I_{p a}=I_{a m}+I_{a f}+I_{a u}
$$

where $I_{p a}=$ total information about assets in place if no uncertainty existed

$I_{a m}=$ information about assets in place known to the market (and the firm)

$I_{a f}=$ information about assets in place known only to the firm

$I_{a u}=$ information that is unknowable because of uncertainty.

As noted above, in most cases, the management of the firm will have information superior to the information known to the participants within the markets. Consequently, the management of the firm is in a superior position to the participants in the financial markets in estimating the value of the assets in place. But the amount of information known by the management is not much greater than the amount 
of information known by market participants. This slight difference results because a great deal of background information is available if a product has been on the market for any length of time. In addition, information from competitors, suppliers, marketing surveys and other non-firm sources can be used to estimate future sales and future risk of the existing product.

However, the second subset of information about the firm's options on future projects has a different distribution between the firm and the market. The second subset of information can be divided in the same fashion as the information about the assets in place. However, financial markets have little information regarding the value of the future options of the firm. Because competition causes secrecy about future projects, firms cannot give the financial markets much specific information about future projects. The total information about future projects on which the firm has options can be defined as:

$$
I_{\text {op }}=I_{\text {om }}+I_{\text {of }}+I_{\text {ou }}
$$

where $I_{o p}=$ information about future projects assuming perfect certainty

$I_{\text {om }}=$ information about future projects known to financial markets and the firm

$I_{\text {of }}=$ information about future projects known only to the firm

$I_{\text {ou }}=$ information about future projects that is unknowable because of uncertainty. 
As in the case of the assets in place, the firm knows more information than the market, but the difference in information known only by the firm and that known by the market is far greater than for the assets in place. The information known only to the firm may in fact include the existence and feasibility of projects completely unknown to the markets. This would be particularly true in larger firms with many diversified divisions, where research and development endeavors are wide-ranging and where the firm has numerous channels available to develop new ideas.

\section{Changes in Financial structure}

As new information becomes available to the firm, the future prospects of the assets in place and the options on future projects change. Thus, as new information is gained, the business risk of the firm and the estimated future business risk of the firm change. At any given point in time, the firm generally enjoys a slight advantage in information over the market regarding the assets in place and a large advantage in information regarding future projects on which the firm holds options. But this "firm" information, which affects both the business risk and the estimated future business risk of the firm, will become known, at least in part, to the market.

Because part or all of this information will become known to the market, the management of the firm must adjust the financial structure of the firm to maximize the value of 
the firm, given the new level of business risk. This flow of information from that known only to the firm to that known by the financial markets is continuous, although not necessarily regular. Firms realize this and also realize that once this new information is known to the market, the value of the firm will change.

Time Lags in Changing the

Einancial structure

Changes in the level of debt of the firm cannot be made instantaneously. There is a time lag between the perception of the non-optimal debt level and the necessary change. This time lag is influenced by such factors as the amount of time to make the decisions, to gain acceptance of the changes within the firm, to check for legal and regulatory problems, to engage and negotiate with an investment banker, and to fulfill SEC requirements. This lag in changing the financial structure can be greater than one year or at least not be recorded on annual data for a year or more. Since the data available were yearly data, the time periods in this study are considered to be one year.

The time necessary to make changes in the financial structure is also influenced by the method used to change the financial structure. If the financial structure is changed by selling new stocks or bonds, the time necessary to make the change will be longer because of regulatory, legal and marketing constraints. If debt or stock is repurchased, there will be some length of time necessary to. 
carry out the repurchase. If debt is paid off using available cash, the time necessary could be quite slight. In any case, management must allow some time for the change in financial structure.

Because of the constantly changing nature of business risk, managers face a difficult problem in making adjustments in financial leverage. Assume that management makes a change in the financial structure of the firm at a point in time "x" in order to maximize the value of the firm, given the business risk of the firm at time "x". By the time the change in the debt level is completed, the business risk of the firm could have again changed, so, by the time the new financial structure is implemented, the financial structure could be optimal only for the business risk of the firm in a prior period. Consequently, management would end up chasing an optimal debt ratio.

Rather than doing this, management begins the process of changing its financial leverage at time " $x$ ", attempting to move to a financial structure that will maximize the value of the firm in the future, based on an estimated level of business risk in the future. Managers must make decisions, at time "x", about the level of debt that will maximize the value of the firm in the future, at time "x + $f "$, given the future business risk at time $x+f "$, because of the time required to change debt levels. The time period "f" is dependent on the process used to adjust the debt level, the condition of the financial markets at that time, 
and the speed with which the firm can make and implement a decision.

\section{Information content of Financial}

\section{Structure changes}

There is an additional reason that management may change debt levels prior to anticipated changes in business risk. Ross $(73,74)$ and Leland and Pyle (52) suggest that management may be using the change in debt level to "signal" some information to investors and the market about the anticipated situation of the firm. While the market uses all publicly available information in estimating the future value of the firm, "insider" information cannot be released because of the risk of alerting competitors.

Management can, however, "signal" something about the firm's future by announcing financing plans and starting to carry them out. Managers give "honest" signals because to do so is in their best interests. If managers attempt to "signal" dishonestly (i.e., issue a security to mislead the market), the cost to them is quite high, for their wealth is tied to the wealth of the firm through stock options, bonuses, and other agency costs that will affect their compensation. In addition, if they signal dishonestly, they will lose credibility with the market and therefore limit their ability to use the market to signal in the future.

Summary of the Model

Given the time lag involved in changing the financial 
structure, it is necessary that firms change their financial structure prior to changes in the firm's business risk. This is necessary both so that investors know that management is aware of upcoming changes and so that the change in financial structure optimizes firm value given the new level of business risk for the firm.

Because managers enjoy an advantage, although not a certain monopoly, on the information about the future of the firm, managers can both alert investors to upcoming changes in the firm and ensure that firm value is maximized in the future by making changes in financial structure prior to changes in the business risk of the firm. The actions of managers in changing the financial structure is a believable signal because it is a costly signal to managers if wrong, since compensation packages for managers generally include stock options or bonuses tied to firm value.

Only certain firms can approach the full utilization of debt that microeconomic theory would suggest. This is not to suggest that stronger firms issue more debt or have higher debt ratios. As shown by Kim (48) and Turnbull (90), the debt capacity of the firm, as allowed by the market, is greater than the optimal debt ratio. Thus, firms will not move to a maximum debt ratio as allowed by the market, but rather an optimal debt ratio that maximizes market value. Firms which can enjoy the lowest possible costs, or at least costs below where debt will add value to the firm, and have the choice and ability to make optimal financial decisions 
will be best able to move toward an optimal debt level. other firms may be forced to issue non-optimal securities because of past restrictions, lack of market freedom, or control problems. In addition, some firms may not be able to change their financial structures toward a more optimal debt level because of internal or market conditions.

Hence, only a small subset of the total number of firms can use debt to its fullest to maximize value. This does not mean that only certain firms will have high debt ratios. Rather, this means that only some firms will have the market freedom and low cost of new securities that will allow the firms to move constantly toward an optimal debt ratio relative to the business risk of the firm. These stronger firms will have the ability to adjust their financial structures prior to changes in business risk, allowing them to signal investors and ensure that when the change in business risk does occur, the firm is already at or moving toward an optimal debt level.

\section{Implications of the Model}

The implications of the above model are fairly wideranging. First, the model implies a two-tiered grouping of firms, with only upper-tier firms able to use debt as microeconomic theory would suggest (i.e., $A_{i}<Q_{i}$ ). These firms would have a cost of debt that is below the cost where debt no longer adds value to the firm. This lower cost would result from the lower market rates enjoyed by these firms, from their lower agency, bankruptcy and issuing 
costs, and from their ability to make full use of the tax shelter provided by debt. The firms in the upper tier are able to change financial structure prior to changes in business risk, ensuring that when the future change in business risk occurs, the firm has already moved toward optimizing firm value by making adjustments in financial structure. Further, the firms in the upper tier, by changing financial structure prior to changes in business risk, reduce uncertainty in the market and increase confidence that the firm has a good understanding of the future of the firm.

Firms in the lower tier have a lesser ability to use debt in the best possible manner, but still may show changes in financial structure. These firms still have needs for funding of new projects, but may be forced to postpone projects until markets for funds are more favorable or to use sub-optimal financing plans.

These lower tier firms may be unable to issue debt at a cost below the cost where debt increases value. This higher cost may be due to a weak financial history or weak potential future earnings. These firms may be unable to fully use the tax shelter provided by the debt. Or, the firms in these lower tiers may be smaller firms which makes their effective interest rate, after agency and issuing costs, too high to be of advantage to the firm, in terms of maximizing market value.

The firms in the lower tier may have prior restrictions 
on borrowing or may have control problems that preclude issuing the optimal security at a particular time. This inability to use financial structure consistently to improve firm value means that many of the firms in the market are not at an optimal financial structure. Firms with the inability to use debt effectively are essentially forced either to try constantly to adjust financial structure after business risk has changed or to accept constant sub-optimal decisions, either using too expensive debt or waiting until funds become available from internal sources or equity. Equity, however, may be a risky option if there are possible control problems or takeover possibilities.

Thus, firms in the lower tier still issue securities, but because of the particular situation of the firm, it is impossible for the firm to follow an optimal path in regard to financial structure. Firms in the lower tier must follow a sub-optimal path, since the firm's particular situation effectively closes off the optimal path. These firms are unable to issue securities at a cost that maximizes the value of the firm or to issue at a time that will ensure the proper financial structure when the condition of the firm changes.

If this two-tiered grouping of firms, in terms of ability to use debt, actually exists, then it explains, in part, why cross-sectional empirical studies have been generally disappointing. The firms in the upper tier, able to take full advantage of debt as microeconomic theory would suggest, adjust financial structure prior to changes in 
business risk. Thus, any cross-sectional studies would miss the relationship of business risk and financial structure. Firms in the lower tier would adjust financial structure after business risk had changed, and possibly adjust their financial structure in a non-optimal way, because of the restrictions or costs peculiar to that firm. Again, crosssectional empirical studies would not be able to isolate the relationship between business risk and financial structure.

This model also provides a possible explanation of the conflict between macroeconomic and microeconomic theories of the value of debt. Debt may not have positive value to all firms in the entire market, but this does not preclude debt having value to some firms. The value of debt is tied to the actual cost to the firm. If a firm is able to keep its real cost below some point, then debt will have value to the firm $(60)$. While numerous studies, as referred to by Modigliani (66), have suggested that clientele effects have some importance in explaining debt policies of firms, most of these arguments assume that, on average, individuals can borrow at a rate close to the rate enjoyed by the firm, thus making "homemade" leverage more attractive. However, these first tier firms can borrow at actual rates below the rates available to investors. In addition, since debt ratios for large firms do not vary significantly over time because of the size of these firms, any changes in financial structure will not involve a significant change in clientele. This model also helps explain why empirical studies, 
whether using cross-sectional methods or a time series method, have been unable to isolate a relationship between business risk and financial structure. If there is a varying ability among firms to use debt effectively, then a sample picked according to criteria other than strong, consistent earnings will be a sample of firms that have widely varying actual costs of debt $\left(A_{i}\right)$ and a great difference in the timing of changes in financial structure between firms. With a sample that does not discriminate between firms with varying costs of debt and market flexibility, even a time series model will not identify any consistent relationship between financial structure and business risk. 
CHAPTER IV

THE EMPIRICAL MODEL

Purpose of the Empirical Model

The empirical model of this study is designed to test the theoretical model postulated in Chapter Three. This theoretical model postulates that firms tend to change financial structure prior to changes in business risk when firms have the ability to maximize value. Firms are able to maximize value when the cost of raising funds for the firm is low and the firms have the market freedom and managerial expertise to carry out optimal funding and financial structure changes.

This low cost implies that the firms enjoy lower market rates, lower bankruptcy, agency and issuing costs, and are able to make maximum use of the tax shelter available through the use of debt. Market freedom results from strong past performances and expected strong future earnings. Managerial expertise implies firms are able to hire the best managers and provide them with sufficient incentive to maximize value of the firm. 
Specific Hypotheses

\author{
Hypothesis I \\ Changes in the debt level of the firm are \\ strongly correlated with changes in business \\ risk.
}

Hypothesis II

Changes in the debt level of the firm occur prior to changes in business risk.

The first hypothesis is concerned with whether there is a relationship between changes in debt and changes in business risk. To test this hypothesis, a correlation model was used to ascertain whether there is a relationship between changes in debt and changes in business risk. The second hypothesis is concerned with whether the relationship between changes in debt and changes in business risk is leading or lagging. To test the second hypothesis, the timing of the significant relationships was analyzed.

\title{
Assumptions
}

In developing an empirical model to test relationships over time between changes in debt and changes in business risk, several assumptions are necessary. First, it is assumed that there is some time delay in carrying out a change in debt ievel. Second, it is assumed that the amount of time necessary to effect this change is not constant within any firm or any industry. This time to adjust debt 
levels, defined in Chapter 3 as " $f$ ", is dependent on such factors as the state of the economy, the method used to effect the change in debt level, and the particular situation of the firm at the time of the change. Third, it is assumed that management consistently attempts to maximize the value of the firm, using, as possible, changes in debt level.

Overall View of the Model

The empirical model tests for significant correlations between changes in business risk and changes in debt level across time periods. It is hypothesized that there is a leading relationship between changes in debt and changes in business risk. This type of relationship would suggest that managers use their information to estimate the future business risk of the firm and begin to adjust the debt level to maximize firm value, based on the estimated future business risk.

The model tested six different relationships between changes in business risk and changes in debt level. Because the data available were annual data, the time period ( $t$ ) is defined as one year, so that $(t-3)$ refers to a point in time three years prior to ( $t)$. The six relationships are identified by the relationship of the change in debt relative to the change in business risk.

-3 Changes in Debt ( $t-3)$ with Changes in Risk ( $t)$

-2 Changes in Debt ( $t-2)$ with Changes in Risk ( $t)$ 
-1 Changes in Debt (t-1) with Changes in Risk ( $t$ )

+1 Changes in Debt $(t+1)$ with Changes in Risk ( $t)$

+2 Changes in Debt $(t+2)$ with Changes in Risk ( $t)$

+3 Changes in Debt $(t+3)$ with Changes in Risk ( $t)$

The figure in parentheses indicating the relative timing of the change and the number in front of the description is used in the tables to identify the different relationships.

The six relationships were used in testing the two hypotheses by first, testing for the total number of relationships for Hypothesis $I$, and second, testing for the distribution of relationships for HYpothesis II.

\section{The Sample}

The data used in the empirical tests are annual data from Compustat for the twenty years from 1959 to 1978. The firms in the sample are predominantly from the manufacturing sector and are listed by name and industry in Appendix A. The firms were screened in several ways. First, all firms have mostly "pure" debt and "pure" equity. pure debt is defined in a manner similiar to the method used by Ang (3). Pure debt is debt that is not convertible or "quasi-debt," such as leasing. Pure equity means that only one class of common stock has been issued.

These definition avoid problems of classification of hybrid and convertible issues. As a result of the large offerings of convertible bonds in the late sixties and early seventies, it was necessary to allow some firms with "non- 
pure" financing into the sample, in order to develop a statistically satisfactory sample size. All of the firms in the sample have at least seventy-five percent of their nonequity sources of funds resulting from pure debt in at least seventeen out of the twenty years.

The second screening required all firms to be large. All firms in the sample are listed on the New York Stock Exchange and the Standard and Poor's 400 Industrial Index. This requirement ensured that the firms had access to major financial markets and, because of their size, had low agency and issuing costs relative to their total costs.

The final screening required that all firms show a consistent profitability during the twenty years used in the study. This profitability requirement ensures that the firms in the sample have consistently positive cashflow, and hence, a low probability of bankruptcy. This low probability of bankruptcy ensured lower market costs for securities, and further, the consistent profitability increased the probability that the firms in the sample could always use the full benefit of the tax shelter of debt.

This sample used to test the hypotheses is critical to the empirical model. It is hypothesized that managers estimate the future business risk of the firm and, acting on this information, change the debt level of the firm to maximize value. This hypothesis assumes that, generally, managers of firms in the sample are correct in their estimates of future business risk, are able to correctly 
decide the debt levels that maximize value, and are able to implement their decision. Miller and Modigliani (62) assumed that the market forces all firms to adjust to an optimal debt level. While there are no studies that have investigated possible debt optimization differences between firms, it is assumed that firms that consistently generate positive cashflows are better able to optimize the value of the firm by using debt since these firms will have a higher probability of producing the minimum cashflows necessary to service the debt. Because of the lower risk of default, these firms have the widest range of debt levels open to them. Further, it is assumed that firms that consistently generate positive cashflows are, in part, generating these consistent, positive cashflows because management in these firms is better able to estimate the future. These firms are able to attract the better management because of their higher and more consistent profitability. No specific studies have shown that firms with consistently positive cashflows hire management that is better able to predict future business risk, but such a relationship appears reasonable.

As a result of these two assumptions, a sample was selected that minimized the probability of bankruptcy and maximized the probability of having superior management since it was felt that firms that had shown consistent profitability had a lower probability of bankruptcy and could attract better managers. While it is not assumed that managers of the firms in the sample always made correct 
estimates of business risk and always made the optimal debt level decision, it is assumed that managers of the firms in the sample are most likely to make good estimates of future business risk, to make good decisions regarding optimal debt levels, and to have available the maximum range of debt level options.

As noted above, the firms in the sample were drawn from the manufacturing sector, and while they differ greatly in size and industry, all were consistently profitable, debtusing firms. While individual firms showed great variation in their debt levels over the twenty years studied, in terms of overall average debt level, the sample was relatively homogeneous. During the years 1959 to 1978 the majority of the firms ( $89 \%$ ) had between $24 \%$ and $50 \%$ of their total book value financed by debt (book value). The use of long term debt had a somewhat larger spread, with between $3 \%$ and $42 \%$ of their total value financed by long term debt. However, the majority of the firms ( $83 \%$ ) had between $9 \%$ and $27 \%$ of their total value financed by long term debt. The variation in debt level over time, measured either in terms of total debt to total assets or long term debt to total assets, varied greatly for the individual firms. These findings support Spies' hypothesis that temporary financing is orten utilized for both dividends and investments.

These relatively small ranges of average debt usage and large variations in individual debt levels suggest that the relevant question in investigating debt policy is concerned 
with the debt level change response of firms to changes in business risk rather than the relationship of their absolute debt level to some measure of their absolute business risk. While earlier studies (62) (76) have focused on the massive differences in absolute debt levels between industries (especially between utilities and other industries), in the manufacturing sector there appears to be little difference in debt policy in terms of absolute debt levels. As noted by Wippern (95), the major differences in debt levels shown in earlier studies was due to the massive differences between utilites and other industries. The sample in this study reinforces this view, showing little difference in absolute debt levels between firms or industries.

From the results of these earlier studies and the evidence from the sample, the measure of importance is the change in debt level rather than the absolute debt level, since the absolute debt levels seem to be so similar. If the managers of the firm are constantly attempting to maximize value, then the only time they would change debt level is when there is a chance to further optimize the value of the firm. Since the firm is already at, or moving toward, an optimal financial structure for the given conditions, the only reason to change debt levels would be if the conditions for the firm change. 
The Empirical Model

The Use of Changes in Debt and

Changes in Risk

The empirical model concentrates on changes in debt and changes in business risk rather than absolute values because it is assumed that management attempts to maximize value of the firm at all times. The debt level that maximizes value is dependent on conditions in the company and the environment at that time period. Thus, the optimal debt level or ratio for a firm could vary from year to year. This assumption means that management uses all the information available to optimize the debt level of the firm. Hence, the only time management will change the debt level occurs when new information re-defines that optimal debt level. This means that the driving force for change is new information. Only when this new information affects the optimal debt level for the firm will there be a change in the debt level. The driving force is change and, hence, the model must define the relationship between debt and business risk by evaluating the relationship between changes in debt and changes in business risk.

The Reasons for a Time series Model

The empirical model is designed to allow investigation of the relationship of changes in debt and changes in business risk. It has been assumed that changes in debt level require some time "f", which is not necessarily 
constant either between or within firms. This time required between the perception of the need to adjust the debt level and the actual recording of the change. in debt level on the firm's balance sheet could extend over more than one period. This lag in the recording of changes in debt levels is in part the result of the utilization of yearly data and in part the result of the non-constant time "f" required to actually carry out the change. As an example of this problem, assume that a firm, using a calendar accounting year, decides to change the optimal debt level (debt/total assets) of the firm in september, 19xl, by selling a new issue of debt. By the time the debt issue is actually recorded on the year end balance sheet, possibly fifteen months have passed, since it would be very difficult to carry out a new issue in time to record the issue on the balance sheet for 19xl. However, if the same change in debt level was made by buying back stock from one large investor using available cash, it is possible that the change in the debt level could have been recorded in $19 \times 1$ rather than 19x2. In both cases, the debt level would have changed in the same direction, but the time of recording would be one period different.

It is apparent that these two different methods to affect a change in the debt level (measured by debt/total assets) would have differing effects on the overall riskiness of the firm. The major point, however, is that changing the debt level of the firm can be accomplished in a 
number of ways, and the time necessary to effect this change depends in part on the method used. Because the model is attempting to relate changes in debt and changes in risk, and these changes in debt may be recorded in periods different from the decision to change the debt level, a time series model is necessary. Further, since it is hypothesized that there is a leading relationship between changes in debt and changes in business risk, a time series model is necessary.

Development of the Business Risk Measure

The risk measure is designed to measure changes in business risk while allowing for two adjustments to normalize the raw measure of business risk change. These adjustments are necessary because the management of a firm does not merely look at the raw change in the business risk, but must also make allowances for the overall changes in the economy and for what is a "normal" change within the company. This normal change is what past experience would indicate is a reasonable change in the operating income of the company. Any firm shows some variation in its earning before interest and taxes (EBIT) over time. This variation, usually measured by standard deviation, gives the management a range within which variations can be judged as normal or otherwise. Hence, the actual raw measure of the change in business risk must first be adjusted for the normal changes expected in business risk for the firm.

The measure must also be adjusted for the changes in 
the economy as managers and the market judge the firm in relation to the rest of the market. In this study, the change in the market is measured by a "proxy", the performance of the other firms in the sample.

The raw measure of business risk change is the yearly change in earnings before interest and taxes. This measure was used for several reasons. First, EBIT is a traditional measure of business risk. Second, the change in EBIT captures both changes in sales and changes in operating leverage. Finally, the use of changes in EBIT as a measure of business risk has been empirically tested and found to be a very strong indicator of business risk by zumwalt and Shin (96).

The change in EBIT risk was first adjusted for the normal business risk change expected in the firm. The raw measure of change in business risk, change in EBIT, was adjusted using the standard deviation of the EBIT for the firm over the period. After the first adjustment, the risk measure becomes

$$
R M_{t, i}=\left(E B I T_{t, i}-E B I T_{t-1, i}\right) / S . D \cdot i
$$

where $R M_{t, i}=$ riskmeasure for time period t for firm i

$$
\begin{gathered}
\text { S.D. } i=\text { standard deviation of EBIT for firm } i \text { over the } \\
\text { twenty year period. }
\end{gathered}
$$

The resulting risk measure relates the amount of change in EBIT from one year to the next relative to a measure of "normal" change in the EBIT of the firm. This 
adjustment is made by using one standard deviation as a measure of the "normal" change experienced by the firm. In addition, since there is wide variation in total asset size between firms, this use of the standard deviation of EBIT scales the changes in EBIT for the relative sizes of the EBIT of different size firms.

This change in EBIT must also be evaluated in terms of the rest of the economy. If all firms are showing a great increase in EBIT, then a larger than normal change for the firm may not signify any real change in the business risk of the firm. The second adjustment is to adjust for the changes in the economy and essentially "de-trend" results over the twenty year period. A ranking and differencing procedure is used. The change in EBIT, relative to the standard deviation, is ranked for each firm relative to all firms in the sample for each year. Hence, for each year there is a number assigned to each firm, based on the firm's change in EBIT, relative to its standard deviation of EBIT. The change in this number from one year to the next is the relative business risk change of the firm. The larger the change in EBIT, relative to the standard deviation of EBIT for the firm and relative to the changes in firms in the sample, the larger the relative change in business risk.

A diagram of the development of the business risk measure is shown in Figure 1. There are four steps to the process. First, the change in EBIT is developed by differencing the EBIT of each year. Second, the change in EBIT is divided by the standard deviation of EBIT for the 


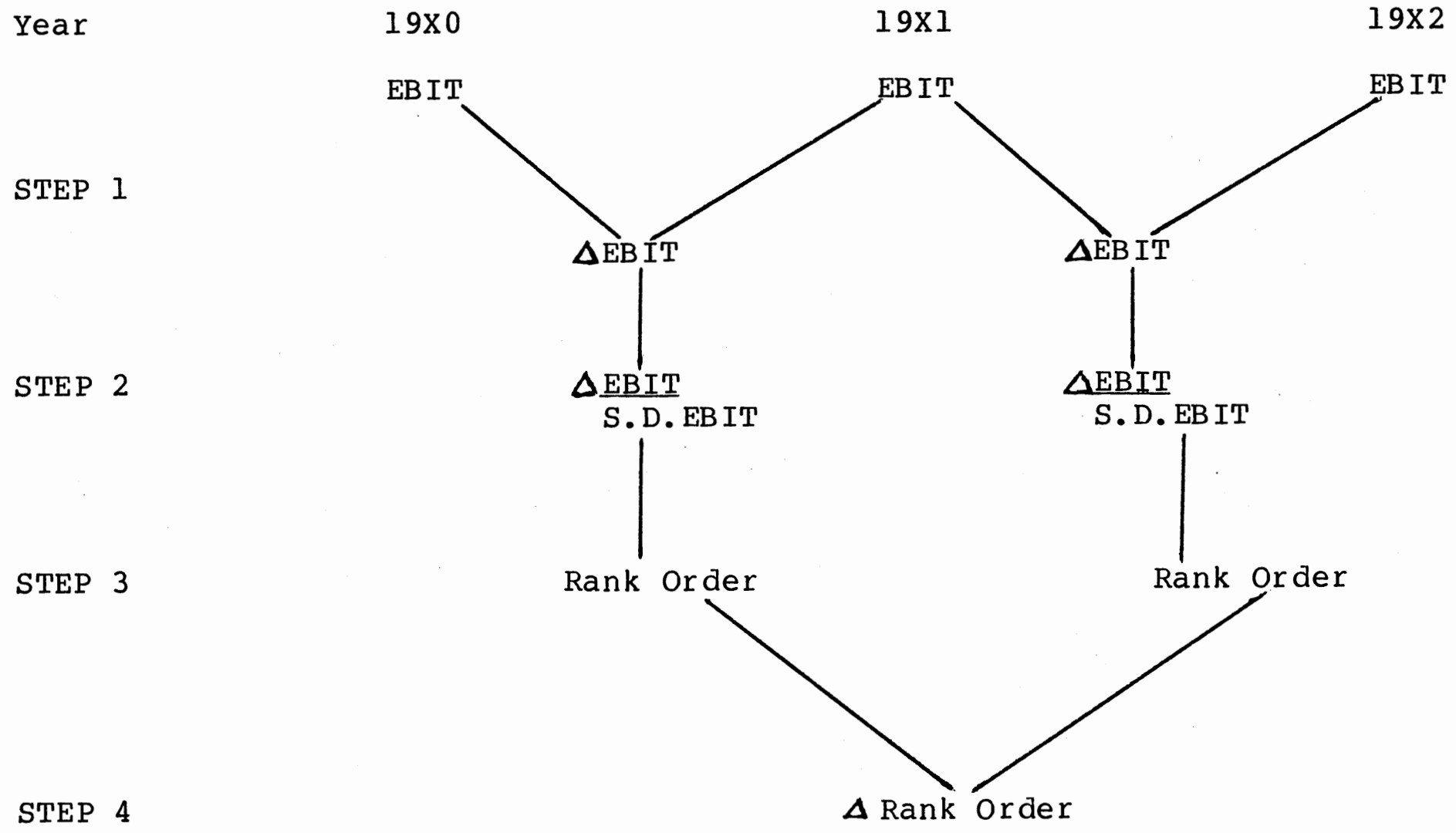

Figure 1 The Development of the Risk Measure 
firm. Third, the resultant measure is ranked with all other firms in the sample. Finally, the change in rank order is found for each firm. The series, composed of the changes in rank order, represents the measure of change in business risk for the firm, over the twenty years of the sample.

These last two procedures of ranking and differencing the rank orders de-trend the data by ensuring that the firm registers a change in business risk only if the level of EBIT changes relative to the normal changes expected for the firm, and relative to the changes in all firms in the sample. Hence, a firm can show a change in business risk only if the change in EBIT is large relative to the standard deviation of the EBIT of the firm over the twenty year period and this change is large relative to the changes in the EBIT of other firms. If all firms are showing a gain (or loss) in EBIT, then the ranking of any one firm which shows a similar change in EBIT will not change. A change in EBIT, even if it is large relative to the standard deviation of EBIT for the firm, may not be large enough to register as a change in business risk. If all other firms are also experiencing a large increase in EBIT (as in an upswing in the economy), then the change in the individual firm's EBIT will not result in a change in business risk measure.

This numerical rank ordering of the firms in each year, dependent upon the ratio of the change in EBIT to the standard deviation of EBIT of the firm, has been tested by zumwalt and Shin (96). They found that when rank ordered 
business risk variables were used, all of the eight variables tested were significant in ANOVA tests of industry financial structure. When the raw variables were tested, only three of the eight variables were significant.

This measure of business risk was not designed to measure exactly the business risk of a firm at a particular time. Rather, this measure is designed to indicate changes in business risk for the firm, relative to the changes in business risk that the firm would generally expect and relative to the changes in other firms in the economy.

The purpose of this risk measure is to integrate two sets of information used by the management to assess the business risk of the firm. The management uses the (estimated) performance of the firm and this performance relative to other firms to judge the business risk of the firm. As mentioned before, the performance of other firms in the sample is used as a "proxy" to measure change in the overall economy.

Development of the Debt Measure

Two separate sets of correlations were run as two different variables are used to measure the change in debt level. The debt level was measured first using total debt as a percentage of total assets and then long term debt as a percentage of total assets. Both of these measures were found to be significant indicators of differences in financial structure between industries by $z$ umwalt and shin (96). Zumwalt and Shin tested the variables used by numerous 
earlier studies and their own study, using an ANOVA procedure to test for differences between industries. They found that total debt to total assets, as used by Ferri and Jones (32) and Remmers et al.(71), and long-term debt to total assets, used in their own study, were consistently significant variables.

The change in debt level percentage (debt as a percentage of total assets) for each firm was used to measure the change in debt. Two different measures of debt level were used, total debt to total assets and long term debt to total assets, because, as noted by spies (82) firms often use temporary financing during their adjustment of financial structure. The resultant two series of debt level measures had nineteen changes in debt for each firm for the twenty years studied.

\section{Correlation Method}

The two measures for each firm, the measure of cnange in risk and the measure of change in debt, were correlated using a Pearson product-moment correlation. Two sets of six different correlations were calculated for each company in the sample, using the appropriate leads and lags described in the section on the overall View of the Model. The two different sets of correlations used two different measures of debt, changes in long term debt to total assets and changes in total debt to total assets. These two debt series were individually correlated with the series representing 
the changes in business risk.

For the first hypothesis, the null hypothesis was that there was no correlation between changes in debt level and changes in business risk. For the second hypothesis the testing was involved with the timing of the significant relationships. The null hypothesis was that there was no predominant lead or lag relationship between changes in debt and changes in business risk.

For testing the correlation between change in debt and change in business risk an alpha of 0.10 was selected. Fisher's approximation was used to to determine the critical values for $r$, the correlation coefficient. Fisher's approximation calculates the critical value of $r$ for a given alpha. The approximation is

$$
z=((n-3) \cdot 5 / 2)(\ln (1+r) /(1-r)-\ln (1+p) /(1-p))
$$

where $r=$ the correlation coefficient for the sample

$$
\mathrm{n}=\text { the sample size }
$$

and $p=$ the correlation coefficient for the population. In this case, since the null hypothesis is that $p=0$, the terms involving $\mathrm{p}$ drop out. The formula, for $\mathrm{n}=19$, becomes

$$
\begin{aligned}
& \mathrm{z}=2 \ln ((1+r) /(1-r)) \\
& \text { or } \quad r=\left(e^{z / 2}-1\right) /\left(e^{z / 2}-1\right)
\end{aligned}
$$

For a alpha of 0.10 , which implies $z=1.645$, the critical value is $r= \pm 0.39$. 


\section{Raw Results of Empirical Testing}

The raw results of the empirical testing are presented in Appendix B. These results are summarized in the following tables.

Table I shows that for the one hundred fifty-three firms in the sample, approximately half of those firms showed a significant relationship between changes in debt and changes in business risk. The correlation between changes in long term debt and changes in business risk was significant for 85 firms, or $56 \%$ of the sample. The correlation between changes in total debt and changes in business risk was significant for 81 firms, or $53 \%$ of the sample. Of the firms that showed significant correlations, there was a great deal of commonality, with 54 firms, or approximately two-thirds of the firms with significant correlations being identified in the correlations using long-term debt to total assets and total debt to total assets. In using both measures of change in debt, a total of 109 firms, or $71 \%$ of the sample, were found to have significant correlations between changes in debt and changes in risk. 
TABLE I

Firms showing Significant Leading or Lagging Relationships

Number of Firms Percent of Total

Long Term Debt $\quad 85 \quad 56 \%$

Total Debt $81 \quad 53 \%$

Both $54 \quad 35 \%$

$\begin{array}{lll}\text { Either } & 109 . & 71 \%\end{array}$

The six different relationships referred to are as listed earlier. The meaning of these relationships is explained in Figure 2. In Figure 2 the change in debt measures are numbered from 1 to 4 as are the changes in rank ordering. These numbers designating the change in debt and the change in rank ordering are for explanatory purposes only. Assume that the sample data begin in year 19x0. Since yearly data were used, all references to period refer to a yearly period. From the yearly data, two series were developed, one for the change in business risk and one for the change in debt, as explained earlier. These two series were correlated, using six different leading and lagging relationships.

Since two measures were used to define the cnange in debt, all of the correlations were performed twice, once 


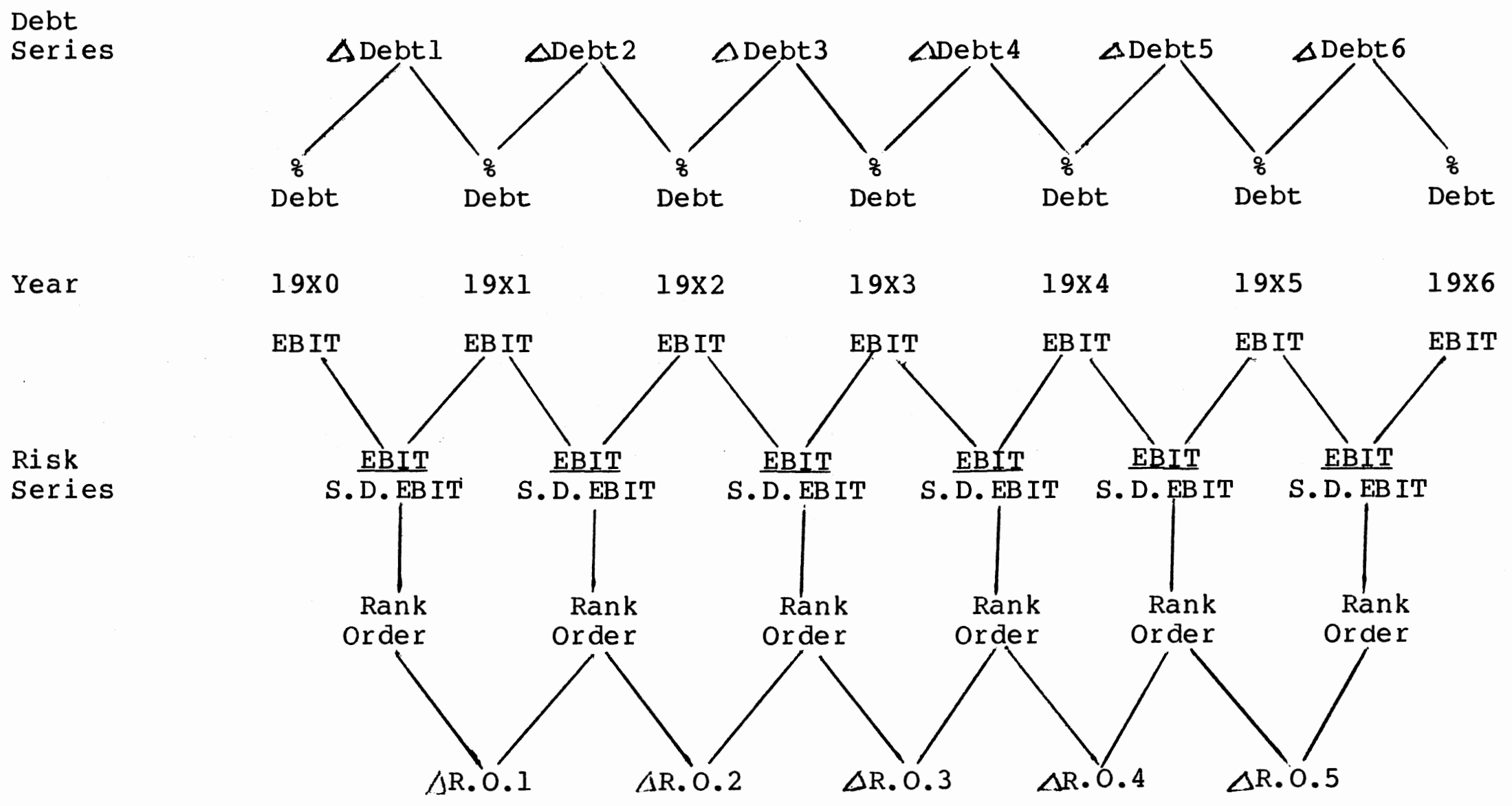

Figure 2 An Explanation of the Development of the Correlation Series Used in the Six Different Correlations 
using the change in long term debt to total assets and once using the change in total debt to total assets as the measure of change in debt. Both of these measures of change in debt were used in testing the two hypotheses, as it is unknown which of the two measures of change in debt is the correct one.

The correlation between changes in debt and changes in business risk were performed on the series resulting from the one hundred fifty-three companies in the sample for each of the six leading and lagging relationships. Relationship -3 is the result of correlating a series beginning with change in debt 1 to a series beginning with change in rank ordering 3. In other words, the change in debt is leading the change in business risk by three periods. Relationship -2is the result of correlating the series beginning with change in debt 1 with the series beginning with change in rank order 2. The change in debt is leading the change in business risk by two periods. Relationship -1 is the result of correlating the series beginning with change in debt 1 with change in rank ordering 1. The change in debt is leading the change in business risk by one period. Relationship +1 is the result of correlating the series beginning with change in debt 2 with change in rank ordering 1. The change in debt is lagging the change in business risk by one period. Relationship +2 is the result of correlating the series beginning with the change in debt 3 with the change in rank ordering 1. The change in debt is lagging the change in business risk by two periods. Relationship +3 is 
the result of correlating the series beginning with change in debt 3 with the series beginning with change in business risk 1. The change in debt is lagging the change in business risk by three periods.

It was expected that a firm would show only one significant relationship out of the six possible relationships between changes in debt and changes in business risk. However, it was found that many of the firms had more than one significant relationship. The total number of the correlations and their distribution are shown in Table II.

There was no estimate made of the probable distribution of significant correlations between the six relationships, because both the time " $f$ " necessary to make a change in debt and the amount of time firms would lead changes in business risk if, indeed, signaling were operational, were unknown. Because it is not possible to estimate the distribution of these significant relationships, no statistical tests are possible, other than an analysis of the relative percentage of significant correlations in each relationship, and the the distribution of significant correlations between leading and lagging relationships.

In Table I the total significant correlations are listed by relationship and sign. As can be seen, the leading relationships are favored in both cases, with $65 \%$ of the total significant correlations in the leading relationships for the long term debt measure, and $52 \%$ with the total debt 
measure. The distribution of the positive and negative correlations is inconclusive, with $46 \%$ of the correlations being positive with the long term debt measure, and $45 \%$ positive with the total debt measure. No prior hypothesis about this distribution had been made because it was thought that market conditions would affect the optimal debt ratio for firms. From the initial evidence of high variation in debt ratios over time for individual firms, it would appear that the optimal debt ratio for firms changed greatly over time, and hence, the sign of the correlation could be either positive or negative as the optimal debt ratio changed.

TABLE II

Total Significant Correlations by Relationship

$\begin{array}{llllllll}-3 & -2 & -1 & +1 & +2 & +3 & \text { Total }\end{array}$

Long Term Debt

Positive

$\begin{array}{lllllll}15 & 8 & 4 & 8 & 9 & 7 & 51\end{array}$

Negative

1211

22

6

36

60

Total

$\begin{array}{lll}27 & 19 & 26\end{array}$

$\begin{array}{lll}14 & 12 & 13\end{array}$

111

Total Debt

Positive

Negative

$9 \quad 12$

10

10

9

11

$19 \quad 21$

21

27

$7 \quad 1$

118

117 
Since it was hypothesized that firms used changes in debt as a signal, the value of the signal was dependent on the change in debt occurring prior to the change in business risk. Thus, significant correlations in relationships -3 , -2 , or -1 would mean that the change in debt occurred prior to the change in business risk. If the significant correlation occurred in relationship $+1,+2$, or +3 then the change in debt was contemporaneous or after the change in business risk. The distribution and frequency of the initial significant correlations is presented in Table III. 
TABLE III

First Significant Relationship

Long Term Debt

\begin{tabular}{|c|c|c|c|c|c|c|}
\hline & -3 & -2 & -1 & +1 & +2 & +3 \\
\hline $\begin{array}{l}\text { Number of Significant } \\
\text { Correlations }\end{array}$ & 28 & 14 & 20 & 10 & 5 & 8 \\
\hline $\begin{array}{l}\text { Percentage of Total Firms } \\
\text { in Sample (153) }\end{array}$ & $18 \%$ & $9 \%$ & $13 \%$ & $7 \%$ & $3 \%$ & $5 \%$ \\
\hline $\begin{array}{l}\text { Percentage of Significar } \\
\text { Relationships }\end{array}$ & $32 \%$ & $17 \%$ & $24 \%$ & $12 \%$ & $6 \%$ & $10 \%$ \\
\hline
\end{tabular}

Total Number of Significant Correlations $=85$ or $56 \%$ of total firms.

\section{Total Debt}

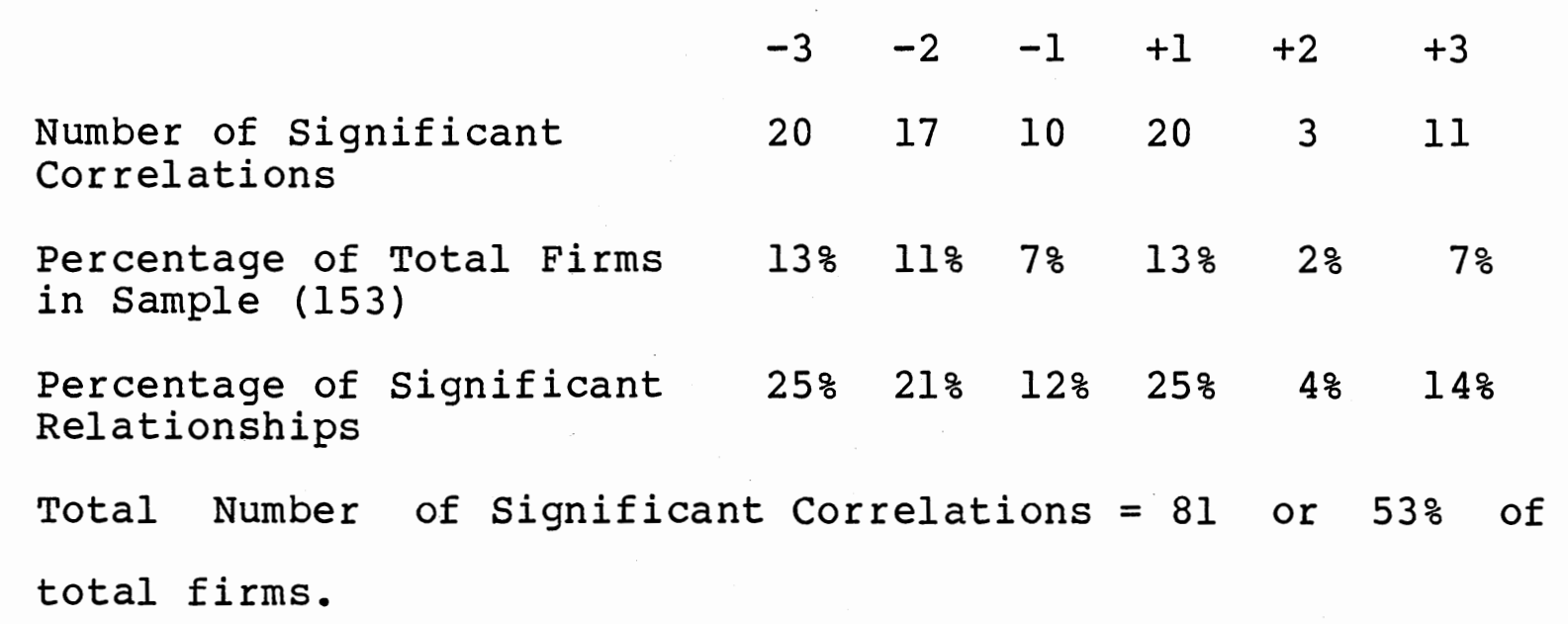


TABLE III (Continued)

Either

$\begin{array}{lccccccc} & -3 & -2 & -1 & +1 & +2 & +3 \\ \begin{array}{l}\text { Number of Significant } \\ \text { Correlations }\end{array} & 38 & 19 & 21 & 20 & 2 & 9 \\ \begin{array}{l}\text { Percentage of Total Firms } \\ \text { in Sample (153) }\end{array} & 25 \% & 12 \% & 14 \% & 13 \% & 1 \% & 6 \% \\ \begin{array}{l}\text { Percentage of Significant } \\ \text { Relationships }\end{array} & 35 \% & 17 \% & 19 \% & 18 \% & 2 \% & 8 \% \\ \text { Total number of Significant Correlations } & =109 \text { or } & 71 \% \text { of } \\ \text { total firms. }\end{array}$

The importance of the initial relationship is that, from a standpoint of forecasting an upcoming change in business risk, the change in debt is the first signal to investors that a change in business risk is upcoming. The earlier this signal, the more useful it will be to investors. From Table III it is obvious that either method lacks strong explanatory power. Only slightly more than half of the firms showed significant relationships and even when both methods were used, only $71 \%$ of the firms showed significant relationships. Also, as noted in Table II, the distribution, while favoring a leading relationship between changes in debt and changes in business risk, is far from conclusive. These findings could result from weakness in the initial model or from firms being far more erratic in their 
adjustment of debt levels than heretofore thought. It could be that firms are not consistent over time in response to changes in business risk in terms of the direction of change in debt level and in terms of whether long or short term debt is utilized. Further, the model does not include any factor for changes in the securities markets, which could greatly affect the choice of financing instrument and, hence, the strength of the correlation over time between changes in business risk and changes in debt.

A serious problem of the study is concerned with the methodology used in the correlation. The correlating of a series developed from a change in the percentage of debt with the change in rank order presents some possible statistical problems.

A further serious difficulty with the results is concerned with the absolute number of significent correlations. The number of significant correlations identified by the model were approximately the same number of significant correlations that would be expected by chance, given the number of correlations performed. However, the distibution of these correlations does seem to support Hypothesis II.

Despite the weakness of the results, it does appear that generally, firms change financial structures prior to changes in business risk. When using changes in long term debt to total assets as the measure of change in debt, $73 \%$ of the initial significant correlations were in leading relationships. When using changes in total debt to total 
assets as the measure of change in debt, $58 \%$ of the initial significant correlations were in leading relationships. When using both measures of debt, $71 \%$ of the initial significant correlations are leading. If the assumption is made that the occurances of significant correlations should be evenly distributed, the argument favoring a leading relationship is stronger. In Table IV the results are presented as percentages of the expected amounts in that relationship if the assumption is made that the distribution of significant relationships were evenly distributed.

TABLE IV

Significant Initial Relationships as a Percent of Expected Equal Distribution of Relationships

\begin{tabular}{lcccccc}
\hline & -3 & -2 & -1 & +1 & +2 & +3 \\
Long Term Debt & $200 \%$ & $100 \%$ & $143 \%$ & $71 \%$ & $36 \%$ & $57 \%$ \\
Total Debt & $148 \%$ & $126 \%$ & $74 \%$ & $148 \%$ & $22 \%$ & $81 \%$ \\
Either & $210 \%$ & $105 \%$ & $116 \%$ & $110 \%$ & $11 \%$ & $50 \%$ \\
\hline
\end{tabular}

It appears that there is a definite tendency for firms to change debt prior to changes in business risk. Further, it is clear that cross-sectional studies, even if they identify 
the near contemporaneous significant changes in debt and business risk of relationships -1 and +1 , would identify little more than a third (37\%) of the actual significant correlations. In terms of the total sample, such a method would identify less than $27 \%$ of the total sample as showing significant correlations. Even if a model used a leading or lagging variable, the distribution of significant relationships is too great to be identified unless a variable is included for the three leading and three lagging relationships of changes in debt and changes in business risk.

The Results of the Hypotheses Testing

Hypothesis I

The first hypothesis stated that the changes in debt level are stongly correlated with changes in business risk. This hypothesis was tested, using an alpha of 0.10 , with the null hypothesis being that there was no correlation between changes in debt and changes in business risk. Using as a measure of change in debt, change in long term debt to total assets, it was found that over half of the firms (56\%) in the sample showed a strong correlation between changes in debt and changes in business risk. Using as a measure of change in debt, change in total debt to total assets, it was again found that over half the firms ( $53 \%$ ) showed a strong correlation between changes in debt and changes in business risk. When using both methods of measuring debt, $71 \%$ of the 
firms in the sample showed a strong correlation between changes in debt and changes in business risk.

These results are far from conclusive, as there is a serious statistical problem in the overall number of correlations identified by the model, as the total number of significant correlations are approximately the number that would be expected in such a sample size of correlations by chance. The distribution of these significant correlations among firms does provide weak support for some relationship between changes in debt and changes in business risk. It does appear that the correlation between change in debt and changes in business risk is strong for more than half the firms in the sample. Because there is no hypothesized distribution of the firms that show a high correlation and those that show no correlation, no statistical testing of the resulting percentages is possible.

Hypothesis II

The second hypothesis stated that changes in the debt level of the firm occur prior to changes in business risk. This hypothesis was tested by analyzing the distribution of the leading and lagging relationships. It was found that the majority of the relationships tended to be leading among the firms that had significant correlations. For the long term debt correlations, $73 \%$ of the correlations were leading, for the total debt correlations, $58 \%$ were leading, and for the significant relationships identified by either methods, $71 \%$ 
of the significant relationships were leading. If the concept of leading is expanded to include contemporaneous, i.e., relationship +1 , then the evidence becomes even stronger. The long term debt would show $85 \%$, the total debt would show $83 \%$, and either would show $89 \%$. The inclusion of the contemporaneous relationship +1 as a leading relationship is defensible on the grounds that firms may not have been able to issue debt prior to changes in business risk, but the upcoming change in financial structure would probably have been known to the market and, therefore, was a response to a change in business risk. However, with no hypothesized distribution for the leading and lagging relationship, no statistical analysis of these results is possible.

Again the results are far from conclusive, but it appears that for firms that show significant correlations between changes in debt and changes in business risk, the relationship appears to be a leading one, or contemporaneous, with the change in debt leading the change in business risk.

\section{Conclusions of the Study}

The empirical study is unable to support either of the hypotheses strongly. While there is some support for both hypotheses, the evidence is far from overwhelming. The study was weakened by the aforementioned statistical problems and the lack of a definite distribution for the population of firms regarding first, the expected number of firms to show 
significant relationships and second, the timing of these significant relationships. Both of these areas need further research from both a theoretical and empirical basis.

\section{Implications of the Study}

The study points out that a fairly complex time series model can identify a relationship between debt and business risk. This use of non-contemporaneous variables to explain financial structure supports the earlier work of Dhrymes and Kurz (19), Fama (29), McCabe (59), Myers (68) and Myers and Pogue (69). It is obvious that cross-sectional studies or even less complex time series models will miss much of the relationship between debt level and business risk.

Further, it appears that the critical factors to investigate over time are the change in debt and change in business risk, rather than some absolute measure of debt or risk as used in MM (62) and all the later studies based on their methodology. The multiple significant relationships for many firms in the sample and the differing results using long term debt versus total debt suppots the slow adjustments of debt level reported by Ang (3), Taggart (88) and Spies (82).

The study also provides weak empirical support of Heinkel's model (43) and the signaling concept developed by Ross (73) and Leland and Pyle (52). It appears that firms act as if they are attempting to provide information to the market prior to changes in the business risk ot the firm. 
The sample used in testing for the factors that affect debt changes also appears important. Further, it appears that firms are rather erratic in their methods of changing debt, with no consistent relationship between changes in debt and changes in risk over time, and no consistent pattern of using strictly long term or short termdebt. There does appear to be an attempt to change debt levels prior to changes in business risk, but apparently even the better firms are unable to do this consistently. The slightly higher distribution of significant correlations in the leading relationships does tend to support the idea of signaling, but again the results are far from conclusive.

Further Avenues of Approach

The model in this study could be expanded to take into account several other important influences on the decision to change financial structure. These additional variables should include some measure of the condition of the markets for securities, including possibly the rates on different security instruments and other factors which may affect selection. There also should be investigation into the effect of rates on the timing of issues as suggested by Marsh (55) and into the effect of tax shields, such as depreciation, on financial structure decisions as suggested by Cordes and Sheffrin (16).

The question of whether firms defined in this study as being more able to make optimal financial structure decisions are, in fact, different from the rest of the firms 
on the market (i.e., a two-tiered market as suggested in the theoretical model) should be investigated. Finally, a more detailed examination of the actual changes in debt for the firms in the study needs to be undertaken. Since there appears to be no definite direction of change in debt level as a response to change in business risk, the conditions facing the firm before, during and after a change in business risk should be investigated. It is possible that the correlation model used in this study hid many of the significant relationships because firms were neither consistent in the direction of change in debt in response to a change in business risk nor consistent in using long or short term debt to adjust financial structure. 


\section{A SELECTED BIBLIOGRAPHY}

1. Allen, F.B. "Does Going Into Debt Lower the Cost of Capital?" Analysts Journal, (August 1954), pp. 57-61.

2. Anderberg, Michael R. Cluster Analysis for Application. New York: Academic Press, Inc. 1973

3. Ang, James S. "The Intertemporal Behavior of Corporate Debt Policy." Journal of Financial and Quantitative Analysis. (November 1976), pp. 555-565.

4. Arrow, Kenneth J. and Gerard Debreu. "Existence of an Equilibrium for a Competitive Economy." Econometrica. 22, No. 3 (July 1954), pp. 265-290.

5. Baron, D. "Default Risk, Home-Made Leverage and the Modigliani-Miller Theorem." American Economic Review. 64, No. 1 (March 1974), pp. 176-182.

6. --Default Risk and the Modigliani-Miller Theorem: A Synthesis." American Economic Review. 66, No. I (March, 1976), pp. 204-212.

7. Baxter, N.D. "Leverage, Risk of Ruin, and the cost of Capital." Journal of Finance. 22, No.3 (September 1967), pp. 395-404.

8. -..-- and John G. Craig. "Corporate Choice Among Long-Term Financing Instruments. "Review of Economics and Statistics. 52, No. 3 (August 1970), pp. 225-235.

9. Belkaoui, Ahmed. "A Canadian Survey of Financial Structure." Financial Management. (Spring 1975), pp. 74-85.

10. Bierman, Harold Jr. and George S. Oldfield, Jr. "Corporate Debt and Corporate Taxes." Journal of Finance. 84, No. 4 (September 1979), pp. 951-956.

11. Brealey, Richard and S.C. Myers. Principles of Corporate Finance. New York: McGraw-Hill, 1981. 
12. Brennan, M.J. and E.S. Schwartz. "Corporate Income Tax, Valuation and the Problem of Optimal Capital Structure." Journal of Business. 5l, No. 1 , pp.103-114.

13. Chen, Andrew H. and E. Han Kim. "Theories of Corporate Debt Policy." Journal of Finance. 34, No.2, (May 1979), pp. 371-384.

14. - "Recent Developments in the Cost of Debt Capital." Journal of Finance. 33 , No. 3 (June 1978), pp. 863-877.

15. Copeland, Thomas E. and J.F. Weston. Financial Theory and Corporate Policy. 2nd ed. Reading: AddisonWesley, 1983.

16. Cordes, Joseph J. and Steven M. Sheffrin. "Estimating the Tax Advantage of Corporate Debt." Journal of Finance. 38, No. 1 (March 1983), pp. 95-105.

17. DeAngleo, Harry and Ronald W. Masulis. "Leverage and Dividend Irrelevancy Under Corporate and Personal Taxation." Journal of Finance. 35 , No. 2 (May 1980), pp. 453-464.

18. -----. "Optimal Capital Structure Under Corporate and Personal Taxation." Journal of Financial Economics. 8 (1980), pp. 3-29.

19. Dhrymes, Phoebus J. and Mordecai Kurz. "Investment, Dividends, and External Finance Behavior of Firms." Determinants of Investment Behavior. Conference No. 18 of the Universities - National Bureau Committee for Economic Research at the University of Wisconsin. (June, 1963), edited by Robert Ferber. New York: Columbia University Press, 1967.

20. Donaldson, Gordon. Corporate Debt Capacity. Boston: Division of Research, Harvard Business School, 1961.

21. - - New Framework for Corporate Debt Policy." Harvard Business Review. (September-October 1978), pp. 149-164.

22. - - Strategy for Financial Mobility. Boston: Division of Research, Harvard Business School, 1969.

23. Durand, David. "Cost of Capital and Equity Funds for Business: Trends and Problems of Measurement." National Bureau of Economic Research, Conference on Research in Business Finance. New York, 1952, pp. 215-247. 
24. Elton, Edwin J. and Martin J. Gruber. "Homogeneous Groups and the Testing of Economic Hypothesis." Journal of Financial and Quantitative Analysis. (January 1970), pp. 581-602.

25. --_---. "Marginal Stockholder Tax Rates and the Clientele Effect." The Review of Economics and Statistics. 52 (1970), pp. 68-74.

26. Fama, Eugene F. "Agency Problems and the Theory or the Firm." Journal of Political Economy. 88, pp. 288-307.

27. -- Foundations of Finance. New York: Basic Books, 1976.

28.

"The Effects of a Firm's Investment and Financing Decisions on the Welfare of its Security Holders." American Economic Review. 68, No. 3 (June 1978), pp. 272-284.

29. -----. "The Empirical Relationship Between the Dividend and Investment Decisions of the Firm." American Economic Review. (June 1974), pp. 304-318.

30. -...- and Merton $\mathrm{H}$, Miller. The Theory of Finance. New York:1972.

31. Farrar D. and L.L. Selwyn. "Taxes, Corporate Financial Policy and Returns to Investors." National Tax Journal. 20 (December 1967), pp. 444-454.

32. Ferri, Michael G. and Wesley H. Jones. "Determinants of Financial Structure: A New Methodological Approach." Journal of Finance. 34, No. 3 (June 1979), pp. 631-644.

33. Gordon, M.J. "Toward a Theory of Financial Distress." Journal of Finance. 26, No. 2, (May 1971), pp. $347-356$.

34. Gordon, M.J. and L.I. Gould. "The Cost of Equity Capital: A Reconsideration." Journal of Finance. 33, No. 3 (June 1978), pp. 849-861.

35. Gonedes, Nicholas J. "A Test of the Equivalent Risk Class Hypothesis." Journal of Financial and Quantitative Analysis. (June 1969), pp. 159-177.

36. Gibaldi, Joseph and Walter S. Achtert. MLA Handbook for Writers of Research Papers, Theses, and Dissertations. New York: Modern Language Association, 1980 . 
37. Haley, C.W. and L.D. Schall. The Theory of Financial Decisions. "2nd ed. New York: McGraw-Hill, 1979 .

38. Hamada, Robert S. "The Effect of the Firm's Capital Structure on the Systematic Risk of Common Stocks." Journal of Finance. 27, No. 2, (May, 1972), pp. $435-452$.

39. -- "Portfolio Analysis, Market Equilibrium and Corporation Finance." Journal of Finance. 24, No.1, (March 1969), pp. 13-31.

40. Harris, John M. Jr., Rodney L. Roenfeldt, and Phillip L. Cooley. "Personal Income Taxation and Capital Structure." Paper presented at Financial Management Association, Dallas, 1979.

41. Hartigan, John A. Clustering Algorithms. New York: John Wiley and Sons, 1975.

42. Haugen, Robert $A$. and Lemma $W$. Senbet. "The Insignificance of Bankruptcy Costs to the Theory of Optimal Capital Structure." Journal of Finance. 33, No. 2, (May 1978), pp. 383-393.

43. Heinkel, Robert. "A Theory of Capital Structure Relevance under Imperfect Information." Journal of Finance. 37, No. 5 (December 1982), pp. 1141-1150.

44. Hirshleifer, J. "Investment Decisions Under Uncertainty: Applications of the State-Preference Approach." Quarterly Journal of Economics. 80, No. 2, (May 1966), pp. 252-277.

45. --.--. "Investment Decisions Under Uncertainty: Choice Theoretic Approaches." Quarterly Journal of Economics. 79, (November 1965), pp. 509-536.

46. Hong, Hai and Alfred Rappaport. "Debt Capacity, Optimal Capital Structure, and Capital Budgeting Analysis." Financial Management. (Autumn 1978), pp. 7-11.

47. Jensen, Michael C. and William H. Meckling. "Theory ot the Firm: Managerial Behavior, Agency Costs and Ownership Structure." Journal of Financial Economics. 3 (1976), pp. 305-360.

48. Kim, E. Han. "A Mean-Variance Theory of Optimal Capital Structure and Corporate Debt Capacity." Journal of Finance. 33, No. 1, (March 1978), pp. 45-63. 
49 .

"Miller's

Equilibrium, Shareholder

Leverage Clienteles, and Optimal Capital Structure." Journal of Finance. 37, No. 2 (May 1982), pp. 301-318.

50. Kim, E.Han, W.G. Lewellen and J.J. McConnell. "Financial Leverage Clienteles: Theory and Evidence." Journal of Financial Economics. 7 (March 1979), pp. 83-109.

51. Kraus, A. and R. Litzenberger. "A State-Preference Model of Optimal Financial Structure." 28, No. 3, Journal of Finance. (September 1973), pp. 911-922.

52. Leland, Hayne E. and David F. Pyle. "Informational Asymmetries, Financial Structure and Financial Intermediation." Journal of Finance. 32, No. 1, (May 1977), pp. 371-384.

53. Lintner, John. "The Cost of Capital and Optimal Financing of Corporate Growth." Journal of Finance. 18, No. 2 (May, 1963), pp. 292-310.

54. Malkiel, Burton G. "The Capital Formation Problem in the United States." Journal of Finance. 34, No. 2 (May 1979), pp. 291-306.

55. Marsh, Paul. "The Choice Between Equity and Debt: An Empirical Study." Journal of Finance. 38, No. I, (March, 1983), pp. 121-144.

56. Martin, John D.,David F. Scott, Robert F. Vandell. "Equivalent Risk Classes: A Multidimensional Examination." Journal of Financial and Quantitative Analysis. (March 1979), pp. 101-118.

57. Martin, John D., William J. Petty and David F. Scott. "An Empirical Assessment of the Determinants of Corporate Financial Policy." Working Paper presented at Financial Management Association, (Fall 1979).

58. Masulis, Ronald W. "The Impact of Capital structure Change on Firm Value: Some Estimates." Journal of Finance. 38, No. 1, (March, 1983), pp. 107-126.

59. McCabe, George M. "The Empirical Relationship Between Investment and Financing: A New Look." Journal of Financial and Quantitative Analysis. (March 1979), pp. 119-135.

60. Miller, Merton H. "Debt and Taxes." Journal of Finance. (May 1977), pp. 261-275. 
61.

------. "The Corporate Income Tax and Corporate Financial Policies." In Stabilization Policies, Commission on Money and Credit. New Jersey: Prentice Hall, 1963.

62. Modigliani, Franco and Merton H. Miller. "The Cost of Capital, Corporation Finance, and the Theory of Investment." American Economic Review. (June 1958), pp. 261-297.

63. -- "The Cost of Capital, Corporation Finance, and the Theory of Investment: Reply. "American Economic Review. (September 1959), pp. 655-669.

64. --.--. "Corporate Income Taxes and the cost of Capital: A Correction." American Economic Review. (June 1963), pp. 433-443.

65. -----. "Some Estimates of the Cost of Capital to the Electric Utility Industry, 1954-57." American Economic Review. 56, No. 3 (June 1966), pp 335391 .

66. Modigliani, Franco. "Debt, Dividend Policy, Taxes, Inflation and Market Valuation." Journal of Finance. 37, No. 2 (May 1982), pp. 255-273.

67. Myers, S.C. "Determinants of Corporate Borrowing." Journal of Financial Economics. 5 (May 1977), pp. 147-175.

68. --.--. "Interactions of Corporate Financing and Investment Decisions-Implications for Capital Budgeting." Journal of Finance. 29, No. 1 (March $1974)$, pp. $1-25$.

69. --arorald A. Pogue. "A Programming Approach to Corporate Financial Management." Journal of Finance. 29, No. 2, (May 1974) pp. 579-599.

70. Rao, N. Krishna. "Equivalent-Risk Class Hypothesis: An Empirical Study." Journal of Financial and Quantitative Analysis. (June 1972), pp. 1763-1765.

71. Remmers, L. et al. "Industry and Size as Debt Ratio Determinants in Manufacturing Internationally." Financial Management. (Summer 1974), pp. 24-32.

72. Robichek, A.A. and S.C. Myers. "Problems in the Theory of Optimal Capital Structure. "Journal of Financial and Quantitative Analysis. 1 (1966), pp. 1-35.

73. Ross, S.A. "The Determination of Financial Structure: The Incentive Signaling Approach." Bell Journal of Economics. 8 (1977), pp. 23-40. 
74. - "Some Notes on Financial IncentiveSignalling Models, Activity Choice and Risk Preferences." Journal of Finance. 33, No. 3 (June 1978), pp. 777-792.

75. Rubinstein, M. "A Mean-Variance Synthesis of Corporate Financial Theory." Journal of Finance. 28, No. 1, (March 1973), pp. 167-181.

76. Schwartz, Eli and J. Richard Aronson. "Some Surrogate Evidence in Support of the Concept of Optimal Financial Structure." Journal of Finance. 22, No. 1, (March 1967), pp. 10-18.

77. Scott, David F. "Evidence on the Importance of Financial Structure." Financial Management. (Summer 1972), pp. 45-50.

78. Scott, David F. and John A. Martin. "Industry Influence on Financial Structure." Financial Management. (Spring 1975), pp. 67-73.

79. Scott, James H. "A Theory of Optimal Capital Structure." Bell Journal of Economics. (Spring 1976), pp. 33-54.

80. Smith, R. "Cost of Capital in the Oil Industry." (hectograph), Pittsburgh: Carnegie Institute of Technology, 1955.

81. Solomon, Ezra. "Leverage and the Cost of Capital." Journal of Finance. 18, No. 2 (May, 1963), pp 273-279.

82. Spies, R. "The Dynamics of Corporate Capital Budgeting." Journal of Finance. 29, No. 3, (June 1974), pp. 829-845.

83. Stiglitz, Joseph "A Reexamination of the ModiglianiMiller Theorem." American Economic Review. 59, No.5 (December 1969), pp. 784-793.

84. - "On the Irrelevance of Corporate Financial Policy." American Economic Review. 64, No.6, (December 1974), pp. 851-866.

85. - "Some Aspects of the Pure Theory of Corporate Finance: Bankruptcies and Take-overs." Bell Journal of Economics and Management Science. 3, No. 2 (Autumn 1972), pp. 458-482.

86. --.-.-. "Taxation, Corporate Financial Policy, and the Cost of Capital." Journal of Public Economics. 2, No. 1 (February 1973), pp. 1-34. 
87. Taub, Allen J. "Determinants of the Firm's Capital Structure." The Review of Economics and Statistics. (1975), pp. 410-416.

88. Taggart, Robert A. Jr. "A Model of Corporate Financing Decisions." Journal of Finance. 82, No. 5, (December 1977), pp. 1467-1484.

89. - - Taxes and Corporate Capital Structure in an Incomplete Market." Journal of Finance. 35, No. 3, (June 1980), pp. 645-659.

90. Turnbull, Stuart M. "Debt Capacity." Journal of Finance. 34, No. 4 (September 1979), pp. 931-940.

91. Warner, J.B. "Bankruptcy Costs: Some Evidence." Journal of Finance. 32, No. 2, (May 1977), pp. 337-347.

92. Webster's New World Dictionary. 2nd College ed. David B. Guralink, editor. Cleveland: William Collins and World Publishing Company, 1974.

93. Weston, J. Fred. "A Test of Cost of Capital Propositions." Southern Economic Journal. (October 1963), pp. 105-112.

94. Williamson, Scott H. "The Moral Hazard Theory of Corporate Financial Structure: Empirical Tests." (Unpub. Ph.D Thesis, Mass. Institute of Technolugy, 1981.)

95. Wippern, Ronald F. "A Note on the Equivalent Risk Class Assumptions." Engineering Economist. (Spring 1966), pp. 13-22.

96. Zumwalt, J. Kenton and Tai S. Shin. "Industry Classification, Business Risk, and Optimal Financial Structure." University of Illinois at Urbana-Champaign Working Paper, presented at Financial Management Association, (Fall 1979). 


\section{Appendix A}

List of Companies Included in Study

Company number, industry description, and industry number are from the Compustat system of organization of all companies and industries.

\begin{tabular}{|c|c|c|c|}
\hline Company & $\begin{array}{l}\text { Company } \\
\text { Number }\end{array}$ & Industry & $\begin{array}{l}\text { Industry } \\
\text { Number }\end{array}$ \\
\hline $\mathrm{ACF}$ Industries & 800 & Railroad Equip & 3740 \\
\hline Abbott Labs & 2824 & Drugs & 2830 \\
\hline Alcan Aluminium & 13716 & $\begin{array}{l}\text { Prim.Smelt-Refin } \\
\text { Nonfer Metals }\end{array}$ & 3330 \\
\hline Allied Chemicals & 19087 & Chemicals & 2800 \\
\hline Allied Stores & 19519 & Retail-Dept.Stores & 5311 \\
\hline $\begin{array}{l}\text { Alum. Co. of } \\
\text { America }\end{array}$ & 22249 & $\begin{array}{l}\text { Prim Smelt-Refin } \\
\text { Nonfer Metals }\end{array}$ & 3330 \\
\hline Amac Inc. & 23127 & Metal Mining & 1000 \\
\hline American Brands & 24703 & Cigarettes & 2111 \\
\hline $\begin{array}{l}\text { American Broad- } \\
\text { casting }\end{array}$ & 24735 & $\begin{array}{l}\text { Radio-TV } \\
\text { Broadcasting }\end{array}$ & 4830 \\
\hline American Can Corp. & 24843 & Glass Containers & 3221 \\
\hline American Cyanimid & 25321 & $\begin{array}{l}\text { Chemicals \& } \\
\text { Allied Products }\end{array}$ & 2800 \\
\hline American Standard & 29717 & $\begin{array}{l}\text { Heating Eqpt \& } \\
\text { Plumbing Fixtures }\end{array}$ & 3430 \\
\hline American Stores Co. & 30095 & Retail-Groc Stores & 5411 \\
\hline
\end{tabular}




\begin{tabular}{|c|c|c|c|}
\hline Company & $\begin{array}{l}\text { Company } \\
\text { Number }\end{array}$ & Industry & $\begin{array}{l}\text { Industry } \\
\text { Number }\end{array}$ \\
\hline American Tel \& Tel & 30177 & $\begin{array}{r}\text { Telephone } \\
\text { Communications }\end{array}$ & 4811 \\
\hline AMP Inc & 31897 & $\begin{array}{l}\text { Electronic } \\
\text { Components \& Acces }\end{array}$ & 3670 \\
\hline Amstar Corp. & 32172 & $\begin{array}{l}\text { Cane Sugar } \\
\text { Refining }\end{array}$ & 2062 \\
\hline $\begin{array}{l}\text { Assoc.Dry Goods } \\
\text { Corp. }\end{array}$ & 45573 & Retail-Dept. Stores & 5311 \\
\hline $\begin{array}{l}\text { Atlantic Richfield } \\
\text { Co. }\end{array}$ & 48825 & Petroleum Refining & 2911 \\
\hline Avon Products & 54303 & $\begin{array}{l}\text { Perfumes Cosmetics } \\
\text { Toiletries Prod. }\end{array}$ & 2844 \\
\hline Beckman Indus. & 75815 & $\begin{array}{l}\text { Engineering Lab \& } \\
\text { Research Equip. }\end{array}$ & 3811 \\
\hline Bendix Corp. & 81689 & $\begin{array}{l}\text { Motor Vehicle Parts } \\
\text { \& Acces. }\end{array}$ & 3714 \\
\hline Black \& Decker & 91797 & $\begin{array}{l}\text { Special Industry } \\
\text { Machinery }\end{array}$ & 3550 \\
\hline Boeing & 97023 & Aircraft & 3721 \\
\hline Borden, Inc. & 99599 & Dairy Products & 2020 \\
\hline Borg-Warner & 99725 & Motor Vehicle Parts & 3714 \\
\hline Braun Group, Inc. & 115657 & $\begin{array}{l}\text { Footwear Except } \\
\text { Rubber }\end{array}$ & 3140 \\
\hline Burlington Ind. & 121691 & Textile Mill prod. & 2200 \\
\hline $\mathrm{CBS}$, Inc. & 124845 & $\begin{array}{l}\text { Radio TV } \\
\text { Broadcasting }\end{array}$ & 4830 \\
\hline CPC Intl & 126149 & Wet Corn Milling & 2046 \\
\hline $\begin{array}{l}\text { Capital Cities } \\
\text { Communications }\end{array}$ & 129861 & $\begin{array}{l}\text { Newspapers-Print } \\
\& \text { Publishing }\end{array}$ & 2711 \\
\hline Carter Hawley Hale & 146227 & Retail-Dept. Stores & 5311 \\
\hline Caterpillar Tracto & r139123 & $\begin{array}{l}\text { Construction } \\
\text { Mach \& Equip }\end{array}$ & 3531 \\
\hline
\end{tabular}




\begin{tabular}{|c|c|c|c|}
\hline Company & $\begin{array}{l}\text { Company } \\
\text { Number }\end{array}$ & Industry & $\begin{array}{l}\text { Industry } \\
\text { Number }\end{array}$ \\
\hline Celanese Corp. & 150843 & $\begin{array}{l}\text { Chemicals \& Allied } \\
\text { Prods }\end{array}$ & 2800 \\
\hline Cities Service & 173036 & Petroleum Refining & 2911 \\
\hline $\begin{array}{l}\text { Colgate-Palmolive } \\
\text { Co. }\end{array}$ & 194162 & $\begin{array}{l}\text { Soap \& Other } \\
\text { Detergents }\end{array}$ & 2841 \\
\hline $\begin{array}{l}\text { Combustion Engi- } \\
\text { neering }\end{array}$ & 200273 & Engines \& Turbines & 3510 \\
\hline Cone Mills Corp. & 206813 & Textile Mill prod. & 2200 \\
\hline Conoco, Inc. & 208251 & Petroleum Refining & 2911 \\
\hline Continental Group & 211452 & Glass Containers & 3221 \\
\hline Copper Inds., Inc. & 216669 & $\begin{array}{l}\text { General Indus. } \\
\text { Mach. \& Eqpt. }\end{array}$ & 3560 \\
\hline Corning Glass Works & s219217 & Flat Glass & 3210 \\
\hline Crown Cork \& Seal & 228255 & Glass Containers & 3221 \\
\hline Crown Zellerbach & 228669 & $\begin{array}{l}\text { Paper \& Allied } \\
\text { Prod. }\end{array}$ & 2600 \\
\hline J. Deere \& Co. & 244199 & $\begin{array}{l}\text { Farm \& Garden } \\
\text { Mach. \& Eqpt. }\end{array}$ & 3520 \\
\hline Diamond Intl. & 252669 & $\begin{array}{l}\text { Paperboard } \\
\text { Containers }\end{array}$ & 2650 \\
\hline Dow Chemical & 260543 & $\begin{array}{l}\text { Chemical \& Allied } \\
\text { Prods. }\end{array}$ & 2800 \\
\hline Dresser Indus. & 261597 & $\begin{array}{l}\text { Oilfield Mach. } \\
\text { \& Eqpt. }\end{array}$ & 3533 \\
\hline Eastern Gas \& Fuel & 276461 & $\begin{array}{l}\text { Bituminous Coal } \\
\text { \& Lignite MN }\end{array}$ & 1211 \\
\hline Esmark, Inc. & 296470 & Meat Products & 2010 \\
\hline Exxon & 302290 & Petroleum Refining & 2911 \\
\hline Faberge, Ind. & 302808 & $\begin{array}{l}\text { Perfumes Cosmetics } \\
\text { Toiltries Prod. }\end{array}$ & 2844 \\
\hline $\begin{array}{l}\text { Federated Dept. } \\
\text { Stores }\end{array}$ & 314099 & Retail Dept. Stores & 5311 \\
\hline
\end{tabular}




\begin{tabular}{|c|c|c|c|}
\hline Company & $\begin{array}{l}\text { Company } \\
\text { Number }\end{array}$ & Industry & $\begin{array}{l}\text { Industry } \\
\text { Number }\end{array}$ \\
\hline Flinthote Co. & 339711 & $\begin{array}{l}\text { Paving \& Roofing } \\
\text { Materials }\end{array}$ & 2950 \\
\hline Ford Motor Co. & 345370 & $\begin{array}{l}\text { Motor Vehicles } \\
\text { \& Car Bodies }\end{array}$ & 3711 \\
\hline GK Technologies & 361765 & $\begin{array}{l}\text { Rolling \& Drawing } \\
\text { Nonfer Metals }\end{array}$ & 3350 \\
\hline General Electric & 369604 & $\begin{array}{l}\text { Elec. \& Elec. Mach. } \\
\text { Eqpt. \& Supply }\end{array}$ & 3600 \\
\hline General Foods & 369856 & $\begin{array}{l}\text { Food \& Related } \\
\text { Products }\end{array}$ & 2000 \\
\hline General Motors & 370442 & $\begin{array}{l}\text { Motor Vehicles } \\
\text { \& Car Bodies }\end{array}$ & 3711 \\
\hline General Portland & 370514 & Cement Hydraulic & 3241 \\
\hline Getty oil Co. & 374280 & $\begin{array}{l}\text { Crude Petroleum } \\
\& \text { Natural Gas }\end{array}$ & 1311 \\
\hline B F Goodrich & 382388 & $\begin{array}{l}\text { Rubber \& Plastic } \\
\text { Products }\end{array}$ & 3000 \\
\hline $\begin{array}{l}\text { Goodyear Tire } \\
\& \text { Rubber }\end{array}$ & 382550 & $\begin{array}{l}\text { Rubber \& Plastic } \\
\text { Products }\end{array}$ & 3000 \\
\hline Gulf oil co. & 402460 & Petroleum Refining & 2911 \\
\hline Halliburton Co. & 406216 & $\begin{array}{l}\text { Construction - Not } \\
\text { Bldg. Constr. }\end{array}$ & 1600 \\
\hline $\begin{array}{l}\text { Harcourt Brace } \\
\text { Jovanovich }\end{array}$ & 411631 & $\begin{array}{l}\text { Books-Publishing } \\
\text { \& Printing }\end{array}$ & 2731 \\
\hline $\begin{array}{l}\text { Hart Schaffner } \\
\& \text { Marx }\end{array}$ & 416162 & $\begin{array}{l}\text { Apparel \& Other } \\
\text { Finished Prods. }\end{array}$ & 2300 \\
\hline Holiday Inn, Inc. & 435081 & Hotels-Motels & 7011 \\
\hline Honeywell, Inc. & 438506 & $\begin{array}{l}\text { Electronic Comput- } \\
\text { ing Eqpt. }\end{array}$ & 3573 \\
\hline Ideal Basic Indus. & 451542 & Cement Hydraulic & 3241 \\
\hline Inland Steel & 457470 & $\begin{array}{l}\text { Blast Furnaces } \\
\text { \& Steel Works }\end{array}$ & 3310 \\
\hline Interco, Inc. & 458506 & $\begin{array}{l}\text { Footwear Except } \\
\text { Rubbr }\end{array}$ & 3140 \\
\hline
\end{tabular}




\begin{tabular}{|c|c|c|c|}
\hline Company & $\begin{array}{l}\text { Company } \\
\text { Number }\end{array}$ & Industry & $\begin{array}{l}\text { Industry } \\
\text { Number }\end{array}$ \\
\hline Interlake, Inc. & .458702 & $\begin{array}{l}\text { Blast Furnaces } \\
\text { \& Steel Works }\end{array}$ & 3310 \\
\hline IB M & 459200 & $\begin{array}{l}\text { Office Computing } \\
\text { \& Acctg. Mach. }\end{array}$ & 3570 \\
\hline $\begin{array}{l}\text { Intl. Harvester } \\
\text { Co. }\end{array}$ & 459578 & Truck \& Bus. Bodies & 3713 \\
\hline Intl. Minerals \& & 459884 & $\begin{array}{l}\text { Agricultural } \\
\text { Chemicals }\end{array}$ & 2870 \\
\hline $\begin{array}{l}\text { Intl. Telephone } \\
\& \text { Tele. }\end{array}$ & 460470 & Congolomerate & 9997 \\
\hline Joy Mfg. Co. & 481196 & Special Indus. Mach. & .3550 \\
\hline Kaiser Alum \& Chem & 483008 & $\begin{array}{l}\text { Prim Smelt-Refin. } \\
\text { Nonfer Metals }\end{array}$ & 3380 \\
\hline $\begin{array}{l}\text { Kimberly-Clark } \\
\text { Corp. }\end{array}$ & 494368 & $\begin{array}{l}\text { Paper \& Allied } \\
\text { Prods. }\end{array}$ & 2600 \\
\hline Koehning Co. & 500170 & $\begin{array}{l}\text { Construction } \\
\text { Mach. \& Eqpt. }\end{array}$ & 3531 \\
\hline Kraft, Inc. & 500755 & Dairy Prods. & 2020 \\
\hline Kroger Co. & 501044 & Retail-Grocery & 5411 \\
\hline Lone Star Inds. & 542290 & Cement Hydraulics & 3241 \\
\hline Macy $(R \quad H) \&$ Co. & 556139 & Retail-Dept.Stores & 5311 \\
\hline $\begin{array}{l}\text { Marshall Fields, } \\
\text { Inc. }\end{array}$ & 572342 & Retail-Dept.Stores & 5311 \\
\hline May Dept. Stores & 577778 & Retail-Dept.stores & 5311 \\
\hline Mayer (Oscar) \& Co. & 577896 & Meat Products & 2010 \\
\hline MC Dermott \& Co. & 580022 & $\begin{array}{l}\text { Construction-Not } \\
\text { Bldg. Const. }\end{array}$ & 1600 \\
\hline MC Graw-Edison Co. & 580628 & $\begin{array}{l}\text { Elec. Transmission } \\
\text { \& Distr. Eqpt. }\end{array}$ & 3610 \\
\hline Meredith Corp. & 589433 & $\begin{array}{l}\text { Periodicals- } \\
\text { Publish \& Print }\end{array}$ & 2721 \\
\hline
\end{tabular}




\begin{tabular}{|c|c|c|c|}
\hline Company & $\begin{array}{l}\text { Company } \\
\text { Number }\end{array}$ & Industry & $\begin{array}{l}\text { Industry } \\
\text { Number }\end{array}$ \\
\hline Metromedia, Inc. & 591690 & $\begin{array}{l}\text { Radio-TV } \\
\text { Broadcasters }\end{array}$ & 4830 \\
\hline $\begin{array}{l}\text { Minnesota Mining } \\
\& \text { Mfg. Co. }\end{array}$ & 604059 & $\begin{array}{l}\text { Photographic } \\
\text { Eqpt. \& Suppl. }\end{array}$ & 3861 \\
\hline Mobil Corp. & 607059 & Petroleum Refining & 2911 \\
\hline Mohasco Corp. & 608030 & Household Furniture & 2510 \\
\hline Monsanto Co. & 611662 & $\begin{array}{l}\text { Chemicals \& Allied } \\
\text { Prods. }\end{array}$ & 2800 \\
\hline Motorola, Inc. & 620076 & $\begin{array}{l}\text { Radio-TV } \\
\text { Trasmitting Eqpt. }\end{array}$ & 3662 \\
\hline $\begin{array}{l}\text { National Dist. } \\
\text { \& Chem. }\end{array}$ & 635655 & $\begin{array}{l}\text { Distilled Rectif. } \\
\text { Blend Beveg. }\end{array}$ & 2085 \\
\hline National Gypsum Co. & 0.636316 & $\begin{array}{l}\text { Paving \& Roofing } \\
\text { Materials }\end{array}$ & 2950 \\
\hline $\begin{array}{l}\text { National Steel } \\
\text { Corp. }\end{array}$ & $\begin{array}{l}637844 \\
637844\end{array}$ & $\begin{array}{l}\text { Blast Furnces \& } \\
\text { Steel Works }\end{array}$ & 3310 \\
\hline $\begin{array}{l}\text { North American } \\
\text { Coal Co. }\end{array}$ & 656780 & $\begin{array}{l}\text { Bituminous Coal } \\
\text { \& Lignite MN }\end{array}$ & 1211 \\
\hline Outboard Marine Co. & 0.690020 & Engines \& Turbines & 3510 \\
\hline Owens-Corning & 690734 & Abrasive Asbestos \& & 3290 \\
\hline Fiberglas Corp. & & Misc. Min. & \\
\hline Owens Illinois & 690768 & Glass Containers & 3221 \\
\hline PPG Industries & 693506 & $\begin{array}{l}\text { Indl. Inorganic } \\
\text { Chem. }\end{array}$ & 2810 \\
\hline Pfizer, Inc. & 717081 & Drugs & 2830 \\
\hline Phillip Morris, Inc & c. 718167 & Cigarettes & 2111 \\
\hline Phillips Petroleum & m 718507 & Petroleum Refining & 2911 \\
\hline Pitney-Bowes, Inc. & 724479 & $\begin{array}{l}\text { Office Computing } \\
\text { \& Acctg. Mach. }\end{array}$ & 3570 \\
\hline Pittston Co. & 725701 & $\begin{array}{l}\text { Bituminous Coal } \\
\text { Lignite Min. }\end{array}$ & 1211 \\
\hline
\end{tabular}




\begin{tabular}{|c|c|c|c|}
\hline Company & $\begin{array}{l}\text { Company } \\
\text { Number }\end{array}$ & Industry & $\begin{array}{l}\text { Industry } \\
\text { Number }\end{array}$ \\
\hline Potlatch Corp. & 737628 & $\begin{array}{l}\text { Paper \& Allied } \\
\text { Prod. }\end{array}$ & 2600 \\
\hline Proctor \& Gamble & 742718 & $\begin{array}{l}\text { Soap \& Other } \\
\text { Detergents }\end{array}$ & 2841 \\
\hline Quaker Oats & 747402 & $\begin{array}{l}\text { Foods \& Kindred } \\
\text { Prod. }\end{array}$ & 2000 \\
\hline RCA Corp. & 749285 & $\begin{array}{l}\text { Radio-TV } \\
\text { Receiving Sets }\end{array}$ & 3651 \\
\hline Ray theon Co. & 755111 & $\begin{array}{l}\text { Radio-TV } \\
\text { Transm. Eqpt. }\end{array}$ & 3662 \\
\hline Reliance Electric & 759457 & $\begin{array}{l}\text { Electric Transm. } \\
\text { Eqpt. }\end{array}$ & 3610 \\
\hline $\begin{array}{l}\text { Republic Steel } \\
\text { Corp. }\end{array}$ & 760779 & $\begin{array}{l}\text { Blast Furnaces \& } \\
\text { Steel Works }\end{array}$ & 3320 \\
\hline Rexnord, Inc. & 761688 & $\begin{array}{l}\text { Construction Mach. } \\
\text { \& Eqpt. }\end{array}$ & 3531 \\
\hline Reynolds (R J) & 762753 & Cigarettes & 2111 \\
\hline Reynolds Metal & 761763 & $\begin{array}{l}\text { Prim Smelt-Refin. } \\
\text { Nonfer Metals }\end{array}$ & 3330 \\
\hline $\begin{array}{l}\text { Royal Dutch } \\
\text { Petroleum }\end{array}$ & 780257 & Petroleum Refning & 2911 \\
\hline Safeway Stores & 786514 & $\begin{array}{l}\text { Retail-Grocery } \\
\text { Stores }\end{array}$ & 5411 \\
\hline $\begin{array}{l}\text { St. Joe Mineral } \\
\text { Corp. }\end{array}$ & 790155 & $\begin{array}{l}\text { Bituminous Coal } \\
\& \text { Lignite MN }\end{array}$ & 1211 \\
\hline St. Regis Paper C & 0.793453 & Paper \& Allied Prod. & .2600 \\
\hline Scott Paper Co. & 809877 & Paper \& Allied Prod. & . 2600 \\
\hline Seagram Co., Lta. & 811850 & $\begin{array}{l}\text { Beverages } \\
\text { Distillers }\end{array}$ & 2085 \\
\hline Sears Roebuck \& C & 0.812387 & Retail-Dept. Stores & 5311 \\
\hline Shell oil Co. & 822635 & Petroleum Refining & 2911 \\
\hline Standard Brands & 853139 & Food \& Kindred Prod. & - 2000 \\
\hline
\end{tabular}




\begin{tabular}{|c|c|c|c|}
\hline Company & $\begin{array}{l}\text { Company } \\
\text { Number }\end{array}$ & Industry & $\begin{array}{l}\text { Indust } \\
\text { Numbe }\end{array}$ \\
\hline $\begin{array}{l}\text { Standard Oil Co. } \\
\text { (CAL) }\end{array}$ & 853683 & Petroleum Refining & 2911 \\
\hline Standard Oil Co. & 853700 & Petroleum Refining & 2911 \\
\hline Stauffer Chem Co. & 857721 & INDL Inorganic Chem & 2810 \\
\hline Sterling Drug Inc. & 859264 & Drugs & 2830 \\
\hline Sun Co. & 866762 & Petroleum Refining & 2911 \\
\hline Superior Oil Co. & 868273 & $\begin{array}{l}\text { Crude Petroleum } \\
\& \text { Natural Gas }\end{array}$ & 1311 \\
\hline TRW Inc. & 872649 & $\begin{array}{l}\text { Motor Vehicles } \\
\text { Parts \& Acces }\end{array}$ & 3714 \\
\hline Taft Broadcasting & 873635 & $\begin{array}{l}\text { Radio-TV } \\
\text { Broadcasting }\end{array}$ & 4830 \\
\hline Tenneco Inc & 880370 & Conglomerate & 9997 \\
\hline Texaco Inc & 881694 & Petroleum Refining & 2911 \\
\hline Texas Instruments & 882508 & $\begin{array}{l}\text { Electromic Compnts } \\
\text { \& Acces }\end{array}$ & 3670 \\
\hline Textron Inc & 883203 & Conglomerate & 9997 \\
\hline Time Inc & 887224 & $\begin{array}{l}\text { Periodicals Pub } \\
\text { \& Print }\end{array}$ & 2721 \\
\hline Times Mirror & 887360 & $\begin{array}{l}\text { Newspaper Pub } \\
\& \text { Print }\end{array}$ & 2711 \\
\hline UMC Industries & 902878 & $\begin{array}{l}\text { Refrig \& Service } \\
\text { Ind Machine }\end{array}$ & 3580 \\
\hline Unilever NV & 904784 & $\begin{array}{l}\text { Soap \& Other } \\
\text { Detergents }\end{array}$ & 2841 \\
\hline Union Carbide & 905581 & Chem \& Allied Prod & 2800 \\
\hline Union Oil of Calif & 907770 & Petroleum Refining & 3922 \\
\hline US Steel Corp & 912656 & $\begin{array}{l}\text { Blast Furnaces \& } \\
\text { Steel Works }\end{array}$ & 3310 \\
\hline Walter (Jim) Corp & 933169 & $\begin{array}{l}\text { Paving \& Roofing } \\
\text { Materials }\end{array}$ & 295 \\
\hline
\end{tabular}




$\begin{array}{lllc}\text { Company } & \begin{array}{l}\text { Company } \\ \text { Number }\end{array} & \text { Industry } & \begin{array}{c}\text { Industry } \\ \text { Number }\end{array} \\ \text { Warner \& Swasey } & 934408 & \begin{array}{l}\text { Metal Working } \\ \text { Mach \& Eqpt }\end{array} & 3540 \\ \text { Westinghouse Elec } & 960402 & \begin{array}{l}\text { Elec \& Electr Mach } \\ \text { Eqpt \& Supp }\end{array} & 3600 \\ \text { Whirlpool Corp } & 963320 & \begin{array}{l}\text { Household } \\ \text { Appliances } \\ \text { Retail-Grocery } \\ \text { Stores }\end{array} & 3630 \\ \text { Winn Dixie Stores } & 974280 & 5411 \\ \text { Woolworth (FW) } & 980881 & \begin{array}{l}\text { Retail-Variety } \\ \text { Stores }\end{array} & 5331\end{array}$


Appendix B

Raw Results of Correlations

The following data are the raw empirical resulcs. The numbers represent the correlation coefficients between changes in debt and changes in risk. For each company, two sets of correlations were done, with the first six correlations representing the correlations of the cnange in long term debt with the change in risk and the second line of six correlations representing the correlations ot the change in total debt with the change in risk.

The six columns, numbered one through six, represent the different lagged and lead relationships between changes in debt and changes in risk. Column one is change in debt leading change in risk by three periods. Column two is the change in debt leading the change in risk by two periods. Column three is the change in debt leading the change in risk by one period. Column four is the change in debt lagging the change in risk by one period. Column Five is the change in debt lagging the change in risk by two periods. Column six is the change in debt lagging the change in risk by three periods.

The last column, Results, is a summation of when significant correlations occurred. A significant correlation was when the correlation betwen change in debt and change in risk was greater than .39 or less than-.39. An asterisk (*) denotes a significant relationship.

The company is listed using the compstat numbering system and cross-reference is available in Appendix A.

\begin{tabular}{|c|c|c|c|c|c|c|c|}
\hline$\frac{\text { Company }}{800}$ & $\begin{array}{r}\frac{1}{91} \\
-.191 \\
-.009\end{array}$ & $\begin{array}{r}\frac{2}{-.098} \\
.043\end{array}$ & $\begin{array}{r}\frac{3}{2} \\
-.024 \\
.137\end{array}$ & $\begin{array}{l}\frac{4}{87} \\
-.187 \\
-.459 *\end{array}$ & $\begin{array}{r}\frac{5}{161} \\
.150\end{array}$ & $\begin{array}{r}\frac{6}{6} \\
-.275 \\
-.097\end{array}$ & $\underline{\text { Results }}$ \\
\hline 2824 & $\begin{array}{r}-.150 \\
.101\end{array}$ & $\begin{array}{r}.404^{*} \\
-.086\end{array}$ & $\begin{array}{l}-.502 * \\
-.122\end{array}$ & $\begin{array}{r}.060 \\
-.067\end{array}$ & $\begin{array}{l}.169 \\
.036\end{array}$ & $\begin{array}{r}-.195 \\
.154\end{array}$ & 2,3 \\
\hline 13716 & $\begin{array}{c}.069 \\
-.420 *\end{array}$ & $\begin{array}{c}-.502 * \\
.085\end{array}$ & $\begin{array}{l}.154 \\
.438 *\end{array}$ & $\begin{array}{r}.158 \\
.104\end{array}$ & $\begin{array}{l}-.107 \\
-.018\end{array}$ & $\begin{array}{l}-.101 \\
-.035\end{array}$ & $\begin{array}{l}2 \\
1,3\end{array}$ \\
\hline
\end{tabular}




\begin{tabular}{|c|c|c|c|c|c|c|c|}
\hline$\frac{\text { Company }}{19087}$ & $\begin{array}{c}\frac{1}{18} \\
-.118 \\
-.273\end{array}$ & $\begin{array}{r}-.0 \frac{2}{11} \\
.123\end{array}$ & $\begin{array}{l}.2 \frac{3}{17} \\
.162\end{array}$ & $\begin{array}{l}-.407 \\
-.217\end{array}$ & $\begin{array}{l}.5 \frac{5}{6} 4 * \\
.136\end{array}$ & $\begin{array}{l}. \frac{6}{32} \\
.400 *\end{array}$ & $\frac{\text { Results }}{4,5}$ \\
\hline 19519 & $\begin{array}{l}.430 * \\
.375\end{array}$ & $\begin{array}{l}-.295 \\
-.426 *\end{array}$ & $\begin{array}{c}.305 \\
-.394 *\end{array}$ & $\begin{array}{l}-.359 \\
-.240\end{array}$ & $\begin{array}{l}.145 \\
.030\end{array}$ & $\begin{array}{r}-.210 \\
.194\end{array}$ & $\begin{array}{l}1 \\
2,3\end{array}$ \\
\hline 22249 & $\begin{array}{r}-.377 \\
.001\end{array}$ & $\begin{array}{l}.205 \\
.193\end{array}$ & $\begin{array}{r}.230 \\
-.087\end{array}$ & $\begin{array}{l}-.249 \\
-.343\end{array}$ & $\begin{array}{l}-.313 \\
-.145\end{array}$ & $\begin{array}{l}.195 \\
.277\end{array}$ & \\
\hline 23127 & $\begin{array}{r}.133 \\
-.027\end{array}$ & $\begin{array}{r}-.173 \\
.233\end{array}$ & $\begin{array}{l}-.059 \\
-.105\end{array}$ & $\begin{array}{l}-.176 \\
-.482 *\end{array}$ & $\begin{array}{l}.244 \\
.440 *\end{array}$ & $\begin{array}{r}.129 \\
-.090\end{array}$ & 4,5 \\
\hline 24703 & $\begin{array}{r}.184 \\
-.071\end{array}$ & $\begin{array}{r}-.068 \\
.110\end{array}$ & $\begin{array}{r}-.084 \\
.034\end{array}$ & $\begin{array}{r}.066 \\
-.0147\end{array}$ & $\begin{array}{l}-.127 \\
-.065\end{array}$ & $\begin{array}{l}-.142 \\
-.124\end{array}$ & \\
\hline 24735 & $\begin{array}{r}.157 \\
-.101\end{array}$ & $\begin{array}{r}-.084 \\
.125\end{array}$ & $\begin{array}{l}-.510^{*} \\
-.672^{*}\end{array}$ & $\begin{array}{l}.257 \\
.216\end{array}$ & $\begin{array}{l}-.213 \\
-.082\end{array}$ & $\begin{array}{l}.258 \\
.178\end{array}$ & $\begin{array}{l}3 \\
3\end{array}$ \\
\hline 24843 & $\begin{array}{r}-.005 \\
.316\end{array}$ & $\begin{array}{r}.035 \\
-.085\end{array}$ & $\begin{array}{r}-.129 \\
.176\end{array}$ & $\begin{array}{r}.348 \\
-.135\end{array}$ & $\begin{array}{r}-.110 \\
.098\end{array}$ & $\begin{array}{l}-.341 \\
-.246\end{array}$ & \\
\hline 25321 & $\begin{array}{r}.054 \\
-.052\end{array}$ & $\begin{array}{l}-.174 \\
-.001\end{array}$ & $\begin{array}{r}-.163 \\
.116\end{array}$ & $\begin{array}{r}.107 \\
-.138\end{array}$ & $\begin{array}{r}.037 \\
-.052\end{array}$ & $\begin{array}{l}.449 * \\
.442 *\end{array}$ & $\begin{array}{l}6 \\
6\end{array}$ \\
\hline 29717 & $\begin{array}{l}.404 * \\
.364\end{array}$ & $\begin{array}{l}.103 \\
.193\end{array}$ & $\begin{array}{l}-.098 \\
-.108\end{array}$ & $\begin{array}{l}-.316 \\
-.226\end{array}$ & $\begin{array}{l}.170 \\
.095\end{array}$ & $\begin{array}{l}-.050 \\
-.112\end{array}$ & 1 \\
\hline 30095 & $\begin{array}{c}-.633 * \\
.193\end{array}$ & $\begin{array}{l}.044 \\
.865 *\end{array}$ & $\begin{array}{r}.032 \\
-.147\end{array}$ & $\begin{array}{l}-.006 \\
-.412 *\end{array}$ & $\begin{array}{l}-.192 \\
-.122\end{array}$ & $\begin{array}{l}.184 \\
.307\end{array}$ & $\begin{array}{l}1 \\
2,4\end{array}$ \\
\hline 30177 & $\begin{array}{r}.056 \\
-.161\end{array}$ & $\begin{array}{l}.115 \\
.041\end{array}$ & $\begin{array}{l}-.136 \\
-.057\end{array}$ & $\begin{array}{l}-.267 \\
-.086\end{array}$ & $\begin{array}{l}.147 \\
.269\end{array}$ & $\begin{array}{l}.312 \\
.063\end{array}$ & \\
\hline 31897 & $\begin{array}{c}.266 \\
-.713 *\end{array}$ & $\begin{array}{c}-.478 * \\
.112\end{array}$ & $\begin{array}{r}-.376 \\
.576 *\end{array}$ & $\begin{array}{r}.329 \\
-.237\end{array}$ & $\begin{array}{r}.091 \\
-.303\end{array}$ & $\begin{array}{l}.040 \\
.098\end{array}$ & $\begin{array}{l}2 \\
1,3\end{array}$ \\
\hline 32172 & $\begin{array}{l}.354 \\
.513 *\end{array}$ & $\begin{array}{l}-.322 \\
-.495 *\end{array}$ & $\begin{array}{r}-.160 \\
.077\end{array}$ & $\begin{array}{r}.344 \\
-.114\end{array}$ & $\begin{array}{l}.181 \\
.187\end{array}$ & $\begin{array}{c}-.398 * \\
.135\end{array}$ & $\begin{array}{l}6 \\
1,2\end{array}$ \\
\hline 45573 & $\begin{array}{l}-.110 \\
-.075\end{array}$ & $\begin{array}{r}.377 \\
-.114\end{array}$ & $\begin{array}{l}-.665^{*} \\
-.049\end{array}$ & $\begin{array}{l}-.008 \\
-.059\end{array}$ & $\begin{array}{l}.312 \\
.015\end{array}$ & $\begin{array}{r}.194 \\
-.200\end{array}$ & 3 \\
\hline 48825 & $\begin{array}{l}-.452 * \\
-.569 *\end{array}$ & $\begin{array}{l}.359 \\
.344\end{array}$ & $\begin{array}{l}-.313 \\
-.163\end{array}$ & $\begin{array}{l}.328 \\
.098\end{array}$ & $\begin{array}{l}-.309 \\
-.225\end{array}$ & $\begin{array}{l}-.108 \\
-.196\end{array}$ & $\begin{array}{l}1 \\
1\end{array}$ \\
\hline 54303 & $\begin{array}{l}.023 \\
.291\end{array}$ & $\begin{array}{r}.140 \\
-.066\end{array}$ & $\begin{array}{l}-.279 \\
-.093\end{array}$ & $\begin{array}{r}-.144 \\
.043\end{array}$ & $\begin{array}{r}.166 \\
-.018\end{array}$ & $\begin{array}{l}-.270 \\
-.192\end{array}$ & \\
\hline 75815 & $\begin{array}{r}.175 \\
-.111\end{array}$ & $\begin{array}{r}-.260 \\
.051\end{array}$ & $\begin{array}{l}-.195 \\
-.192\end{array}$ & $\begin{array}{c}.397 * \\
-.234\end{array}$ & $\begin{array}{l}-.225 \\
-.108\end{array}$ & $\begin{array}{r}-.067 \\
.197\end{array}$ & 4 \\
\hline 81689 & $\begin{array}{c}-.527 * \\
.079\end{array}$ & $\begin{array}{l}.320 \\
.250\end{array}$ & $\begin{array}{l}.049 \\
.217\end{array}$ & $\begin{array}{r}.165 \\
-.213\end{array}$ & $\begin{array}{r}.034 \\
-.0206\end{array}$ & $\begin{array}{l}-.220 \\
-.336\end{array}$ & 1 \\
\hline
\end{tabular}




\begin{tabular}{|c|c|c|c|c|c|c|c|}
\hline$\frac{\text { Company }}{91797}$ & $\begin{array}{l}-. \frac{1}{28} \\
-.249\end{array}$ & $\begin{array}{l}.2 \\
.059 \\
.391 *\end{array}$ & $\begin{array}{l}.0 \frac{3}{02} \\
.012\end{array}$ & $\begin{array}{r}.14 \\
-.215\end{array}$ & $\begin{aligned} & \frac{5}{7} \\
&-.075 \\
&-.047\end{aligned}$ & $\begin{array}{r}-.0 \frac{6}{53} \\
.233\end{array}$ & $\frac{\text { Results }}{2}$ \\
\hline 97023 & $\begin{array}{l}.278 \\
.094\end{array}$ & $\begin{array}{l}.293 \\
.028\end{array}$ & $\begin{array}{l}-.432 * \\
-.274\end{array}$ & $\begin{array}{l}.279 \\
.129\end{array}$ & $\begin{array}{l}.182 \\
.105\end{array}$ & $\begin{array}{l}-.563^{*} \\
-.443^{*}\end{array}$ & $\begin{array}{l}3,6 \\
6\end{array}$ \\
\hline 99599 & $\begin{array}{l}-.479 * \\
-.430 *\end{array}$ & $\begin{array}{l}-.282 \\
-.187\end{array}$ & $\begin{array}{l}.595 * \\
.433 *\end{array}$ & $\begin{array}{r}.046 \\
-.321\end{array}$ & $\begin{array}{r}-.158 \\
.220\end{array}$ & $\begin{array}{l}.105 \\
.153\end{array}$ & $\begin{array}{l}1,3 \\
1,3\end{array}$ \\
\hline 99725 & $\begin{array}{c}.413 * \\
-.300\end{array}$ & $\begin{array}{l}-.425 * \\
-.125\end{array}$ & $\begin{array}{c}-.005 \\
.519 *\end{array}$ & $\begin{array}{r}.380 \\
-.092\end{array}$ & $\begin{array}{l}-.053 \\
-.177\end{array}$ & $\begin{array}{r}-.279 \\
.220\end{array}$ & $\frac{1}{3}^{1,2}$ \\
\hline 115657 & $\begin{array}{l}-.215 \\
-.256\end{array}$ & $\begin{array}{l}.163 \\
.364\end{array}$ & $\begin{array}{l}.027 \\
.077\end{array}$ & $\begin{array}{r}.025 \\
-.264\end{array}$ & $\begin{array}{r}-.064 \\
.381\end{array}$ & $\begin{array}{r}.295 \\
-.084\end{array}$ & \\
\hline 121691 & $\begin{array}{l}-.650 * \\
-.378\end{array}$ & $\begin{array}{l}.177 \\
.143\end{array}$ & $\begin{array}{r}-.075 \\
.286\end{array}$ & $\begin{array}{c}.144 \\
-.586 *\end{array}$ & $\begin{array}{r}-.198 \\
.234\end{array}$ & $\begin{array}{l}.237 \\
.189\end{array}$ & $\begin{array}{l}1 \\
4\end{array}$ \\
\hline 124845 & $\begin{array}{r}-.006 \\
.179\end{array}$ & $\begin{array}{l}-.316 \\
-.143\end{array}$ & $\begin{array}{l}.285 \\
.091\end{array}$ & $\begin{array}{l}-.129 \\
-.295\end{array}$ & $\begin{array}{r}-.189 \\
.391 *\end{array}$ & $\begin{array}{l}.531 * \\
.253\end{array}$ & $\begin{array}{l}6 \\
5\end{array}$ \\
\hline 126149 & $\begin{array}{l}-.216 \\
-.064\end{array}$ & $\begin{array}{l}.071 \\
.205\end{array}$ & $\begin{array}{l}-.181 \\
-.296\end{array}$ & $\begin{array}{l}.151 \\
.212\end{array}$ & $\begin{array}{r}.190 \\
-.193\end{array}$ & $\begin{array}{l}-.339 \\
-.315\end{array}$ & \\
\hline 139861 & $\begin{array}{l}.018 \\
.017\end{array}$ & $\begin{array}{l}.329 \\
.429 *\end{array}$ & $\begin{array}{l}-.190 \\
-.112\end{array}$ & $\begin{array}{r}.049 \\
-.109\end{array}$ & $\begin{array}{l}.357 \\
.397 *\end{array}$ & $\begin{array}{l}-.325 \\
-.184\end{array}$ & 2,4 \\
\hline 146227 & $\begin{array}{r}-.082 \\
.040\end{array}$ & $\begin{array}{l}.294 \\
.043\end{array}$ & $\begin{array}{r}.049 \\
-.267\end{array}$ & $\begin{array}{r}-.175 \\
.134\end{array}$ & $\begin{array}{l}-.163 \\
-.331\end{array}$ & $\begin{array}{l}.265 \\
.063\end{array}$ & \\
\hline 149123 & $\begin{array}{r}-.225 \\
.101\end{array}$ & $\begin{array}{r}-.139 \\
.242\end{array}$ & $\begin{array}{l}-.101 \\
-.561 *\end{array}$ & $\begin{array}{l}-.197 \\
-.061\end{array}$ & $\begin{array}{l}.421 * \\
.370\end{array}$ & $\begin{array}{r}.012 \\
-.0134\end{array}$ & $\begin{array}{l}5 \\
3\end{array}$ \\
\hline 150843 & $\begin{array}{r}.163 \\
-.038\end{array}$ & $\begin{array}{l}.119 \\
.183\end{array}$ & $\begin{array}{r}-.059 \\
.105\end{array}$ & $\begin{array}{l}.166 \\
.003\end{array}$ & $\begin{array}{l}-.038 \\
-.139\end{array}$ & $\begin{array}{l}.102 \\
.189\end{array}$ & \\
\hline 173036 & $\begin{array}{l}-.236 \\
-.256\end{array}$ & $\begin{array}{l}.099 \\
.356\end{array}$ & $\begin{array}{l}-.270 \\
-.087\end{array}$ & $\begin{array}{r}.503^{*} \\
-.062\end{array}$ & $\begin{array}{r}-.178 \\
.117\end{array}$ & $\begin{array}{l}-.269 \\
-.270\end{array}$ & 4 \\
\hline 194162 & $\begin{array}{l}-.070 \\
-.361\end{array}$ & $\begin{array}{l}.086 \\
.098\end{array}$ & $\begin{array}{l}-.011 \\
-.078\end{array}$ & $\begin{array}{l}.167 \\
.130\end{array}$ & $\begin{array}{l}.144 \\
.261\end{array}$ & $\begin{array}{l}-.268 \\
-.179\end{array}$ & \\
\hline 200273 & $\begin{array}{r}.078 \\
-.186\end{array}$ & $\begin{array}{l}-.086 \\
-.448 *\end{array}$ & $\begin{array}{r}.136 \\
-.080\end{array}$ & $\begin{array}{l}.225 \\
.140\end{array}$ & $\begin{array}{r}-.067 \\
.016\end{array}$ & $\begin{array}{l}-.540 * \\
-.218\end{array}$ & $\begin{array}{l}6 \\
2\end{array}$ \\
\hline 206813 & $\begin{array}{r}.391 \\
-.094\end{array}$ & $\begin{array}{l}-.555^{*} \\
-.258\end{array}$ & $\begin{array}{l}-.121 \\
-.255\end{array}$ & $\begin{array}{l}.213 \\
.013\end{array}$ & $\begin{array}{r}-.117 \\
.254\end{array}$ & $\begin{array}{l}.071 \\
.399 *\end{array}$ & $\begin{array}{l}2 \\
6\end{array}$ \\
\hline 208251 & $\begin{array}{r}-.073 \\
.466 *\end{array}$ & $\begin{array}{l}-.181 \\
-.057\end{array}$ & $\begin{array}{l}-.008 \\
-.455 *\end{array}$ & $\begin{array}{r}.257 \\
-.250\end{array}$ & $\begin{array}{l}.046 \\
.312\end{array}$ & $\begin{array}{l}.030 \\
.118\end{array}$ & 1,3 \\
\hline 211452 & $\begin{array}{r}.005 \\
-.174\end{array}$ & $\begin{array}{r}.140 \\
-.087\end{array}$ & $\begin{array}{r}-.353 \\
.263\end{array}$ & $\begin{array}{r}.265 \\
-.293\end{array}$ & $\begin{array}{l}.278 \\
.298\end{array}$ & $\begin{array}{r}-.091 \\
.180\end{array}$ & \\
\hline
\end{tabular}




\begin{tabular}{|c|c|c|c|c|c|c|c|}
\hline$\frac{\text { Company }}{216669}$ & -.106 & $\begin{array}{r}\frac{2}{.144} \\
-.352\end{array}$ & $\begin{array}{l}-.39 \\
-.083\end{array}$ & $\begin{array}{l}.2 \frac{4}{11} \\
.100\end{array}$ & $\begin{aligned} & \frac{5}{5} \\
-.103 & -.067\end{aligned}$ & $\begin{array}{l}.4 \frac{6}{44} \text { * } \\
.333\end{array}$ & $\frac{\text { Results }}{3,6}$ \\
\hline 219327 & $\begin{array}{l}-.259 \\
-.444 *\end{array}$ & $\begin{array}{l}-.239 \\
-.146\end{array}$ & $\begin{array}{l}.340 \\
.314\end{array}$ & $\begin{array}{l}-.065 \\
-.298\end{array}$ & $\begin{array}{r}-.074 \\
.046\end{array}$ & $\begin{array}{l}.045 \\
.084\end{array}$ & 1 \\
\hline 228255 & $\begin{array}{l}-.068 \\
-.394 *\end{array}$ & $\begin{array}{r}-.039 \\
.127\end{array}$ & $\begin{array}{r}-.295 \\
.225\end{array}$ & $\begin{array}{r}.242 \\
-.213\end{array}$ & $\begin{array}{r}.069 \\
-.242\end{array}$ & $\begin{array}{l}.101 \\
.626 \text { * }\end{array}$ & 1,6 \\
\hline 228669 & $\begin{array}{l}-.182 \\
-.224\end{array}$ & $\begin{array}{l}.081 \\
.035\end{array}$ & $\begin{array}{l}-.388 * \\
-.086\end{array}$ & $\begin{array}{l}.264 \\
.239\end{array}$ & $\begin{array}{r}.116 \\
-.269\end{array}$ & $\begin{array}{l}-.115 \\
-.046\end{array}$ & 3 \\
\hline 244199 & $\begin{array}{l}.145 \\
.218\end{array}$ & $\begin{array}{l}-.059 \\
-.346\end{array}$ & $\begin{array}{l}.027 \\
.327\end{array}$ & $\begin{array}{r}-.271 \\
.292\end{array}$ & $\begin{array}{l}.088 \\
.016\end{array}$ & $\begin{array}{l}.246 \\
.223\end{array}$ & \\
\hline 252669 & $\begin{array}{l}.495 * \\
.476 *\end{array}$ & $\begin{array}{r}.008 \\
-.087\end{array}$ & $\begin{array}{l}-.057 \\
-.034\end{array}$ & $\begin{array}{l}-.389 * \\
-.431 *\end{array}$ & $\begin{array}{l}.275 \\
.224\end{array}$ & $\begin{array}{l}.147 \\
.011\end{array}$ & $\begin{array}{l}1,4 \\
1,4\end{array}$ \\
\hline 260543 & $\begin{array}{r}.163 \\
-.062\end{array}$ & $\begin{array}{l}-.163 \\
-.155\end{array}$ & $\begin{array}{l}-.190 \\
-.243\end{array}$ & $\begin{array}{r}.262 \\
-.040\end{array}$ & $\begin{array}{l}.157 \\
.332\end{array}$ & $\begin{array}{l}.250 \\
.181\end{array}$ & \\
\hline 261597 & $\begin{array}{l}.176 \\
.306\end{array}$ & $\begin{array}{l}-.102 \\
-.011\end{array}$ & $\begin{array}{r}.045 \\
-.072\end{array}$ & $\begin{array}{c}.252 \\
-.400 *\end{array}$ & $\begin{array}{c}-.154 \\
.461 *\end{array}$ & $\begin{array}{l}.020 \\
.001\end{array}$ & 4,5 \\
\hline 276461 & $\begin{array}{r}-.235 \\
.006\end{array}$ & $\begin{array}{l}-.224 \\
-.357\end{array}$ & $\begin{array}{l}-.239 \\
-.153\end{array}$ & $\begin{array}{l}.349 \\
.160\end{array}$ & $\begin{array}{l}.166 \\
.138\end{array}$ & $\begin{array}{r}-.044 \\
.247\end{array}$ & \\
\hline 296470 & $\begin{array}{l}-.350 \\
-.128\end{array}$ & $\begin{array}{l}.137 \\
.278\end{array}$ & $\begin{array}{r}-.096 \\
.038\end{array}$ & $\begin{array}{r}.267 \\
-.255\end{array}$ & $\begin{array}{r}-.060 \\
.063\end{array}$ & $\begin{array}{l}-.330 \\
-.035\end{array}$ & \\
\hline 302290 & $\begin{array}{l}-.332 \\
-.371\end{array}$ & $\begin{array}{c}-.514 * \\
.344\end{array}$ & $\begin{array}{l}.126 \\
.332\end{array}$ & $\begin{array}{r}.099 \\
-.337\end{array}$ & $\begin{array}{l}-.211 \\
-.187\end{array}$ & $\begin{array}{r}.022 \\
-.146\end{array}$ & 2 \\
\hline 302808 & $\begin{array}{l}-.335 \\
-.129\end{array}$ & $\begin{array}{l}.630 * \\
.464 *\end{array}$ & $\begin{array}{l}-.242 \\
-.226\end{array}$ & $\begin{array}{l}-.132 \\
-.057\end{array}$ & $\begin{array}{r}-.004 \\
.033\end{array}$ & $\begin{array}{r}.112 \\
-.074\end{array}$ & $\begin{array}{l}2 \\
2\end{array}$ \\
\hline 314099 & $\begin{array}{l}-.180 \\
-.087\end{array}$ & $\begin{array}{r}.012 \\
-.382\end{array}$ & $\begin{array}{l}.121 \\
.491 *\end{array}$ & $\begin{array}{l}.303 \\
.077\end{array}$ & $\begin{array}{l}-.552 * \\
-.272\end{array}$ & $\begin{array}{l}.461 * \\
.213\end{array}$ & $\begin{array}{l}5,6 \\
3\end{array}$ \\
\hline 339711 & $\begin{array}{r}.145 \\
-.195\end{array}$ & $\begin{array}{r}-.112 \\
.163\end{array}$ & $\begin{array}{l}.069 \\
.001\end{array}$ & $\begin{array}{l}.184 \\
.182\end{array}$ & $\begin{array}{r}.144 \\
-.124\end{array}$ & $\begin{array}{l}.028 \\
.136\end{array}$ & \\
\hline 345370 & $\begin{array}{r}.048 \\
-.260\end{array}$ & $\begin{array}{r}-.081 \\
.195\end{array}$ & $\begin{array}{r}-.215 \\
.184\end{array}$ & $\begin{array}{l}-.203 \\
-.523 *\end{array}$ & $\begin{array}{l}.356 \\
.556 *\end{array}$ & $\begin{array}{l}.329 \\
.101\end{array}$ & 4,5 \\
\hline 361765 & $\begin{array}{l}.484 * \\
.424 *\end{array}$ & $\begin{array}{l}.052 \\
.330\end{array}$ & $\begin{array}{l}-.301 \\
-.507 *\end{array}$ & $\begin{array}{r}-.141 \\
.036\end{array}$ & $\begin{array}{l}.267 \\
.091\end{array}$ & $\begin{array}{c}.030 \\
-.009 *\end{array}$ & $\begin{array}{l}1 \\
1,3,\end{array}$ \\
\hline 369604 & $\begin{array}{l}.101 \\
.163\end{array}$ & $\begin{array}{l}-.190 \\
-.201\end{array}$ & $\begin{array}{l}.450 * \\
.372\end{array}$ & $\begin{array}{l}-.070 \\
-.329\end{array}$ & $\begin{array}{r}-.083 \\
.133\end{array}$ & $\begin{array}{r}-.011 \\
.206\end{array}$ & 3 \\
\hline 3698 & $\begin{array}{r}.002 \\
-.064\end{array}$ & $\begin{array}{l}-.074 \\
-.053\end{array}$ & $\begin{array}{l}.079 \\
.0726\end{array}$ & $\begin{array}{l}.013 \\
.063\end{array}$ & $\begin{array}{r}.009 \\
-.200\end{array}$ & $\begin{array}{r}.137 \\
-.057\end{array}$ & \\
\hline
\end{tabular}




\begin{tabular}{|c|c|c|c|c|c|c|c|}
\hline$\frac{\text { Company }}{370442}$ & $\begin{array}{r}\frac{1}{9} \\
-.199 \\
-.012\end{array}$ & $\begin{array}{r}.2 \frac{2}{63} \\
.094\end{array}$ & $\begin{array}{r}-.2 \frac{3}{86} \\
.259\end{array}$ & $\begin{array}{l}\frac{4}{10} \\
-.1081 \text { * }\end{array}$ & $\begin{array}{l}.52 \\
.020 \\
.370\end{array}$ & $\begin{array}{l}.2 \frac{6}{05} \\
.147\end{array}$ & $\frac{\text { Results }}{4}$ \\
\hline 370514 & $\begin{array}{l}.186 \\
.132\end{array}$ & $\begin{array}{l}.394 \\
.339\end{array}$ & $\begin{array}{l}.248 \\
.152\end{array}$ & $\begin{array}{l}-.541 * \\
-.473^{*}\end{array}$ & $\begin{array}{l}.301 \\
.395 *\end{array}$ & $\begin{array}{l}-.242 \\
-.114\end{array}$ & $\begin{array}{l}4 \\
4,5\end{array}$ \\
\hline 374280 & $\begin{array}{l}-.086 \\
-.189\end{array}$ & $\begin{array}{l}.209 \\
.282\end{array}$ & $\begin{array}{l}.020 \\
.116\end{array}$ & $\begin{array}{l}-.448 * \\
-.634 *\end{array}$ & $\begin{array}{l}.139 \\
.024\end{array}$ & $\begin{array}{r}-.117 \\
.141\end{array}$ & $\begin{array}{l}4 \\
4\end{array}$ \\
\hline 382388 & $\begin{array}{l}-.142 \\
-.221\end{array}$ & $\begin{array}{l}-.136 \\
-.243\end{array}$ & $\begin{array}{r}-.152 \\
.086\end{array}$ & $\begin{array}{l}.377 \\
.121\end{array}$ & $\begin{array}{r}-.109 \\
.097\end{array}$ & $\begin{array}{r}-.089 \\
.003\end{array}$ & \\
\hline 382550 & $\begin{array}{r}.066 \\
-.092\end{array}$ & $\begin{array}{r}.176 \\
-.036\end{array}$ & $\begin{array}{r}-.230 \\
.013\end{array}$ & $\begin{array}{l}.257 \\
.101\end{array}$ & $\begin{array}{r}-.386 \\
.184\end{array}$ & $\begin{array}{c}.156 \\
-.428 *\end{array}$ & 6 \\
\hline 402460 & $\begin{array}{l}-.147 \\
-.119\end{array}$ & $\begin{array}{r}-.346 \\
.102\end{array}$ & $\begin{array}{r}-.153 \\
.151\end{array}$ & $\begin{array}{c}.166 \\
-.405 *\end{array}$ & $\begin{array}{l}-.140 \\
-.203\end{array}$ & $\begin{array}{r}-.114 \\
.169\end{array}$ & 4 \\
\hline 406216 & $\begin{array}{l}-.132 \\
-.209\end{array}$ & $\begin{array}{l}.151 \\
.046\end{array}$ & $\begin{array}{r}-.034 \\
.149\end{array}$ & $\begin{array}{r}.127 \\
-.047\end{array}$ & $\begin{array}{l}-.172 \\
-.027\end{array}$ & $\begin{array}{r}.156 \\
-.063\end{array}$ & \\
\hline 411631 & $\begin{array}{l}.167 \\
.003\end{array}$ & $\begin{array}{l}.211 \\
.263\end{array}$ & $\begin{array}{l}-.456 * \\
-.549 *\end{array}$ & $\begin{array}{l}.386 \\
.278\end{array}$ & $\begin{array}{l}-.320 \\
-.035\end{array}$ & $\begin{array}{l}-.037 \\
-.207\end{array}$ & $\begin{array}{l}3 \\
3\end{array}$ \\
\hline 416162 & $\begin{array}{l}.537 * \\
.223\end{array}$ & $\begin{array}{r}.011 \\
-.059\end{array}$ & $\begin{array}{r}-.165 \\
.341\end{array}$ & $\begin{array}{r}.185 \\
-.180\end{array}$ & $\begin{array}{l}-.062 \\
-.278\end{array}$ & $\begin{array}{l}-.039 \\
-.128\end{array}$ & 1 \\
\hline 435081 & $\begin{array}{r}-.045 \\
.042\end{array}$ & $\begin{array}{l}.132 \\
.035\end{array}$ & $\begin{array}{l}.118 \\
.058\end{array}$ & $\begin{array}{l}.006 \\
.030\end{array}$ & $\begin{array}{r}.056 \\
-.162\end{array}$ & $\begin{array}{r}-.078 \\
.121\end{array}$ & \\
\hline 438506 & $\begin{array}{l}-.466 * \\
-.601 *\end{array}$ & $\begin{array}{l}.264 \\
.178\end{array}$ & $\begin{array}{r}-.306 \\
.169\end{array}$ & $\begin{array}{r}.269 \\
-.198\end{array}$ & $\begin{array}{r}-.101 \\
.206\end{array}$ & $\begin{array}{l}-.140 \\
-.257\end{array}$ & $\begin{array}{l}1 \\
1\end{array}$ \\
\hline 451542 & $\begin{array}{l}.072 \\
.062\end{array}$ & $\begin{array}{l}.159 \\
.231\end{array}$ & $\begin{array}{l}-.288 \\
-.262\end{array}$ & $\begin{array}{l}.314 \\
.125\end{array}$ & $\begin{array}{l}-.144 \\
-.084\end{array}$ & $\begin{array}{l}.148 \\
.225\end{array}$ & \\
\hline 457470 & $\begin{array}{r}-.306 \\
.207\end{array}$ & $\begin{array}{l}.358 \\
.040\end{array}$ & $\begin{array}{l}-.563 * \\
-.392 *\end{array}$ & $\begin{array}{l}.387 \\
.140\end{array}$ & $\begin{array}{l}-.175 \\
-.301\end{array}$ & $\begin{array}{l}.056 \\
.387\end{array}$ & $\begin{array}{l}3 \\
3\end{array}$ \\
\hline 458506 & $\begin{array}{l}.520 * \\
.458 *\end{array}$ & $\begin{array}{l}-.387 \\
-.487 *\end{array}$ & $\begin{array}{l}.195 \\
.222\end{array}$ & $\begin{array}{r}.049 \\
-.118\end{array}$ & $\begin{array}{l}.097 \\
.108\end{array}$ & $\begin{array}{r}-.131 \\
.009\end{array}$ & $\begin{array}{l}1 \\
1,2\end{array}$ \\
\hline 458702 & $\begin{array}{l}-.379 \\
-.021\end{array}$ & $\begin{array}{l}.461 * \\
.288\end{array}$ & $\begin{array}{r}-.156 \\
.046\end{array}$ & $\begin{array}{l}-.190 \\
-.567 \text { * }\end{array}$ & $\begin{array}{l}.322 \\
.505 *\end{array}$ & $\begin{array}{l}.006 \\
.259\end{array}$ & $\begin{array}{l}2 \\
4,5\end{array}$ \\
\hline 459200 & $\begin{array}{l}.374 \\
.102\end{array}$ & $\begin{array}{l}.119 \\
.195\end{array}$ & $\begin{array}{l}-.551 * \\
-.016\end{array}$ & $\begin{array}{r}.188 \\
-.255\end{array}$ & $\begin{array}{r}.032 \\
-.184\end{array}$ & $\begin{array}{r}-.034 \\
.393\end{array}$ & 3 \\
\hline 459578 & $\begin{array}{l}-.142 \\
-.254\end{array}$ & $\begin{array}{l}.157 \\
.420 *\end{array}$ & $\begin{array}{r}.071 \\
-.096\end{array}$ & $\begin{array}{r}.004 \\
-.084\end{array}$ & $\begin{array}{l}.013 \\
.006\end{array}$ & $\begin{array}{l}-.157 \\
-.198\end{array}$ & 2 \\
\hline 459 & $\begin{array}{l}.359 \\
.173\end{array}$ & $\begin{array}{l}.206 \\
.350\end{array}$ & $\begin{array}{l}-.246 \\
-.086\end{array}$ & $\begin{array}{r}.023 \\
-.273\end{array}$ & $\begin{array}{l}.083 \\
.114\end{array}$ & $\begin{array}{l}.032 \\
.192\end{array}$ & \\
\hline
\end{tabular}




\begin{tabular}{|c|c|c|c|c|c|c|c|}
\hline$\frac{\text { Company }}{460470}$ & $\begin{array}{r}\frac{1}{1} \\
. .004 \\
.032\end{array}$ & $\begin{array}{r}\frac{2}{-.036} \\
.300\end{array}$ & $\begin{array}{r}\frac{3}{193} \\
-.193 \\
-.171\end{array}$ & $\begin{array}{r}-.4 \frac{4}{52} \\
. .131\end{array}$ & $\begin{array}{r}\frac{5}{325} \\
-.310\end{array}$ & $\begin{array}{c}-.4 \frac{6}{95} \\
.118\end{array}$ & $\frac{\text { Results }}{6}$ \\
\hline 481196 & $\begin{array}{r}.128 \\
.370\end{array}$ & $\begin{array}{r}-.024 \\
.129\end{array}$ & $\begin{array}{l}-.118 \\
-.149\end{array}$ & $\begin{array}{l}-.101 \\
-.348\end{array}$ & $\begin{array}{r}.128 \\
-.014\end{array}$ & $\begin{array}{l}.227 \\
.391 *\end{array}$ & 6 \\
\hline 483008 & $\begin{array}{l}-.006 \\
-.034\end{array}$ & $\begin{array}{l}.181 \\
.235\end{array}$ & $\begin{array}{l}-.225 \\
-.316\end{array}$ & $\begin{array}{l}-.249 \\
-.106\end{array}$ & $\begin{array}{l}.442 * \\
.165\end{array}$ & $\begin{array}{l}-.273 \\
-.292\end{array}$ & 5 \\
\hline 494368 & $\begin{array}{l}.215 \\
.085\end{array}$ & $\begin{array}{l}.113 \\
.214\end{array}$ & $\begin{array}{l}-.227 \\
-.294\end{array}$ & $\begin{array}{l}.068 \\
.133\end{array}$ & $\begin{array}{r}-.057 \\
.009\end{array}$ & $\begin{array}{l}-.440 * \\
-.411\end{array}$ & 6 \\
\hline 500170 & $\begin{array}{r}.287 \\
-.090\end{array}$ & $\begin{array}{l}-.244 \\
-.084\end{array}$ & $\begin{array}{c}-.400 * \\
.265\end{array}$ & $\begin{array}{r}-.001 \\
.043\end{array}$ & $\begin{array}{r}.476 * \\
-.108\end{array}$ & $\begin{array}{l}-.219 \\
-.064\end{array}$ & 3,5 \\
\hline 500755 & $\begin{array}{l}.066 \\
.008\end{array}$ & $\begin{array}{l}.447 * \\
.441 *\end{array}$ & $\begin{array}{l}-.172 \\
-.669 *\end{array}$ & $\begin{array}{r}-.306 \\
.239\end{array}$ & $\begin{array}{l}.518 * \\
.416 *\end{array}$ & $\begin{array}{l}-.365 \\
-.258\end{array}$ & $\begin{array}{l}2,5 \\
2,3,5\end{array}$ \\
\hline 501044 & $\begin{array}{c}-.650 * \\
.014\end{array}$ & $\begin{array}{l}.433 * \\
.407 *\end{array}$ & $\begin{array}{l}-.101 \\
-.095\end{array}$ & $\begin{array}{c}.026 \\
-.419 *\end{array}$ & $\begin{array}{r}.187 \\
.361\end{array}$ & $\begin{array}{l}-.242 \\
-.447 *\end{array}$ & $\begin{array}{l}1,2 \\
2,4,6\end{array}$ \\
\hline 542290 & $\begin{array}{l}-.178 \\
-.129\end{array}$ & $\begin{array}{r}.258 \\
.153\end{array}$ & $\begin{array}{r}-.016 \\
.201\end{array}$ & $\begin{array}{l}-.235 \\
-.272\end{array}$ & $\begin{array}{r}.204 \\
-.130\end{array}$ & $\begin{array}{l}.134 \\
.286\end{array}$ & \\
\hline 556139 & $\begin{array}{r}-.055 \\
.220\end{array}$ & $\begin{array}{l}.053 \\
.011\end{array}$ & $\begin{array}{l}-.541 * \\
-.329\end{array}$ & $\begin{array}{r}.245 \\
.089\end{array}$ & $\begin{array}{l}-.304 \\
-.194\end{array}$ & $\begin{array}{l}.366 \\
.013\end{array}$ & 3 \\
\hline 572342 & $\begin{array}{r}.379 \\
.322\end{array}$ & $\begin{array}{r}.079 \\
.139\end{array}$ & $\begin{array}{l}-.561 * \\
-.554 *\end{array}$ & $\begin{array}{r}.235 \\
.242\end{array}$ & $\begin{array}{l}-.413 * \\
-.458 *\end{array}$ & $\begin{array}{r}.257 \\
.345\end{array}$ & $\begin{array}{l}3,5 \\
3,5\end{array}$ \\
\hline 577778 & $\begin{array}{l}.315 \\
.418 *\end{array}$ & $\begin{array}{r}.486 * \\
-.182\end{array}$ & $\begin{array}{r}-.354 \\
.315\end{array}$ & $\begin{array}{r}.082 \\
-.198\end{array}$ & $\begin{array}{l}.165 \\
.387\end{array}$ & $\begin{array}{l}-.332 \\
-.325\end{array}$ & $\begin{array}{l}2 \\
1\end{array}$ \\
\hline 577896 & $\begin{array}{l}.133 \\
.235\end{array}$ & $\begin{array}{l}.094 \\
.310\end{array}$ & $\begin{array}{l}.014 \\
.083\end{array}$ & $\begin{array}{c}.169 \\
-.478 *\end{array}$ & $\begin{array}{r}-.112 \\
.269\end{array}$ & $\begin{array}{r}-.052 \\
.183\end{array}$ & 4 \\
\hline 580033 & $\begin{array}{l}-.047 \\
-.289\end{array}$ & $\begin{array}{l}.324 \\
.513 *\end{array}$ & $\begin{array}{l}-.443 * \\
-.378\end{array}$ & $\begin{array}{r}.060 \\
-.238\end{array}$ & $\begin{array}{l}.372 \\
.563 *\end{array}$ & $\begin{array}{l}-.293 \\
-.550\end{array}$ & $\begin{array}{l}3 \\
2,5\end{array}$ \\
\hline 580628 & $\begin{array}{r}-.027 \\
.049\end{array}$ & $\begin{array}{l}.389 * \\
.024\end{array}$ & $\begin{array}{l}-.238 \\
-.278\end{array}$ & $\begin{array}{r}-.078 \\
.048\end{array}$ & $\begin{array}{r}-.037 \\
.190\end{array}$ & $\begin{array}{r}.163 \\
-.245\end{array}$ & 2 \\
\hline 589433 & $\begin{array}{l}-.287 \\
-.220\end{array}$ & $\begin{array}{r}.143 \\
.003\end{array}$ & $\begin{array}{l}-.136 \\
-.157\end{array}$ & $\begin{array}{l}.100 \\
.189\end{array}$ & $\begin{array}{r}-.198 \\
.029\end{array}$ & $\begin{array}{l}.624 * \\
.121\end{array}$ & 6 \\
\hline 591690 & $\begin{array}{r}.163 \\
.170\end{array}$ & $\begin{array}{l}-.221 \\
-.281\end{array}$ & $\begin{array}{l}.201 \\
.217\end{array}$ & $\begin{array}{r}.088 \\
-.065\end{array}$ & $\begin{array}{l}.114 \\
.233\end{array}$ & $\begin{array}{l}-.004 \\
-.006\end{array}$ & \\
\hline 604059 & $\begin{array}{r}.162 \\
-.382\end{array}$ & $\begin{array}{l}-.469 * \\
-.420 *\end{array}$ & $\begin{array}{c}-.438 * \\
.218\end{array}$ & $\begin{array}{l}.191 \\
.652 *\end{array}$ & $\begin{array}{l}.669 * \\
.208\end{array}$ & $\begin{array}{l}-.035 \\
-.234\end{array}$ & $\begin{array}{l}2,3,5 \\
2,4\end{array}$ \\
\hline 607059 & $\begin{array}{l}-.256 \\
-.271\end{array}$ & $\begin{array}{r}-.102 \\
.082\end{array}$ & $\begin{array}{l}.397 * \\
.499 *\end{array}$ & $\begin{array}{l}-.279 \\
-.570 *\end{array}$ & $\begin{array}{l}.108 \\
.268\end{array}$ & $\begin{array}{l}.063 \\
.066\end{array}$ & $\begin{array}{l}3 \\
3,4\end{array}$ \\
\hline
\end{tabular}




\begin{tabular}{|c|c|c|c|c|c|c|c|}
\hline$\frac{\text { Company }}{608030}$ & $\begin{array}{l}\frac{1}{1} \\
-.477 * \\
-.343\end{array}$ & $\begin{array}{r}.2 \frac{2}{57} \\
.034\end{array}$ & $.1 \frac{3}{32}$ & $\begin{array}{l}.2 \frac{4}{84} \\
.406\end{array}$ & $\begin{array}{l}-.5 \frac{5}{24} \text { * } \\
-.596 \text { * }\end{array}$ & $\begin{array}{l}.2 \frac{6}{72} \\
.319\end{array}$ & $\frac{\text { Results }}{\frac{1}{5}, 5}$ \\
\hline 611662 & $\begin{array}{r}.293 \\
-.122\end{array}$ & $\begin{array}{l}-.001 \\
-.137\end{array}$ & $\begin{array}{l}-.259 \\
-.104\end{array}$ & $\begin{array}{l}.210 \\
.186\end{array}$ & $\begin{array}{l}.331 \\
.358\end{array}$ & $\begin{array}{l}-.340 \\
-.397 *\end{array}$ & 6 \\
\hline 620076 & $\begin{array}{l}-.232 \\
-.257\end{array}$ & $\begin{array}{l}.081 \\
.185\end{array}$ & $\begin{array}{l}.127 \\
.062\end{array}$ & $\begin{array}{l}.098 \\
.005\end{array}$ & $\begin{array}{l}-.277 \\
-.043\end{array}$ & $\begin{array}{r}.031 \\
-.087\end{array}$ & \\
\hline 635655 & $\begin{array}{l}-.410 \\
-.414 *\end{array}$ & $\begin{array}{l}.081 \\
.213\end{array}$ & $\begin{array}{l}.192 \\
.125\end{array}$ & $\begin{array}{l}-.033 \\
-.194\end{array}$ & $\begin{array}{l}.135 \\
.327\end{array}$ & $\begin{array}{l}-.071 \\
-.239\end{array}$ & 1 \\
\hline 636316 & $\begin{array}{l}-.293 \\
-.151\end{array}$ & $\begin{array}{l}.111 \\
.158\end{array}$ & $\begin{array}{r}-.048 \\
.036\end{array}$ & $\begin{array}{l}-.322 \\
-.410 *\end{array}$ & $\begin{array}{l}-.154 \\
-.233\end{array}$ & $\begin{array}{l}.209 \\
.052\end{array}$ & 4 \\
\hline 637844 & $\begin{array}{c}-.406 * \\
.099\end{array}$ & $\begin{array}{l}-.234 \\
-.480 *\end{array}$ & $\begin{array}{r}-.237 \\
.247\end{array}$ & $\begin{array}{l}.362 \\
.023\end{array}$ & $\begin{array}{l}.110 \\
.152\end{array}$ & $\begin{array}{l}-.058 \\
-.032 *\end{array}$ & $\begin{array}{l}1 \\
2,6\end{array}$ \\
\hline 656780 & $\begin{array}{l}-.045 \\
-.049\end{array}$ & $\begin{array}{l}.161 \\
.193\end{array}$ & $\begin{array}{l}-.277 \\
-.272\end{array}$ & $\begin{array}{l}-.243 \\
-.156\end{array}$ & $\begin{array}{l}-.030 \\
-.191\end{array}$ & $\begin{array}{r}-.063 \\
.019\end{array}$ & \\
\hline 690020 & $\begin{array}{l}-.234 \\
-.297\end{array}$ & $\begin{array}{l}.247 \\
.092\end{array}$ & $\begin{array}{l}-.269 \\
-.102\end{array}$ & $\begin{array}{l}.038 \\
.128\end{array}$ & $\begin{array}{l}.183 \\
.151\end{array}$ & $\begin{array}{l}.375 \\
.083\end{array}$ & \\
\hline 690734 & $\begin{array}{l}.013 \\
.094\end{array}$ & $\begin{array}{l}-.065 \\
-.029\end{array}$ & $\begin{array}{l}.133 \\
.201\end{array}$ & $\begin{array}{l}-.263 \\
-.388 *\end{array}$ & $\begin{array}{l}.186 \\
.204\end{array}$ & $\begin{array}{r}.017 \\
-.006\end{array}$ & 4 \\
\hline 690768 & $\begin{array}{l}.292 \\
.079\end{array}$ & $\begin{array}{l}-.474 * \\
-.370\end{array}$ & $\begin{array}{r}-.080 \\
.027\end{array}$ & $\begin{array}{l}.334 \\
.215\end{array}$ & $\begin{array}{l}.141 \\
.150\end{array}$ & $\begin{array}{l}-.093 \\
-.369\end{array}$ & 2 \\
\hline 693506 & $\begin{array}{l}.215 \\
.227\end{array}$ & $\begin{array}{r}.130 \\
-.085\end{array}$ & $\begin{array}{l}-.489 * \\
-.292\end{array}$ & $\begin{array}{l}.250 \\
.217\end{array}$ & $\begin{array}{l}-.146 \\
-.296\end{array}$ & $\begin{array}{l}.203 \\
.420 *\end{array}$ & $\begin{array}{l}3 \\
6\end{array}$ \\
\hline 717081 & $\begin{array}{r}.065 \\
-.032\end{array}$ & $\begin{array}{l}.072 \\
.005\end{array}$ & $\begin{array}{l}.006 \\
.078\end{array}$ & $\begin{array}{l}-.089 \\
-.076\end{array}$ & $\begin{array}{l}.185 \\
.217\end{array}$ & $\begin{array}{r}.066 \\
-.069\end{array}$ & \\
\hline 718167 & $\begin{array}{l}-.209 \\
-.023\end{array}$ & $\begin{array}{r}.202 \\
-.310\end{array}$ & $\begin{array}{l}-.427 * \\
-.268\end{array}$ & $\begin{array}{l}-.324 \\
-.105\end{array}$ & $\begin{array}{l}.320 \\
.364\end{array}$ & $\begin{array}{r}-.355 \\
.147\end{array}$ & 3 \\
\hline 718507 & $\begin{array}{l}-.148 \\
-.069\end{array}$ & $\begin{array}{l}.074 \\
.465 *\end{array}$ & $\begin{array}{l}-.104 \\
-.259\end{array}$ & $\begin{array}{l}-.107 \\
-.381\end{array}$ & $\begin{array}{r}-.261 \\
.117\end{array}$ & $\begin{array}{r}-.018 \\
.086\end{array}$ & 2 \\
\hline 724479 & $\begin{array}{r}-.059 \\
.042\end{array}$ & $\begin{array}{l}-.141 \\
-.053\end{array}$ & $\begin{array}{l}.519 * \\
.584 *\end{array}$ & $\begin{array}{r}.072 \\
-.186\end{array}$ & $\begin{array}{r}.188 \\
-.307\end{array}$ & $\begin{array}{r}-.045 \\
.1 .46\end{array}$ & $\begin{array}{l}3 \\
3\end{array}$ \\
\hline 725701 & $\begin{array}{l}.011 \\
.286\end{array}$ & $\begin{array}{l}-.059 \\
-.082\end{array}$ & $\begin{array}{l}-.064 \\
-.205\end{array}$ & $\begin{array}{c}.153 \\
-.572 *\end{array}$ & $\begin{array}{l}.540 * \\
.311\end{array}$ & $\begin{array}{r}-.273 \\
.663 *\end{array}$ & $\begin{array}{l}5 \\
4,6\end{array}$ \\
\hline 737628 & $\begin{array}{l}-.088 \\
-.046 *\end{array}$ & $\begin{array}{l}.427 * \\
.724^{*}\end{array}$ & $\begin{array}{l}-.134 \\
-.516 *\end{array}$ & $\begin{array}{r}-.305 \\
.051\end{array}$ & $\begin{array}{r}.022 \\
-.028\end{array}$ & $\begin{array}{r}.082 \\
-.228\end{array}$ & $\begin{array}{l}2 \\
1,2,3\end{array}$ \\
\hline 742718 & $\begin{array}{l}.197 \\
.090\end{array}$ & $\begin{array}{l}-.106 \\
-.111\end{array}$ & $\begin{array}{r}.018 \\
-.010\end{array}$ & $\begin{array}{l}-.211 \\
-.360\end{array}$ & $\begin{array}{l}.090 \\
.241\end{array}$ & $\begin{array}{l}.074 \\
.034\end{array}$ & \\
\hline
\end{tabular}




\begin{tabular}{|c|c|c|c|c|c|c|c|}
\hline$\frac{\text { Company }}{747402}$ & $\begin{array}{l}\frac{1}{194} \\
.210\end{array}$ & $\begin{array}{r}\frac{2}{.129} \\
-.342\end{array}$ & $\begin{array}{r}-.2 \frac{3}{11} \\
.240\end{array}$ & $\begin{array}{r}\frac{4}{2} \\
-.120 \\
-.011\end{array}$ & $\begin{aligned} & \frac{5}{5} \\
&-.255 \\
&-.249\end{aligned}$ & $\begin{array}{r}\frac{6}{2} \\
-. .018\end{array}$ & Results \\
\hline 749285 & $\begin{array}{l}.052 \\
.177\end{array}$ & $\begin{array}{l}.346 \\
.283\end{array}$ & $\begin{array}{l}.016 \\
.053\end{array}$ & $\begin{array}{r}.029 \\
-.195\end{array}$ & $\begin{array}{r}-.028 \\
.080\end{array}$ & $\begin{array}{r}-.073 \\
.197\end{array}$ & \\
\hline 755111 & $\begin{array}{l}-.220 \\
-.118\end{array}$ & $\begin{array}{l}.304 \\
.455 *\end{array}$ & $\begin{array}{l}-.350 \\
-.317\end{array}$ & $\begin{array}{r}.238 \\
-.216\end{array}$ & $\begin{array}{r}-.107 \\
.017\end{array}$ & $\begin{array}{l}.081 \\
.035\end{array}$ & 2 \\
\hline 759457 & $\begin{array}{l}.417 * \\
.048\end{array}$ & $\begin{array}{l}-.226 \\
-.040\end{array}$ & $\begin{array}{l}.230 \\
.281\end{array}$ & $\begin{array}{l}-.211 \\
-.286\end{array}$ & $\begin{array}{l}.214 \\
.013\end{array}$ & $\begin{array}{l}-.322 \\
-.227\end{array}$ & 1 \\
\hline 760779 & $\begin{array}{l}-.222 \\
-.270\end{array}$ & $\begin{array}{l}-.178 \\
-.331\end{array}$ & $\begin{array}{r}-.212 \\
.214\end{array}$ & $\begin{array}{l}.553^{*} \\
.240\end{array}$ & $\begin{array}{r}.004 \\
-.140\end{array}$ & $\begin{array}{l}.053 \\
.080\end{array}$ & 4 \\
\hline 761688 & $\begin{array}{r}-.018 \\
.025\end{array}$ & $\begin{array}{l}-.053 \\
-.284\end{array}$ & $\begin{array}{l}.323 \\
.061\end{array}$ & $\begin{array}{l}-.344 \\
-.244\end{array}$ & $\begin{array}{l}.075 \\
.309\end{array}$ & $\begin{array}{r}-.194 \\
.129\end{array}$ & \\
\hline 761753 & $\begin{array}{l}.069 \\
.243\end{array}$ & $\begin{array}{l}.226 \\
.093\end{array}$ & $\begin{array}{l}-.242 \\
-.033\end{array}$ & $\begin{array}{l}-.093 \\
-.290\end{array}$ & $\begin{array}{l}.254 \\
.303\end{array}$ & $\begin{array}{l}-.360 \\
-.358\end{array}$ & \\
\hline 761763 & $\begin{array}{l}.325 \\
.163\end{array}$ & $\begin{array}{r}-.176 \\
.079\end{array}$ & $\begin{array}{l}-.225 \\
-.134\end{array}$ & $\begin{array}{l}.449 * \\
.130\end{array}$ & $\begin{array}{l}.291 \\
.277\end{array}$ & $\begin{array}{l}-.173 \\
-.096\end{array}$ & 4 \\
\hline 780257 & $\begin{array}{l}.567 * \\
.314\end{array}$ & $\begin{array}{l}-.437 * \\
-.063\end{array}$ & $\begin{array}{l}-.584 * \\
-.243\end{array}$ & $\begin{array}{l}.543 * \\
.078\end{array}$ & $\begin{array}{r}-.009 \\
.127\end{array}$ & $\begin{array}{l}-.220 \\
-.302\end{array}$ & $1,2,3,4$ \\
\hline 786514 & $\begin{array}{r}-.011 \\
.161\end{array}$ & $\begin{array}{r}-.288 \\
.079\end{array}$ & $\begin{array}{r}.102 \\
-.178\end{array}$ & $\begin{array}{l}-.342 \\
-.206\end{array}$ & $\begin{array}{l}.485 * \\
.538 *\end{array}$ & $\begin{array}{l}-.529 * \\
-.447 *\end{array}$ & $\begin{array}{l}5,6 \\
5,6\end{array}$ \\
\hline 790155 & $\begin{array}{l}.143 \\
.185\end{array}$ & $\begin{array}{l}.155 \\
.150\end{array}$ & $\begin{array}{l}-.420 * \\
-.134\end{array}$ & $\begin{array}{r}.174 \\
-.185\end{array}$ & $\begin{array}{l}-.256 \\
-.090\end{array}$ & $\begin{array}{l}.647 * \\
.572 *\end{array}$ & $\begin{array}{l}3,6 \\
6\end{array}$ \\
\hline 793453 & $\begin{array}{l}-.166 \\
-.161\end{array}$ & $\begin{array}{l}.039 \\
.039\end{array}$ & $\begin{array}{l}.191 \\
.165\end{array}$ & $\begin{array}{r}-.094 \\
.117\end{array}$ & $\begin{array}{l}-.208 \\
-.374\end{array}$ & $\begin{array}{l}.044 \\
.038\end{array}$ & \\
\hline 809877 & $\begin{array}{r}.082 \\
-.117\end{array}$ & $\begin{array}{r}-.186 \\
.045\end{array}$ & $\begin{array}{l}-.264 \\
-.195\end{array}$ & $\begin{array}{l}.157 \\
.056\end{array}$ & $\begin{array}{l}-.350 \\
-.248\end{array}$ & $\begin{array}{c}.068 \\
-.418 *\end{array}$ & 6 \\
\hline 811850 & $\begin{array}{r}-.026 \\
.185\end{array}$ & $\begin{array}{r}.013 \\
-.001\end{array}$ & $\begin{array}{l}-.407 * \\
-.440 *\end{array}$ & $\begin{array}{l}.360 \\
.400 *\end{array}$ & $\begin{array}{r}.069 \\
-.095\end{array}$ & $\begin{array}{l}-.011 \\
-.023\end{array}$ & $\begin{array}{l}3 \\
3,4\end{array}$ \\
\hline 812387 & $\begin{array}{l}-.391 * \\
-.106\end{array}$ & $\begin{array}{l}.295 \\
.057\end{array}$ & $\begin{array}{l}-.214 \\
-.012\end{array}$ & $\begin{array}{l}.132 \\
.283\end{array}$ & $\begin{array}{r}.031 \\
-.222\end{array}$ & $\begin{array}{r}.129 \\
-.234\end{array}$ & 1 \\
\hline 822635 & $\begin{array}{l}.046 \\
.355\end{array}$ & $\begin{array}{l}.210 \\
.039\end{array}$ & $\begin{array}{l}-.234 \\
-.199\end{array}$ & $\begin{array}{r}.066 \\
-.177\end{array}$ & $\begin{array}{l}-.094 \\
-.022\end{array}$ & $\begin{array}{l}.152 \\
.004\end{array}$ & \\
\hline 853139 & $\begin{array}{l}.075 \\
.207\end{array}$ & $\begin{array}{l}.068 \\
.039\end{array}$ & $\begin{array}{l}-.179 \\
-.195\end{array}$ & $\begin{array}{r}.088 \\
-.227\end{array}$ & $\begin{array}{l}-.315 \\
-.326\end{array}$ & $\begin{array}{r}-.194 \\
.183\end{array}$ & \\
\hline 853683 & $\begin{array}{r}-.043 \\
.125\end{array}$ & $\begin{array}{c}.091 \\
-.458 *\end{array}$ & $\begin{array}{l}.210 \\
.195\end{array}$ & $\begin{array}{r}-.254 \\
.169\end{array}$ & $\begin{array}{r}.095 \\
-.376\end{array}$ & $\begin{array}{r}-.310 \\
.359\end{array}$ & 2 \\
\hline
\end{tabular}




\begin{tabular}{|c|c|c|c|c|c|c|c|}
\hline$\frac{\text { Company }}{853700}$ & $\begin{array}{l}.2 \frac{1}{55} \\
.557 \text { * }\end{array}$ & $\begin{array}{r}-.2 \frac{2}{81} \\
.006\end{array}$ & $\begin{array}{l}-.0 \frac{3}{18} \\
-.469 *\end{array}$ & $\begin{array}{r}. \frac{4}{1} 8 \\
-.128\end{array}$ & $\begin{array}{r}-.2 \frac{5}{45} \\
.122\end{array}$ & $\begin{array}{l}. \frac{6}{63} \\
.090\end{array}$ & $\frac{\text { Results }}{1,3}$ \\
\hline 857721 & $\begin{array}{l}-.195 \\
-.074\end{array}$ & $\begin{array}{r}.215 \\
-.097\end{array}$ & $\begin{array}{l}.099 \\
.172\end{array}$ & $\begin{array}{l}-.052 \\
-.224\end{array}$ & $\begin{array}{r}-.140 \\
.116\end{array}$ & $\begin{array}{l}-.231 \\
-.290\end{array}$ & \\
\hline 859264 & $\begin{array}{l}-.062 \\
-.048\end{array}$ & $\begin{array}{l}.329 \\
.193\end{array}$ & $\begin{array}{l}-.097 \\
-.107\end{array}$ & $\begin{array}{l}.060 \\
.280\end{array}$ & $\begin{array}{l}-.147 \\
-.140\end{array}$ & $\begin{array}{r}-.250 \\
.130\end{array}$ & \\
\hline 866762 & $\begin{array}{l}-.077 \\
-.080\end{array}$ & $\begin{array}{l}-.167 \\
-.067\end{array}$ & $\begin{array}{l}-.204 \\
-.106\end{array}$ & $\begin{array}{l}-.175 \\
-.338\end{array}$ & $\begin{array}{l}.301 \\
.366\end{array}$ & $\begin{array}{l}.142 \\
.009\end{array}$ & \\
\hline 868273 & $\begin{array}{l}-.444^{*} \\
-.208\end{array}$ & $\begin{array}{l}.153 \\
.067\end{array}$ & $\begin{array}{l}-.266 \\
-.103\end{array}$ & $\begin{array}{l}.209 \\
.192\end{array}$ & $\begin{array}{r}.050 \\
-.108\end{array}$ & $\begin{array}{l}.073 \\
.077\end{array}$ & 1 \\
\hline 872649 & $\begin{array}{l}-.158 \\
-.228\end{array}$ & $\begin{array}{r}-.019 \\
.088\end{array}$ & $\begin{array}{r}-.175 \\
.101\end{array}$ & $\begin{array}{r}.315 \\
-.284\end{array}$ & $\begin{array}{l}-.040 \\
-.065\end{array}$ & $\begin{array}{l}-.213 \\
-.192\end{array}$ & \\
\hline 873635 & $\begin{array}{l}.042 \\
.245\end{array}$ & $\begin{array}{r}.074 \\
-.111\end{array}$ & $\begin{array}{l}.191 \\
.280\end{array}$ & $\begin{array}{l}-.484 * \\
-.491 *\end{array}$ & $\begin{array}{l}.202 \\
.274\end{array}$ & $\begin{array}{r}.311 \\
-.265\end{array}$ & $\begin{array}{l}4 \\
4\end{array}$ \\
\hline 880370 & $\begin{array}{l}.399 * \\
.208\end{array}$ & $\begin{array}{l}-.258 \\
-.236\end{array}$ & $\begin{array}{r}-.030 \\
.116\end{array}$ & $\begin{array}{l}.419 * \\
.161\end{array}$ & $\begin{array}{l}.158 \\
.186\end{array}$ & $\begin{array}{l}.132 \\
.197\end{array}$ & 1,4 \\
\hline 881694 & $\begin{array}{l}.124 \\
.395 *\end{array}$ & $\begin{array}{r}.292 \\
-.174\end{array}$ & $\begin{array}{r}-.311 \\
.191\end{array}$ & $\begin{array}{l}.262 \\
.138\end{array}$ & $\begin{array}{l}-.276 \\
-.088\end{array}$ & $\begin{array}{r}.113 \\
-.217\end{array}$ & 1 \\
\hline 882508 & $\begin{array}{l}-.216 \\
-.079\end{array}$ & $\begin{array}{l}.357 \\
.505 *\end{array}$ & $\begin{array}{l}-.082 \\
-.057\end{array}$ & $\begin{array}{r}.037 \\
-.367\end{array}$ & $\begin{array}{l}-.005 \\
-.038\end{array}$ & $\begin{array}{l}-.206 \\
-.271\end{array}$ & 2 \\
\hline 883203 & $\begin{array}{l}.030 \\
.225\end{array}$ & $\begin{array}{c}.090 \\
-.002 *\end{array}$ & $\begin{array}{l}.128 \\
.363\end{array}$ & $\begin{array}{r}.001 \\
-.266\end{array}$ & $\begin{array}{l}.230 \\
.272\end{array}$ & $\begin{array}{c}.513 * \\
-.350\end{array}$ & $\begin{array}{l}6 \\
2\end{array}$ \\
\hline 887224 & $\begin{array}{l}-.467 * \\
-.468 *\end{array}$ & $\begin{array}{l}.149 \\
.179\end{array}$ & $\begin{array}{l}-.231 \\
-.140\end{array}$ & $\begin{array}{l}.555^{*} \\
.473^{*}\end{array}$ & $\begin{array}{l}-.117 \\
-.394 *\end{array}$ & $\begin{array}{l}.211 \\
.320\end{array}$ & $\begin{array}{l}1,4 \\
1,4,5\end{array}$ \\
\hline 887360 & $\begin{array}{r}-.115 \\
.062\end{array}$ & $\begin{array}{l}.276 \\
.130\end{array}$ & $\begin{array}{r}-.145 \\
.066\end{array}$ & $\begin{array}{r}.099 \\
-.205\end{array}$ & $\begin{array}{l}.073 \\
.116\end{array}$ & $\begin{array}{r}.173 \\
-.233\end{array}$ & \\
\hline 902878 & $\begin{array}{r}.146 \\
-.022\end{array}$ & $\begin{array}{r}-.185 \\
.080\end{array}$ & $\begin{array}{r}-.028 \\
.353\end{array}$ & $\begin{array}{r}.039 \\
-.175\end{array}$ & $\begin{array}{r}.066 \\
-.072\end{array}$ & $\begin{array}{l}.316 \\
.321\end{array}$ & \\
\hline 904784 & $\begin{array}{l}.480 * \\
.389 *\end{array}$ & $\begin{array}{l}-.104 \\
-.307\end{array}$ & $\begin{array}{r}-.264 \\
.109\end{array}$ & $\begin{array}{r}.135 \\
-.141\end{array}$ & $\begin{array}{l}.383 \\
.297\end{array}$ & $\begin{array}{r}.370 \\
-.007\end{array}$ & $\begin{array}{l}1 \\
1\end{array}$ \\
\hline 905581 & $\begin{array}{l}.048 \\
.116\end{array}$ & $\begin{array}{l}-.171 \\
-.086\end{array}$ & $\begin{array}{r}-.249 \\
.051\end{array}$ & $\begin{array}{r}.318 \\
-.067\end{array}$ & $\begin{array}{l}.365 \\
.309\end{array}$ & $\begin{array}{l}.213 \\
.192\end{array}$ & \\
\hline 907770 & $\begin{array}{l}.373 \\
.267\end{array}$ & $\begin{array}{l}-.252 \\
-.107\end{array}$ & $\begin{array}{l}.259 \\
.325\end{array}$ & $\begin{array}{l}-.312 \\
-.488 *\end{array}$ & $\begin{array}{l}.266 \\
.200\end{array}$ & $\begin{array}{l}-.321 \\
-.311\end{array}$ & 4 \\
\hline 912656 & $\begin{array}{l}.222 \\
.520 *\end{array}$ & $\begin{array}{l}-.706 * \\
-.675^{*}\end{array}$ & $\begin{array}{r}-.064 \\
.056\end{array}$ & $\begin{array}{l}.455^{*} \\
.212\end{array}$ & $\begin{array}{l}.313 \\
.024\end{array}$ & $\begin{array}{l}.345 \\
.279\end{array}$ & $\begin{array}{l}2,4 \\
1\end{array}$ \\
\hline
\end{tabular}




\begin{tabular}{|c|c|c|c|c|c|c|c|}
\hline$\frac{\text { Company }}{933169}$ & $\begin{array}{l}.1 \\
.405 * \\
.343\end{array}$ & $\begin{array}{l}-.477 * \\
.110\end{array}$ & $\begin{array}{l}-.3 \\
-.051 \\
-.332\end{array}$ & $\begin{array}{l}. \frac{4}{6} \\
.367 \\
.401 *\end{array}$ & $\begin{array}{l}.399 * \\
-.270\end{array}$ & $\begin{array}{r}\frac{6}{6} \\
-.103 \\
-.210\end{array}$ & $\frac{\text { Results }}{\frac{1}{4}, 2,5}$ \\
\hline 934408 & $\begin{array}{r}.120 \\
-.188\end{array}$ & $\begin{array}{l}.206 \\
.298\end{array}$ & $\begin{array}{l}-.451 * \\
-.025\end{array}$ & $\begin{array}{l}-.156 \\
-.026\end{array}$ & $\begin{array}{r}.362 \\
-.159\end{array}$ & $\begin{array}{l}.171 \\
.163\end{array}$ & 3 \\
\hline 960402 & $\begin{array}{l}.574 * \\
.223\end{array}$ & $\begin{array}{r}.026 \\
-.100\end{array}$ & $\begin{array}{l}-.388 * \\
-.271\end{array}$ & $\begin{array}{l}.293 \\
.585 *\end{array}$ & $\begin{array}{r}.295 \\
-.235\end{array}$ & $\begin{array}{l}.151 \\
.351\end{array}$ & $\frac{1,3}{4}$ \\
\hline 963320 & $\begin{array}{r}-.133 \\
.214\end{array}$ & $\begin{array}{l}-.088 \\
-.369\end{array}$ & $\begin{array}{r}-.183 \\
.212\end{array}$ & $\begin{array}{l}-.069 \\
-.0266\end{array}$ & $\begin{array}{l}.180 \\
.199\end{array}$ & $\begin{array}{l}.271 \\
.137\end{array}$ & \\
\hline 974280 & $\begin{array}{c}-.389 * \\
.202\end{array}$ & $\begin{array}{l}-.156 \\
-.196\end{array}$ & $\begin{array}{r}.132 \\
-.081\end{array}$ & $\begin{array}{l}-.476 * \\
-.577^{*}\end{array}$ & $\begin{array}{l}-.068 \\
-.107\end{array}$ & $\begin{array}{l}.137 \\
.256\end{array}$ & $\begin{array}{l}1,4 \\
4\end{array}$ \\
\hline 980881 & $\begin{array}{r}.239 \\
.230\end{array}$ & $\begin{array}{l}.106 \\
.301\end{array}$ & $\begin{array}{l}-.090 \\
-.101\end{array}$ & $\begin{array}{l}-.069 \\
-.431 *\end{array}$ & $\begin{array}{l}.049 \\
.370\end{array}$ & $\begin{array}{l}.153 \\
.187\end{array}$ & 4 \\
\hline
\end{tabular}




$$
\text { VITA }
$$

Gary Leinberger

$$
\begin{gathered}
\text { Candidate for the Degree of } \\
\text { Doctor of Philosophy }
\end{gathered}
$$

Thesis: AN EMPIRICAL INVESTIGATION OF THE DYNAMIC RELATIONSHIPS OF DEBT LEVEL AND BUSINESS RISK

Major Field: Business Administration

Biographical :

Personal Data: Born in Philadelphia, Pennsylvania, April 5, 1947, the son of Mr. \& Mrs. F. A. Leinberger.

Education: Graduated from Upper Darby High School in Upper Darby, Pennsylvania, in June, 1965; received Bachelor of Arts Degree in American Studies and Bachelor of Arts Degree in Finance from Lehigh University in June, 1970; received Masters Degree in Business Administration from Boston University in August, 1976; completed requirements for Doctor of Philosophy Degree at Oklahoma state University in December, 1983.

Professional Experience: Tank Platoon Leader, U.S. Army, Schweinfurt, Germany 1971-1973; Race Relations Staff Officer, lst Brigade, 3ID, Schweinfurt, Germany, 1973-1974; Graduate Teaching Assistant, Oklahoma State University, Business College, 1976-1979; Lecturer, Oklahoma State University, Business College, 1979-1980; Assistant Professor of Finance, Franklin and Marshall College, Lancaster, Pennsylvania, 19801983 . 